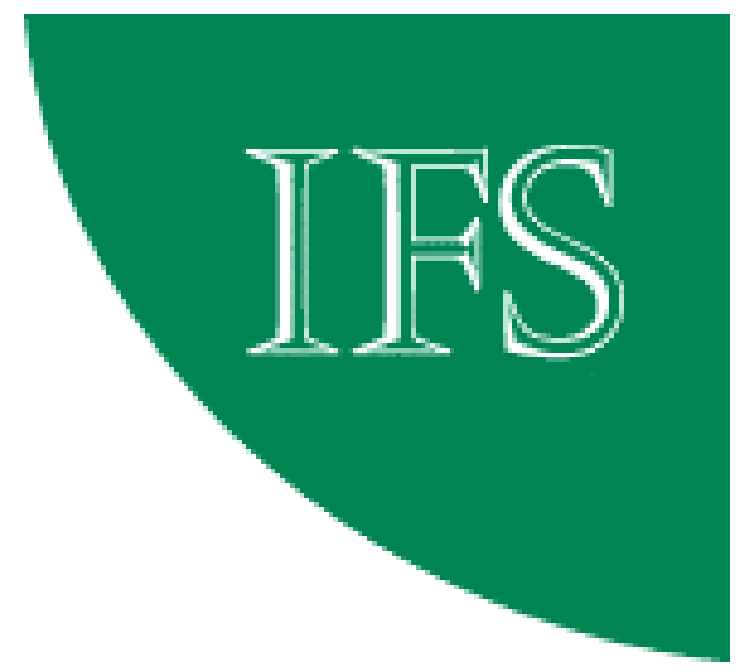

\title{
WAGES, EXPERIENCE AND SENIORITY
}

Christian Dustmann

Costas Meghir 


\title{
Wages, Experience and Seniority*
}

\author{
Christian Dustmann and Costas Meghir \\ Institute for Fiscal Studies, University College London and CEPR
}

\author{
This Version: September 2003
}

\begin{abstract}
In this paper we study the sources of wage growth. We identify the contribution to such growth of general, sector specific and firm specific human capital. Our results are interpretable within the context of a model where the returns to human capital may be heterogeneous and where firms may offer different combinations of entry level wages and firm specific human capital development. We allow for the possibility that wages are match specific and that workers move jobs as a result of identifying a better match. To estimate the average returns to experience, sector tenure and firm specific tenure within this context, we develop an identification strategy which relies on the use of firm closures. Our data source is a new and unique administrative data set for Germany that includes complete work histories as well as individual characteristics. We find positive returns to experience and firm tenure for skilled workers. The returns to experience for unskilled workers are small and insignificant after two years of experience. Their returns to sector tenure are also zero. However their returns to firm tenure are substantial.
\end{abstract}

*We thank three anonymous referees and the editor James Dow for useful comments and suggestions. Discussions with Joe Altonji, Orazio Attanasio, James Banks, Richard Blundell, Ken Burdett, Lorraine Dearden, Jim Heckman, Derek Neal, Gillian Paull, Jean-Mark Robin, Uta Schoenberg, Chris Taber and Yoram Weiss proved particularly useful in developing this paper. We would also like to thank participants in seminars at Universities of Aarhus, (Denmark), Chicago, Copenhagen, Essex (UK), IIES (Sweden), Northwestern, Pennsylvania, Pompeu Fabra (Barcelona), as well as the EUI (Florence) and ECARE (Brussells), for stimulating comments. We thank the ESRC centre for the analysis of Fiscal Policy and the Anglo German foundation for funding the project. We also thank the IAB for letting us use the data and Stefan Bender for his invaluable help with it. We remain responsible for all errors and interpretations. Correspondence: c.dustmann@ucl.ac.uk and c.meghir@ucl.ac.uk 


\section{Introduction}

In this paper we study the growth of wages of young workers in Germany. Knowing the extent and reasons for individual wage growth over the lifecycle is important for a number of areas in Economics. Just to mention two examples: First, it is a key element to understanding and designing active labour market programmes. Many such programmes offer temporary (and often subsidised) work opportunities. Examples are the New Deal in the UK and the Swedish programmes as well as a number of programmes in Germany. These programmes are based on the assumption that general skills are sufficiently enhanced while working, so as to render the workers employable without a wage subsidy. Thus the success of these programs depends on how skills improve on the job for the target population, and whether this skill enhancement is transferable across jobs. Second, it is a key to understanding the benefits and costs of job mobility. This in turn matters for a number of policy issues, including the design of pension policies, relating for example to final salary schemes.

As a result of this widespread interest, a large body of empirical research has focused on obtaining estimates for the returns of experience and seniority. ${ }^{1}$ Our study uses a new and unique administrative data set with a number of features that are important for our analysis and allow us to avoid many problems encountered in earlier work in this field. In our model wages grow due to learning by doing, which may be heterogeneous across individuals. Moreover, since firms offer different career profiles and because we allow for match specific effects on wages, investments take the form of searching for the firm with the most desirable learning by doing characteristics (career structure). ${ }^{2}$

Thus the framework we present leads to a wage equation, which depends on the number of periods the individual has worked (experience), the time spent in the sector (sector tenure) and the time spent in the firm (tenure). The impacts of these factors is allowed to be

\footnotetext{
${ }^{1}$ See Altonji and Shakotko (1987), Topel (1991), Topel and Ward (1992), Altonji and Williams (1996), Altonji and Williams (1997), Neal (1995) and Parent (1995) among others.

${ }^{2}$ In general the acquisition of human capital on the job may be a result of decisions to invest as well as purely learning by doing. Examples of models with explicit investment in Human Capital are Ben Porath (1967), Rosen (1976), Blinder and Weiss, (1976) and Jovanovic (1979), amongst others. Examples of models where learning is a by product of work are given in Rosen (1972). Killingsworth (1982) presents a model unifying the features of the earlier literature.
} 
heterogeneous across individuals, which leads to a correlated random coefficients model for wages. Random coefficient models are not new of course. The Willis and Rosen (1979) model on the returns to education and the Heckman and Sedlacek (1985) model of self selection to the labour market (based on Roy), are early empirical examples. Heckman and Robb (1985) discuss the estimation of such models in the context of evaluation of treatment effects and Bjorklund and Moffitt (1987) apply these ideas to the estimation of the returns to training in Sweden. More recently Imbens and Angrist (1994) and Heckman (1995) consider the interpretability of instrumental variable estimation in the context of random coefficient models.

We discuss how the population average returns to experience and tenure can be identified given individual and firm behaviour. Our approach is partly based on using displaced workers due to firm closure, thus allowing us to distinguish wage growth due to learning by doing from wage growth due to endogenous job mobility, which leads to improved job matches. ${ }^{3}$ However we recognise that even for displaced workers both the fact that they accepted a new job as well as experience itself are endogenous at job entry. We use age as an excluded instrument to allow for such endogeneity by developing an estimator based on the control function approach of Heckman and Robb (1985), and allowing for heterogeneous returns to experience, sector tenure and firm tenure. ${ }^{4}$

Our data allows us to observe all transitions that take place between jobs and between work and unemployment from the start of the worker's labour market career. All wage observations relate to a particular job and are not averaged across jobs; thus when an individual changes employment we observe the new wage at which he is appointed. Because the data is administrative, there is practically no attrition and most probably much less measurement error than that in questionnaire based survey data. In addition, for any firm that closed down and employed any of our workers within our observation window, we know the year of closure.

\footnotetext{
${ }^{3}$ Displaced workers have been used before to control for selection due to unobserved heterogeneity. Examples include Kletzer (1989) and Gibbons and Katz (1992). Kletzer also includes among the exogenously displaced individuals those fired from firms that continue as a going concern.

${ }^{4}$ The approach we follow is parametric and is similar to Heckman and Vytlacil (1998). General nonparametric identification issues in these models are discussed in Florens et al (2002).
} 
From the overall data base, we extract a sample of workers entering the labour market between 1975 to 1995. The oldest worker in our sample is 35. The use of such a young sample has the advantage that we can focus on the age group where most of the job mobility and life-cycle wage growth takes place. Since this data base came into existence in 1975, our sample selection ensures that we choose those cohorts for which the complete labour market history of all individuals is observed.

Our analysis is carried out separately for skilled individuals who have received formal vocational training (apprenticeship) and for those who have not - the unskilled. This reveals important differences between the groups, which is key to the design of policy such as active labour market programmes.

We find that the returns to experience for the skilled workers can be substantial. In the first two years of work, following formal training, wages grow at $7 \%$ and then at $6 \%$ a year. The returns decline thereafter, but even in the longer run experience leads to a wage growth of $1.2 \%$ a year. For the unskilled workers there are substantial returns in the first two years (10\% and $8 \%$ ) but they become effectively zero beyond three years of work. In addition to this growth due to experience, the wages of unskilled workers also grow early on via improved job matches achieved by job mobility; this, however, is not an important source of growth for the skilled workers. The returns to remaining in the same sector (sector or industry tenure) are $1 \%$ a year for skilled workers and basically zero for the unskilled. On the other hand the returns to remaining with the same employer (tenure) for the unskilled workers are quite high for the first 5 years ( $4 \%$ a year) but zero thereafter, despite the fact that we control for sector tenure. Skilled workers have lower returns to tenure $(2.4 \%)$. Thus in Germany unskilled workers benefit most by finding a good match and remaining with it. An implication is that if a labour market program is to be effective for the unskilled it will have to make sure placements are long-lasting. For skilled workers human capital is transferable and tenure is not as important. This may be due to the nature of the apprenticeship system. A series of sensitivity tests demonstrate the robustness of these results to alternative definitions of displacement.

The paper proceeds as follows: In the next section we present a theoretical framework, 
where we describe the model and discuss identification of the parameters of interest under different theoretical assumptions. This is followed by a section where we describe the data and the sample we use, and provide descriptive features of job mobility and wage growth for young workers in Germany. We then present our empirical results. Finally, we summarise our findings and their implications in the concluding section.

\section{Theoretical framework}

Human capital is composed of transferable skills, sector specific skills and firm specific skills. Workers are assumed to obtain the returns to the first two and to share the returns to the latter, based on the proportion invested for its acquisition by the worker relative to the firm. ${ }^{5}$ Thus define by $H_{i f t}^{a}$ that part of human capital for which worker $i$ with education type $a$, working in firm $f$ during period $t$ gets paid for. This is related to the number of periods the workers has worked in firm $f\left(T_{i f t}^{F}\right)$, in sector $s\left(T_{i t}^{S}\right)$ and overall $\left(T_{i t}^{G}\right)$ by the function

$$
\ln H_{i f t}^{a}=g\left(T_{i t}^{G} \mid a_{i}\right)+\eta_{i t} T_{i t}^{G}+s\left(T_{i t}^{S} \mid a_{i}\right)+\varepsilon_{i t} T_{i t}^{S}+f\left(T_{i f t}^{F} \mid a_{i}\right)+\nu_{i f t} T_{i f t}^{F}+m_{i f t}
$$

where $g\left(T_{i t}^{G} \mid a_{i}\right)+\eta_{i t} T_{i t}^{G}$ is general transferable human capital, $s\left(T_{i t}^{S} \mid a_{i}\right)+\varepsilon_{i t} T_{i t}^{S}$ is human capital specific to the sector, and $f\left(T_{i f t}^{F} \mid a_{i}\right)+\nu_{i f t} T_{i f t}^{F}$ is firm specific human capital whose return is enjoyed by the worker. The term $\eta_{i t}$ reflects individual specific returns to general experience. The terms $m_{i f t}$ and $\nu_{i f t}$ reflect the match specific productivity and career structure. Thus the value of a match (given experience and tenure) is characterised by a firm/worker specific component of the wage level $m_{i f t}$ and growth $\nu_{i f t}$. We expect these to be negatively correlated in equilibrium. ${ }^{6}$ Finally, $a_{i}$ is the educational category of individual $i$. Note that the random returns may be persistent over time or even fixed for each individual.

We assume learning by doing is passive and takes place within a job. The individual can

\footnotetext{
${ }^{5}$ See Becker (1993). Equilibrium models that explain why workers get rewarded for specific training and the way the costs and the returns are shared have been developed under many different assumptions. Some examples include Hashimoto (1981), Datta (1995), Scoones and Bernhardt (1996) and Harris and Felli (1996).

${ }^{6}$ No restrictions are imposed on the way that the unobservables $\eta_{i t}, \varepsilon_{i t}, m_{i f t}$ and $\nu_{i f t}$ are correlated. Also note that the firm's willingness to hire the worker or otherwise is reflected in the overall value of the match. Given the pay that this implies it is then up to the worker to take the job or not. See Farber (1983) for an alternative where there may be excess supply of workers, in his case to union jobs.
} 
choose the firm with the desired career profile, the sector in which he works and whether to work or not in a particular period.

In our empirical analysis we distinguish between two skill categories: Those with apprenticeship education $\left(a_{i}=1\right)$ and those without $\left(a_{i}=0\right)$. The market price for human capital of type $a$ is $r_{t}^{a}$. The observed wage of individual $i$ in time period $t$ and of skill level $a$ is $w_{i t}=r_{t}^{a} H_{i f t}^{a} e^{e_{i t}}$ where $e_{i t}$ represents either measurement error and/or transitory shocks to human capital. ${ }^{7}$ The log wage for an individual $i$ in period $t$ can be written as:

$$
\begin{aligned}
\ln w_{i t}= & \ln r_{t}^{a}+g\left(T_{i t}^{G} \mid a_{i}\right)+s\left(T_{i t}^{S} \mid a_{i}\right)+f\left(T_{i f t}^{F} \mid a_{i}\right) \\
& +\eta_{i t} T_{i t}^{G}+\varepsilon_{i t} T_{i t}^{S}+\nu_{i f t} T_{i f t}^{F}+m_{i f t}+e_{i t} .
\end{aligned}
$$

Draws of the match specific effects $\left(u_{i f t}=\left\{m_{i f t}, \nu_{i f t}\right\}\right)$ will in general be correlated across firms, due to individual unobserved characteristics. Preferred draws of $u_{i f t}$ will drive mobility. $^{8}$

\subsection{Identifying the return to experience}

Comparing the wages of workers with different levels of experience is known to provide biased results for the returns to experience (see for example, Altonji and Shakotko, 1986, Topel, 1991 and Altonji and Williams, 1996) for at least two reasons. First, because some of the differences may be attributed to better matches achieved by workers who have been in the labour market longer. Second, because high ability workers are likely to have a stronger labour market attachment and hence end up with more experience. In our model, there is a further source of a potential bias in the estimation of the average returns to experience: Workers with higher returns to experience are likely to spend less time out of the labour market, because for them the opportunity cost of not working is higher. This will lead to a positive correlation of the returns to experience $\eta_{i t}$ with experience $T_{i t}^{G}$.

The dynamic selection induced by this process will generally distort the returns to experience, and it is difficult to model (see Eckstein and Wolpin, 1989). Topel (1991) suggests estimating the returns to experience by using the wages of those starting a new job and who

\footnotetext{
${ }^{7}$ The subscript $f$ is used to emphasise that certain variables on the right hand side depend on the firm. For simplicity of notation however, we drop the firm subscript from the wage rate.

${ }^{8}$ Farber (1994) among others provides interesting evidence on the importance of matching for mobility.
} 
therefore have zero tenure. However, workers who start a new job are a mixture of workers who are improving on their previous wage, workers who have been fired from an ongoing firm, and workers who have been displaced because the firm actually closed down, all of whom find the current offer more attractive than unemployment.

We resolve this problem by using only those workers who start a new job following a displacement caused by the closure of a firm. ${ }^{9}$ We will term these displaced workers. In Appendix A we show why exogenous displacement can simplify the problem. The basic intuition is simple: If, as we assume, firm closure is exogenous conditional on our observables, then workers who have thus been displaced are a random sample of the workforce and are not selected into new jobs on the basis of their past choices, but just on whether this job offer is preferable to unemployment. Thus our approach identifies the returns to experience by comparing the wages of workers with different levels of experience, who start a new job following displacement.

Of course even for this sample there is still the well known ability bias problem (experience is correlated with the permanent part of the unobservables), and the problem that only those displaced workers receiving good enough offers will take up employment. ${ }^{10}$ We solve these endogeneity/selection problems by using age effects as exclusion restrictions, combined with a control function estimator on the displaced sample, where we use residuals from an experience and participation reduced form to allow for the endogenous job acceptance and experience. ${ }^{11}$

In what follows, we state a set of assumptions that justify our approach and present the estimation procedure we use.

\footnotetext{
${ }^{9}$ This strategy is based on a number of assumptions, which we list below. Gibbons and Katz (1992) also argue that displaced workers can be used to control for selection in a matching context. They apply their strategy in a bid to explain inter-industry wage differentials.

${ }^{10} \mathrm{By}$ ability bias we refer to the bias generated by the tendency of individuals who are more productive, or have a higher return to experience, to spend more time in employment and hence be more experienced for any given level of potential experience.

${ }^{11}$ See Heckman and Robb (1985).
} 


\subsection{Assumptions}

Our approach for estimating the average returns to experience for the workforce population is based on the following assumptions:

A.1 Workers cannot predict a closure before joining the firm. Moreover, they cannot predict a closure when working in the firm if the closure is more than a year away.

Assumption A.1 ensures that there is no self-selection of a particular type of worker (in terms of unobserved characteristics) into firms that are subsequently observed to close down. Since we can predict firm closure in terms of certain observables, we can carry out a sensitivity analysis. In particular, we compare the results we obtain using all closures, to those obtained using closures of older firms only, which have much lower exit rates. We develop this idea at the end of the empirical section.

There may also be selection of workers leaving the firm before closure. In our data we know whether a firm closed down, independently of whether the worker remained employed by it. Hence, we can define a displaced worker as someone who left a firm which closed down in $\mathrm{x}$ amount of time following his departure, where $\mathrm{x}$ is chosen by us. A.1 assumes there are no selective departures related to the closure earlier than a year before the event. In the empirical section we develop a sensitivity test, based on alternative definitions of this time window. In particular, we consider a worker as displaced if the firm closes down within different periods of his departure, and we compare the results.

A.2 Workers and firms have full information on the quality of the match.

Assumption A.2 excludes learning about the quality of the match so as to simplify the interpretation of the results. ${ }^{12}$

A.3 Exclusion restriction: For the population of young displaced workers $\left(D_{i t}=1\right)$ the unobservables in the wage equation are mean independent of age, conditional on exogenous observable characteristics $X_{i t}$ (including school education, apprenticeship status, and time).

\footnotetext{
${ }^{12}$ In the presence of learning about the quality of the match it may not be possible to disentangle the growth of wages due to an increase in productivity from growth due to increased remuneration as the quality of the match is revealed. See Nagypal (2002) for a recent attempt to distinguish learning by doing from learning about match quality.
} 
Thus,

$$
\begin{gathered}
E\left(\eta_{i t} \mid a g e_{i t}, X_{i t}, D_{i t}=1\right)=E\left(\varepsilon_{i t} \mid a g e_{i t}, X_{i t}, D_{i t}=1\right)=0 \\
E\left(\nu_{i f t} \mid a g e_{i t}, X_{i t}, D_{i t}=1\right)=E\left(m_{i f t}+e_{i t} \mid a g e_{i t}, X_{i t}, D_{i t}=1\right)=0
\end{gathered}
$$

This assumption ensures that age does not affect wage offers facing exogenously displaced individuals with the same observables. ${ }^{13}$ This assumption may not be true in the overall sample since the quality of matches may improve with age because older workers will have been sampling jobs for longer. The key point of this assumption is that post displacement, workers have lost all earlier match advantages that would have been achieved through search (search capital) and that workers have to start afresh. As a result, being an older or younger worker (within the relatively narrow age range we consider - remember that workers are less than 35 years old) does not in itself confer any advantage in obtaining a better match post-displacement. Implicit also in this assumption is the exclusion of cohort effects from wages. $^{14}$

We also require a condition that ensures that the instruments we use can explain participation and experience and also induce independent variation in the two predictions. Our requirement is that age has an impact on participation in the labour market. We expect this to be the case since labour market attachment changes with age for a variety of reasons, including family formation, housing, better job matches etc.

The instruments will also have explanatory power for experience since actual experience is the sum of past employment outcomes. If age effects on participation are sufficiently nonlinear this exclusion restriction provides all the necessary identifying information. In practice this is the case. In addition, we can also exploit the fact that the impact of age changes with potential experience by using age/potential experience interactions as instruments. Since potential experience is age minus years of education in practice this amounts to using age/education interactions as additional instruments. This leads us to the rank condition, which can be stated as: ${ }^{15}$

\footnotetext{
${ }^{13}$ Since the conditional mean of the unobservables is assumed to be equal to zero, which is their unconditional population mean, these orthogonality conditions identify the population mean of the returns to experience.

${ }^{14}$ Note that age + cohort $=$ year. Since the model also includes time effects, including cohort and time would be the same as including age, at least linearly.

${ }^{15}$ For a recent application of a similar idea see Blundell, Duncan and Meghir (1998) and for the theory of
} 
A.4 Rank condition: Define by $\vartheta^{G}$ the vector coefficients on all excluded instruments in the experience reduced form and by $\vartheta^{P}$ the vector of coefficients of these same variables in the participation reduced form. The rank condition of identification requires that the matrix $\left[\begin{array}{ll}\vartheta^{G} & \vartheta^{P}\end{array}\right]$ has rank 2.

We present a formal test of the rank condition, which is easily satisfied in our data.

The exclusion restriction and the rank condition are not sufficient for identifying average returns in models with heterogeneous returns which may be correlated with the endogenous variables. ${ }^{16}$ In addition we require the following control function assumptions that define how the mean of the unobservables relate to experience $\left(T^{G}\right)$, sector tenure $\left(T^{S}\right)$ and job acceptance following a closure $(P)$.

A.5 For the sample of displaced workers $\left(D_{i t}=1\right)$ starting a new job ${ }^{17}$ following a firm closure, we assume that:

$$
\begin{gathered}
E\left(m_{i f t}+e_{i t} \mid a g e_{i t}, X_{i t}, D_{i t}=1, P_{i t}=1, T_{i t}^{G}, T_{i t}^{S}, T_{i f t}^{F}=0\right)=\delta^{G}\left(c_{i t}\right) v_{i t}^{G}+\delta^{P}\left(c_{i t}\right) v_{i t}^{P}, \\
E\left(\eta_{i t} \mid a g e_{i t}, X_{i t}, D_{i t}=1, P_{i t}=1, T_{i t}^{G}, T_{i t}^{S}, T_{i f t}^{F}=0\right)=\gamma^{G}\left(c_{i t}\right) v_{i t}^{G}+\gamma^{P}\left(c_{i t}\right) v_{i t}^{P}, \\
E\left(\varepsilon_{i t} \mid a g e_{i t}, X_{i t}, D_{i t}=1, P_{i t}=1, T_{i t}^{G}, T_{i t}^{S}, T_{i f t}^{F}=0\right)=\kappa^{G}\left(c_{i t}\right) v_{i t}^{G}+\kappa^{P}\left(c_{i t}\right) v_{i t}^{P},
\end{gathered}
$$

where $P_{i t}=1$ represents those accepting a new job following displacement, $c_{i t}$ is potential experience $^{18}$, and $v_{i t}^{G}=T_{i t}^{G}-E\left(T_{i t}^{G} \mid a g e_{i t}, X_{i t}\right)$, and $v_{i t}^{P}=P_{i t}-E\left(P_{i t} \mid a g e_{i t}, X_{i t}\right)$ are residuals from an experience and participation reduced form. The control function assumption is familiar from standard selection models (e.g. Heckman, 1979). A sufficient (but not necessary) condition for this assumption to hold is that the instrument is independent of the errors. Subject to the exclusion restrictions A.3 and the rank condition A.4, this control function assumption allows us to identify the average return to experience and sector tenure based on rank tests see Robin and Smith (2000).

${ }^{16}$ See Garen (1984), Heckman and Robb (1985), Heckman and Vytlacil (1999), Card (2001) and Florens et al. (2002).

${ }^{17}$ All these workers have zero tenure at that point.

${ }^{18}$ Potential experience is the number of years that the person could have worked for pay since the end of full time education. Since $X$ includes education and we also condition on age, $c_{i t}$ is implicitly included in the set of conditioning variables. 
the wage obtained following displacement. We allow the coefficients (the $\delta$ 's, $\gamma$ 's and $\kappa$ 's) to depend on potential experience $c_{i t}$ because the distribution of experience will vary with the number of years that the individual has been in the labour market. For example, a person with 5 years of potential experience can have no more than 5 years of actual experience. Moreover, as implied by (3) and (4), the above formulation recognises that past and present employment outcomes may depend on the returns to experience $\left(\eta_{i t}\right)$, and sector tenure $\left(\varepsilon_{i t}\right)$.

Assumption A.5 implies that conditional on experience, job acceptance following displacement and the other observable characteristics, a sector tenure residual is not required. We provide a test of this exogeneity assumption, which turns out to be easily acceptable in our data. This is not surprising, since we allow for the returns to sector tenure to affect the mobility and work decisions (see equation 4). We discuss the test in the empirical section.

Finally, note that identification does not rely on linearity of the control function. There are two key elements in the identification of the average treatment effect using the control function estimator. ${ }^{19}$ First an instrument which is continuous or takes on many discrete values. In a non-parametric setting this instrument must satisfy a generalised rank condition which implies that it can explain any function of the endogenous variable. Second, that the dependence of the conditional mean of the unobservables given the endogenous variables and the instrument is only a function of the residuals $v^{P}$ and $v^{G}$ and not of the endogenous variable and the instrument separately. Florens, Heckman, Meghir and Vytlacil (2002) develop arguments relating to the non-parametric identifiability of models with heterogeneous impacts of continuous variables such as experience or tenure.

We do not impose any arbitrary functional form assumptions on the residuals that would force them to have independent variation. The residuals originate from simple linear regressions. We just require the testable rank condition A.4 to be satisfied. Finally note that there are further structural restrictions linking participation and experience but we do not exploit these here.

\footnotetext{
${ }^{19}$ See also Newey, Powell and Vella (1999).
} 


\subsection{Implementation of the estimation method}

To implement this estimation approach, we start by estimating reduced forms for participation, and for experience at the beginning of the current period. These are estimated on all individuals (independently of their current or past work status) using Ordinary Least Squares (OLS). A separate reduced form is estimated for each skill group. The experience reduced form for each skill group $a$ (apprentices and non-apprentices) is

$$
T_{i t}^{G}=\alpha_{0}^{a G}+\alpha_{1}^{a G} a g e_{i t}+\alpha_{2}^{a G} c_{i t}+\alpha_{3}^{a G} a g e_{i t} \times c_{i t}+a d_{i t}^{\prime} \alpha_{4}^{a G}+\left(a d_{i t} \times c_{i t}\right)^{\prime} \alpha_{5}^{a G}+x_{i t}^{\prime} \xi^{a G}+v_{i t}^{G} .
$$

The variables $a d$ are age indicators. ${ }^{20}$ The $x$ variables are the year indicators and the level of school education. The variable $c_{i t}$ is potential experience of individual $i$ in calendar period $t$. We also estimate a reduced form participation equation (job acceptance), which has the same form. Having estimated the reduced forms, we compute the respective residuals $\hat{v}_{i t}^{G}$ and $\hat{v}_{i t}^{P}$.

The next step involves writing wages as $\ln w_{i t}=E\left(\ln w_{i t} \mid a g e_{i t}, X_{i t}, D_{i t}=1, P_{i t}=\right.$ $\left.1, T_{i t}^{G}, T_{i t}^{S}, T_{i f t}^{F}=0\right)+e_{i t}^{*}$, by applying the assumptions (2), (3) and (4) when taking the conditional expectation of wages in (1). We assume that the parameters on the residual terms in (2) and (3) $\left(\delta^{G}\left(c_{i t}\right), \delta^{P}\left(c_{i t}\right), \gamma^{G}\left(c_{i t}\right), \gamma^{P}\left(c_{i t}\right), \kappa^{G}\left(c_{i t}\right), \kappa^{P}\left(c_{i t}\right)\right)$ are linear in potential experience. ${ }^{21}$ Thus we obtain the following regression that can be estimated using ordinary least squares on the subsample of those starting a new job following displacement:

$$
\begin{aligned}
\ln w_{i t}=\ln r_{t}^{a}+g\left(T_{i t}^{G} \mid a_{i}\right)+s\left(T_{i t}^{S} \mid a_{i}\right)+x_{i t}^{\prime} \gamma^{a} & +\delta_{1}^{G} \hat{v}_{i t}^{G}+\delta_{2}^{G} c_{i t} \hat{v}_{i t}^{G}+\delta_{1}^{P} \hat{v}_{i t}^{P}+\delta_{2}^{P} c_{i t} \hat{v}_{i t}^{P} \\
& +\gamma_{1}^{G} T_{i t}^{G} \hat{v}_{i t}^{G}+\gamma_{2}^{G} c_{i t} T_{i t}^{G} \hat{v}_{i t}^{G} \\
& +\gamma_{1}^{P} T_{i t}^{G} \hat{v}_{i t}^{P}+\gamma_{2}^{P} c_{i t} T_{i t}^{G} \hat{v}_{i t}^{P} \\
& +\kappa_{1}^{G} T_{i t}^{S} \hat{v}_{i t}^{G}+\kappa_{2}^{G} c_{i t} T_{i t}^{S} \hat{v}_{i t}^{G} \\
& +\kappa_{1}^{P} T_{i t}^{S} \hat{v}_{i t}^{P}+\kappa_{2}^{P} c_{i t} T_{i t}^{S} \hat{v}_{i t}^{P}+e_{i t}^{*}
\end{aligned}
$$

\footnotetext{
${ }^{20}$ To test for non-linearities, we test for the exclusion of the age dummies, given the inclusion of the linear age term.

${ }^{21}$ For example, $\delta^{G}\left(c_{i t}\right)=\delta_{1}^{G}+\delta_{2}^{G} c_{i t}$.
} 
Any estimator that includes the control functions (residual terms) will be referred to as a control function estimator.

The specification of $g\left(T_{i t}^{G} \mid a_{i}\right)$ and $s\left(T_{i t}^{S} \mid a_{i}\right)$ is stated in the empirical section. The interactions of these residuals with experience $T_{i t}^{G}$ and sector tenure $T_{i t}^{S}$ control for self selection due to heterogeneous returns to experience and sector tenure. Finally, as explained above, the relationship of these residuals to the unobservables in wages are likely to be changing with potential experience $c_{i t}{ }^{22}$ We allow for this by interacting all terms with $c_{i t}$.

\subsection{Estimating the return to tenure}

In estimating the returns to tenure, we use wages in jobs that follow firm closures. This is necessary because the existence of match specific returns to tenure may imply the accumulation of search capital which may be confused with returns to tenure. Consider wages adjusted for average growth due to experience and sector tenure. These are

$$
\widetilde{\ln w_{i t}}=\ln w_{i t}-\widehat{\ln r_{t}^{a}}-g \widehat{\left(T_{i t}^{G} \mid a_{i}\right)}-\widehat{s\left(T_{i t}^{S} \mid a_{i}\right)}
$$

where $\left.\widehat{\ln r_{t}^{a}}, g \widehat{\left(T_{i t}^{G} \mid a_{i}\right.}\right)$ and $\left.\widehat{s\left(T_{i t}^{S} \mid a_{i}\right.}\right)$ are the pre-estimated aggregate growth of wages and the experience and sector tenure components respectively.

The adjusted wage is then given by

$$
\widetilde{\ln w_{i t}}=f\left(T_{i t}^{F} \mid a_{i}\right)+\left[\eta_{i t} T_{i t}^{G}+\varepsilon_{i t} T_{i t}^{S}+\nu_{i f t} T_{i f t}^{F}+m_{i f t}+\tilde{e}_{i t}\right] .
$$

where $\tilde{e}_{i t}$ reflects estimation error from the first stage as well as the original error $e_{i t}$.

With heterogeneous returns and/or heterogeneity that varies over time first differencing does not help. Thus, to estimate the returns to tenure similar to the case of experience, we need to model $E\left[\eta_{i t} T_{i t}^{G}+\varepsilon_{i t} T_{i t}^{S}+\nu_{i f t} T_{i f t}^{F}+m_{i f t}+e_{i t} \mid a g e, T_{i t}^{G}, T_{i t}^{S}, T_{i f t}^{F}, c_{i t}\right]$. Relative to the case where tenure is zero, this expression includes an extra term $\left(\nu_{\text {ift }} T_{i f t}^{F}\right)$. Moreover we need to model the relationship between tenure and all the residual terms. Thus the

\footnotetext{
${ }^{22}$ If nothing else, the maximum number of years of experience increases with potential experience.
} 
assumptions we made earlier are updated to ${ }^{23}$

$$
\begin{aligned}
& E\left(m_{i f t}+e_{i t} \mid a g e_{i t}, X_{i t}, D_{i t}=1, P_{i t}=1, T_{i t}^{G}, T_{i t}^{S}, T_{i f t}^{F}\right)=\lambda^{G}\left(c_{i t}\right) v_{i t}^{G}+\lambda^{P}\left(c_{i t}\right) v_{i t}^{P}+\lambda^{T}\left(c_{i t}\right) v_{i t}^{T}, \\
& E\left(T_{i t}^{G} \eta_{i t} \mid a g e_{i t}, X_{i t}, D_{i t}=1, P_{i t}=1, T_{i t}^{G}, T_{i t}^{S}, T_{i f t}^{F}\right)=\left[\rho^{G}\left(c_{i t}\right) v_{i t}^{G}+\rho^{P}\left(c_{i t}\right) v_{i t}^{P}+\rho^{T}\left(c_{i t}\right) v_{i t}^{T}\right] T_{i t}^{G}, \\
& E\left(T_{i t}^{S} \varepsilon_{i t} \mid a g e_{i t}, X_{i t}, D_{i t}=1, P_{i t}=1, T_{i t}^{G}, T_{i t}^{S}, T_{i f t}^{F}\right)=\left[\theta^{G}\left(c_{i t}\right) v_{i t}^{G}+\theta^{P}\left(c_{i t}\right) v_{i t}^{P}+\theta^{T}\left(c_{i t}\right) v_{i t}^{T}\right] T_{i t}^{S}, \\
& E\left(T_{i t}^{F} \nu_{i f t} \mid a g e_{i t}, X_{i t}, D_{i t}=1, P_{i t}=1, T_{i t}^{G}, T_{i t}^{S}, T_{i f t}^{F}\right)=\left[\xi^{G}\left(c_{i t}\right) v_{i t}^{G}+\xi^{P}\left(c_{i t}\right) v_{i t}^{P}+\xi^{T}\left(c_{i t}\right) v_{i t}^{T}\right] T_{i t}^{F}
\end{aligned}
$$

where $v_{i t}^{T}$ is the residual from the tenure reduced form and where as before the coefficients of each of the residuals are linear functions of potential experience $\left(c_{i t}\right)$.

The tenure reduced form will be of the same form as (5). We expect age to affect mobility between jobs and hence tenure because mobility costs will be higher for older individuals due to family and housing among other things. Thus age effects and age interacted with potential experience should matter for tenure. More generally, identification relies on the matrix of coefficients on the age effects and age effects interacted with potential experience from the three reduced forms (participation, experience and tenure) having rank three. The rank condition is more demanding than for estimating the effects of experience alone. Thus overall the conditions for identifying the returns to tenure are more stringent than the conditions required for identifying the returns to experience. The rank condition is amply satisfied in the data even with the three reduced forms, as shown below. Identification is further aided by the fact that the returns to experience and sector tenure can be estimated at a first step, under weaker conditions by relying on the first job record, where tenure is zero (as discussed above).

Implementation of the estimator involves regressing the adjusted wage $\left(\widetilde{\ln w_{i t}}\right)$ on the function of tenure $\left(f\left(T_{i t}^{F} \mid a_{i}\right)\right)$ and on all pre-estimated residual terms shown in the equations above. The residuals are estimated based on linear reduced forms for experience, participa-

\footnotetext{
${ }^{23}$ Note that $D_{i t}=1$ means that the worker had been displaced in the job immediately preceding the current one.
} 
tion and tenure with the same specification as in equation (5).

\subsubsection{Standard errors and inference}

Our approach requires that the standard errors are corrected for generated regressor bias. We also need to account for serial correlation and heteroskedasticity, both of unknown form. Since computing the standard errors analytically can be very cumbersome in these circumstances we have used the block bootstrap where we treat each individual as a sampling unit, thus allowing for arbitrary serial correlation and heteroskedasticity. We bootstrap the entire estimation procedure thus allowing for the stage by stage nature of our estimator. This also allows us to evaluate whether there is any important small sample bias in our approach (see Hall and Horowitz, 1996 and Horowitz, 2000). ${ }^{24}$ Moreover, many of the test statistics we present use bootstrap critical values. To the extent that the tests are pivotal ( i.e. their asymptotic distribution does not depend on unknown parameters), this will provide small sample refinements. Otherwise this procedure is equivalent to using the asymptotic distribution.

\section{The Data}

The data we use is a 1 percent sample from the German Social Security records (IAB data), which has been supplemented by information from the official unemployment records. We only consider male workers in West Germany. This data is available for the years 1975-1995 (see Bender et al. 1996 for details). Over this period, it records for each worker the exact date of any change to a new job or to (and from) unemployment. Furthermore, it contains an obligatory yearly entry for each worker. Thus an accurate calendar of labour market status is provided with minimal, if any, measurement error for each worker. It further provides information about whether a worker is on an apprenticeship training scheme.

Wages are recorded in the following fashion. If the worker does not change firm over the calendar year, the average daily wage is recorded over this period. If the worker changes jobs, the record includes the average daily wage for the period from the start of the calendar

\footnotetext{
${ }^{24}$ Fitzenberger and Kurz (2002) provide a recent application in the use of the block bootstrap in the context of estimating wage equations.
} 
year (or the start of the spell, whichever is more recent) to the date of termination of employment at the firm. Then we obtain an average daily wage from the beginning of the new employment spell to the end of the calendar year (or to the end of the employment spell, whichever comes sooner). Hence the wage information always relates to a single firm, and never covers more than one calendar year. We deflate wages by the German consumer price index. In addition, we use data on age, educational qualifications and industry. Thus the data allows us to construct very accurate work and earnings histories. The accuracy of our work history information contrasts with information based on recall and individual based responses (such as the US NLSY and PSID or the UK BHPS).

The data does not cover the entire German labour force, as the self employed and civil servants do not pay social security contributions, and are therefore excluded. Moreover, as with many administrative data sets, the data is top coded. In our analysis, we consider only young individuals who went through apprenticeship training, and individuals who did not receive any further training after school. Top coding hardly affects the wages of workers in these groups. $^{25}$

The data base contains also information on the firm in which each worker is employed. Using separate information on the firm we can link in the year that the firm started and closed down. When the firm has many establishments the data refers to one establishment and not to a whole firm. However, for simplicity we just use the term firm throughout.

\section{The Sample}

From this data base, we construct a sample of young male workers whom we observe from the entry to the labour force onwards. To ensure that we do not miss out early employment spells, we restrict our sample to workers who were not older than 15 in 1975 (which is the minimum compulsory full time schooling age).

We distinguish between two levels of qualification: workers who go through an apprenticeship training scheme early on in their careers, and workers who do not acquire any further formal training after school (which could be a high school degree with 13 years of schooling,

\footnotetext{
${ }^{25}$ Less than 1 percent of our sample population experience a right censoring later in their career.
} 
or a lower secondary degree with 9-10 years of schooling), or who drop out of the training scheme. We refer to these two samples as the skilled and the unskilled sample. The longest labour market history in our data set is 19 years, and the shortest 2 years. Our final sample consists of 25649 skilled workers, with 204458 employment records, and 7264 unskilled workers, with 55924 employment records. ${ }^{26}$

\subsection{A descriptive analysis of wage growth and job mobility}

We provide some information on the institutional background, the education system and wage setting in Germany in appendix B. ${ }^{27}$ In this section, we describe the basic features of job mobility and wage growth in our sample.

\section{Mobility}

In figure 1, we illustrate job mobility for the first 10 years of labour market experience, where we brake down our sample into the two different educational categories. The figure shows that mobility is lower for better educated workers throughout. After 10 years, an unskilled worker has held 3.4 jobs on average, while a skilled worker has held 2.8 jobs. The figure also shows that the average number of jobs held in Germany increases only during the first 4 to 5 years, and flattens out afterwards. These numbers confirm that mobility in Germany is relatively low; this contrasts to the US for example where, on average, workers hold their 7th job after 10 years of labour market experience (see Topel and Ward, 1992).

In Table 2 we show the percentage of job moves that result in a job within the same sector and in a different sector. Table 12 in Appendix C provides the list of the 15 sectors we consider and the proportion of workers in our sample employed in each over the entire time period we consider. Here it emerges that the majority of moves between firms involves a change in sector. However, when it comes to the moves caused by closure the proportion staying in the same sector rises. Thus among those making a decision to move between firms a large proportion also decides to change sector. This is consistent with the low number of

\footnotetext{
${ }^{26}$ We delete the few individuals who have one or more part time spells.

${ }^{27}$ Bender et al. (2002), Burda and Mertens (2001) and Fitzenberger and Kurz (2002) provide additional descriptive evidence on the German labour market.
} 


\begin{tabular}{l|c|c|}
\hline \hline Six Month periods & Skilled & Unskilled \\
\hline Job to Job & $49.1 \%$ & $30.8 \%$ \\
$0-1$ & $23.9 \%$ & $30.5 \%$ \\
$1-2$ & $12.6 \%$ & $15.8 \%$ \\
$2-3$ & $7.5 \%$ & $9.9 \%$ \\
$3-4$ & $1.5 \%$ & $3.8 \%$ \\
$4-5$ & $2.0 \%$ & $4.1 \%$ \\
$5+$ & $3.4 \%$ & $5.1 \%$ \\
\hline \hline
\end{tabular}

Table 1: Time to a new job following displacement (six month periods)

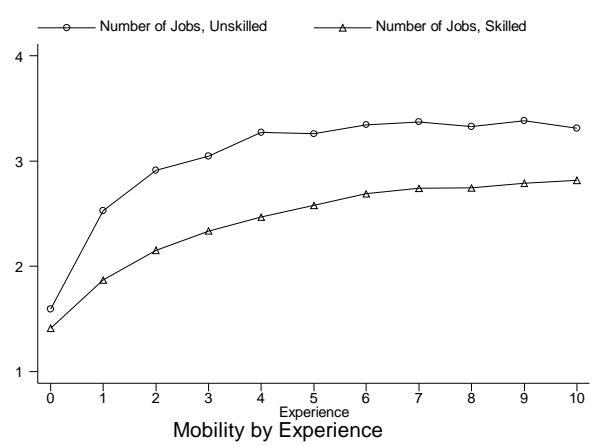

Figure 1: Average number of jobs by years of experience

moves we observe and such mobility may be an important part of job or career "shopping" activity by young workers.

In Table 1 we show the time taken by the displaced to find new jobs. A large proportion move to a new job with no interruption, which probably reflects the advance notice that workers get in Germany (see Appendix B). This is less true for the unskilled workers, who overall have longer spells out of work.

\begin{tabular}{|c|c|c|c|}
\hline \multicolumn{4}{|l|}{ Mobility within and across sectors } \\
\hline & All & Skilled & Unskilled \\
\hline \% Job Termination to New firm, Same Sector & 38.5 & 41.4 & 31.0 \\
\hline \% Job Termination to New firm, New Sector & 61.5 & 58.6 & 69.0 \\
\hline \% Job Termination to New firm, Same Sector (after Displacement) & 44.9 & 47.6 & 39.3 \\
\hline \% Job Termination to New firm, New Sector (after Displacement) & 55.1 & 52.4 & 60.7 \\
\hline
\end{tabular}

Table 2: Percentage of Job Terminations within/across sectors 


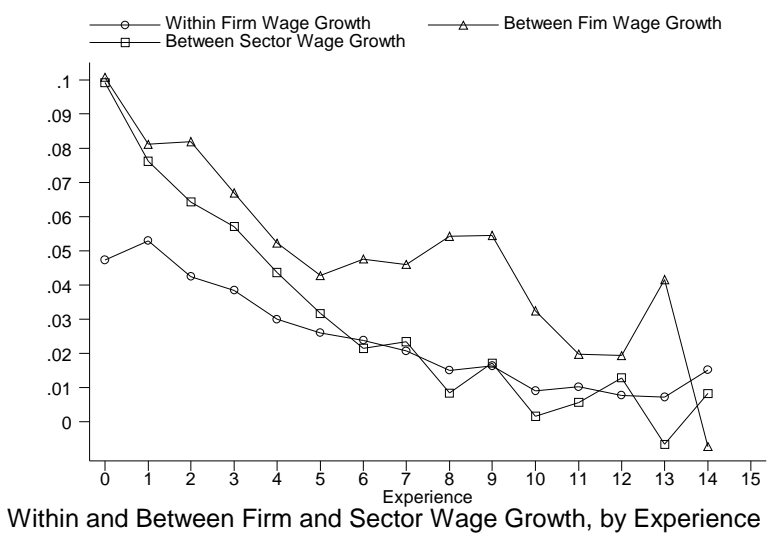

Figure 2:

\section{Between and Within Job Wage Growth}

Figure 2 displays wage growth for workers within firm, between firms of the same sector and between firms of different sectors, against experience. Within job average annual wage growth is lower than between job average wage growth. The difference in within and between job wage growth declines with experience. This may reflect a higher variance of accepted job offers for movers early in the career when workers have not sorted into their best match yet. Between sector wage growth is initially similar to between job wage growth, but declines more rapidly with experience.

Overall average within job wage growth in the first 4 years in the labour market is 4.2 percent, which compares to 7.6 percent for between job wage growth, and 6.8 percent for between job and between sector wage growth. ${ }^{28}$ We also find that the realised gains from moving decline with the number of jobs the individual has held. ${ }^{29}$ This is consistent with the idea that the scope for improvement of a match declines eventually.

\footnotetext{
${ }^{28}$ Within firm wage growth is the annual growth in wages for those staying in the same firm. Between firm wage growth is equal to the difference in log wages between the new firm and the old firm. Between sector wage growth is calculated over those who change sector when they change firm.

${ }^{29}$ This is in line with Topel and Ward (1992), who find for the US that between job wage growth declines with experience. However, they establish a far larger between job wage growth: $12 \%$ for the first 10 years of labour market experience, as compared to $1.75 \%$ within jobs.
} 
Wages, Wage Growth, and the Number of Jobs

Our descriptive analysis suggests that job movers obtain wage gains, as predicted by search theory. However, this does not imply that, on average, job movers have higher wages than non-movers. To investigate this, we regress log wages on dummies for the number of the jobs the individual has held to date (first job, second job etc.), as well as on age and year dummies. ${ }^{30}$ These estimates indicate that workers who have held more jobs have lower wages. When braking this down by skill level we see that the phenomenon is particularly strong for the skilled workers. Those among the unskilled who have held two jobs have the highest wages on average. Wages decline thereafter with more jobs.

When we run the same regression of wages on the number of jobs, including individual fixed effects, the number of jobs is positively associated with wages for all education groups. ${ }^{31}$ Hence, although it seems that movers among the skilled workers are negatively selected, job mobility does lead to wage gains on average for all groups. Moreover, the unskilled with a few (but not too many) job moves seem to be the most productive.

\section{The Firms}

An important component of our identification strategy is information about the closure of the firm in which the worker is employed. In our data we observe establishments, which we always refer to as firms. In multi-establishment firms closure refers to the closure of one of these.

We discussed the assumptions we need to make about selection of workers in these firms above. In figure 3 we plot the survivor function for the firms that came into existence after 1978. The annual exit rates are quite high initially, and they steadily decline. Only just over $60 \%$ of firms observed to start up survive beyond 15 years.

In figure 4, we show the evolution of average employment for German firms known to close down. We distinguish between 3 different categories, according to their age at closure (point 0 on the $\mathrm{x}$-axis in the graph); s1, s2 and s3 refer to firms ehich died 6,11 and 16 years of age respectively. The fourth category ( $\mathrm{s} 0$ ) includes all firms which were founded before

\footnotetext{
${ }^{30}$ See Table 13 in Appendix C, where we report the results for the first eight jobs.

${ }^{31}$ See Table 14 in Appendix C.
} 


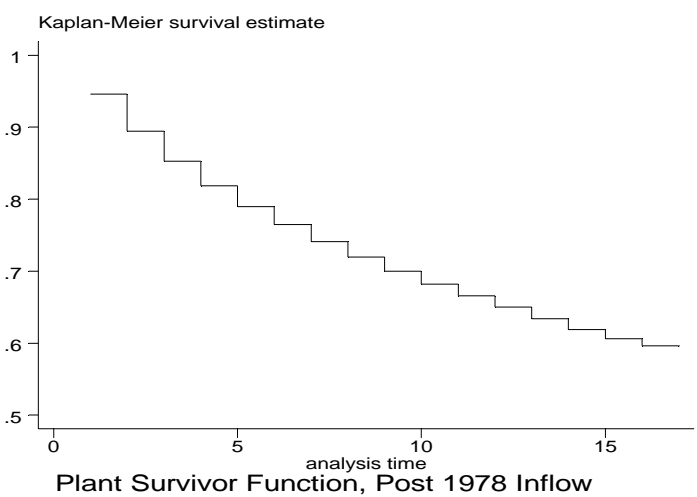

Figure 3:

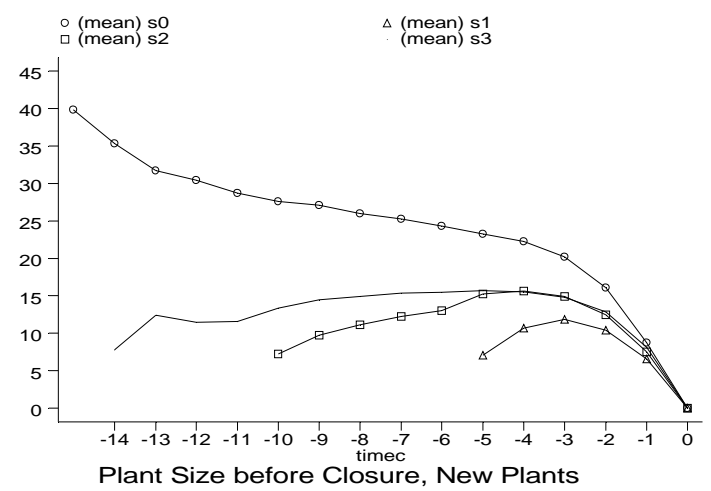

Figure 4: 
1978 (the first year for which firm information is available). ${ }^{32}$ The first obvious drop in employment in firms that will eventually close down is between years minus two and minus one.

As we discuss above, selective firing or quits may impact on the average quality of the workforce in the firm. In fact, we find that the wages of the unskilled workers who remain in the firm within less than a year of its closure are lower by $10 \%$ on average than the average wage of the workforce observed a year earlier (see figure 5, where the upper graph refers to skilled workers, and the lower one to unskilled workers; time zero is the year of closure). This may partly reflects wage drops, and partly composition effects. For the skilled, the drop is only about 1-2\%. Post closure the unskilled seem to recover immediately all wage losses. Moreover, wage growth is higher for that sample for one more year. This may be linked to the fact that post closure these workers become more mobile to recover the lost search capital and may also indicate returns to tenure. ${ }^{33}$

These graphs indicate that selective departures from firms that will close down may start as early as two years before closure. This motivates our robustness check where we define displaced workers in two ways: workers who leave a firm that closes down within one year of their departure and workers who leave a firm that closes down within two years of their departure. We discuss differences between workers displaced due to firm closure and all others in a later section when we carry out sensitivity analysis for our results.

\section{Estimation of the wage equation}

\subsection{The reduced forms}

There are three reduced forms in our model: one for experience (the accumulation of past participation decisions), one for current participation, and one for tenure. Experience is

\footnotetext{
${ }^{32}$ The s0 graph in (4) has to be interpreted with care since its gradient is partly due to the change in the age composition of firms. Thus the breakdown by cohort (s1,s2 and s3) is made so as to avoid the composition effects that are induced by the fact that young firms are both smaller and more likely to close down. The differences in firm size across the lines reflect a different age of each group.

${ }^{33}$ It is worth emphasising that our estimates of wage growth never rely on comparisons pre and post displacement. The graph on the evolution of wages pre and post displacement provide a graphic explanation as to why such comparison may be misleading.
} 


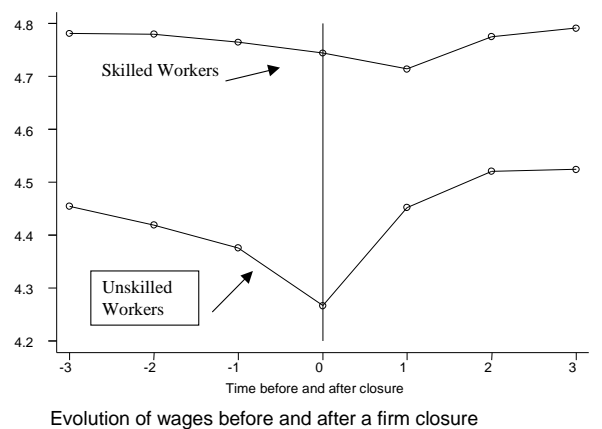

Figure 5:

defined as the number of years (including fractions of a year) worked up to now. To deal with the incredible amount of detail in the data we define current participation as the fraction of the calendar year in employment. ${ }^{34}$ Tenure is defined as the number of years (including fractions of a year) worked in the current firm. The reduced forms include age indicators, potential experience, and interactions (see equation 5), as well as initial education and time effects, and they are estimated separately for apprentices and non-apprentices. All reduced forms are estimated on the entire sample and not only on the sample of displaced workers, to improve precision. They are presented in Appendix D.

In all reduced forms the age dummies as well as the age dummies interacted with potential experience are highly significant and have a p-value of zero, over and above the linear age and potential experience effects. This is necessary (but not sufficient) for the rank condition to be satisfied. Formally the rank condition requires that the rank of the matrix of the coefficients on the age dummies and the age dummies interacted with potential experience has its maximum value of three (i.e. as many as the reduced forms). Based on the eigen value test of Robin and Smith (2000) we tested the null hypotheses of rank 2 against that of three. $^{35}$ We used the bootstrap to derive critical values for the test. We found that the pvalue for this test was 0.0 for 300 replications for both skilled and unskilled workers decisively rejecting rank 2. In other words the rank condition $\mathbf{A . 4}$ as well as the more stringent one

\footnotetext{
${ }^{34} \mathrm{An}$ alternative would be to allocate a whole period of time such as a quarter or a year either to work or to unemployment.

${ }^{35}$ For another application and discussion, see for example Blundell, Duncan and Meghir, 1998.
} 
required to identify the returns to tenure are easily satisfied in our data.

We have also estimated the model excluding the interactions between potential experience and age dummies. The rank condition was again satisfied with a p-value of zero and the estimates of the wage equation were very similar to the ones we present here, with marginally lower precision.

\subsection{The Returns to Experience, Sector Tenure and Firm Tenure}

All wage equations include as conditioning variables indicators for education, as well as annual time effects. The results from the block bootstrap suggests that the small sample bias in all the estimates we present is negligible. Moreover confidence intervals based on the normal distribution using the standard error computed using the bootstrap were basically identical to the ones obtained from the percentiles of the bootstrap. ${ }^{36}$

Throughout we consider 5 different estimation methods: OLS on the whole sample; OLS for the sample of those starting a new job (as in Topel, 1991); OLS on the sample of those starting a job post displacement; our control function approach using the entire sample of new jobs and including the residual terms for endogeneity/selection correction; our control function approach which includes the same residual terms but uses only the first post displacement record.

\section{The returns to experience}

Experience is modelled as a set of annual experience indicators for the first four years of experience and a linear experience effect beyond that. All coefficients are interpreted as the effect of experience on annual growth of wages at different experience levels. All regressions include sector tenure. Results on sector and firm tenure are discussed in later sections.

\footnotetext{
${ }^{36}$ In whatever follows we will compare the skilled to the unskilled workers. The differences between the two groups should not be interpreted necessarily as causal; they may well be due to the unobserved characteristics of individuals choosing the alternative careers.
} 


\begin{tabular}{|c|c|c|c|c|c|}
\hline & \multicolumn{3}{|c|}{ OLS } & \multicolumn{2}{|c|}{ Control Function Estimator } \\
\hline & Whole sample & All New Jobs & $\begin{array}{c}\text { New Jobs after } \\
\text { Displacement }\end{array}$ & All New Jobs & $\begin{array}{c}\text { New Jobs after } \\
\text { Displacement }\end{array}$ \\
\hline \multicolumn{6}{|l|}{ Experience } \\
\hline \multirow[t]{2}{*}{ One year } & 0.146 & 0.146 & 0.087 & 0.17 & 0.099 \\
\hline & 0.0056 & 0.010 & 0.037 & 0.01 & 0.035 \\
\hline \multirow[t]{2}{*}{ two years } & 0.082 & 0.059 & 0.085 & 0.060 & 0.082 \\
\hline & 0.0057 & 0.012 & 0.039 & 0.012 & 0.038 \\
\hline \multirow[t]{2}{*}{ three years } & 0.064 & 0.029 & 0.045 & 0.032 & 0.029 \\
\hline & 0.0057 & 0.013 & 0.036 & 0.012 & 0.036 \\
\hline \multirow[t]{2}{*}{ four years } & 0.043 & 0.034 & 0.041 & 0.021 & 0.033 \\
\hline & 0.0055 & 0.012 & 0.030 & 0.015 & 0.032 \\
\hline \multirow[t]{2}{*}{ five years +} & 0.016 & 0.014 & 0.015 & 0.0012 & -0.004 \\
\hline & 0.0016 & 0.003 & 0.0063 & 0.0038 & 0.01 \\
\hline $\mathrm{N}$ & 55953 & 18923 & 1373 & 18923 & 1373 \\
\hline
\end{tabular}

Column 1: Asymptotic standard errors acounting for serial correlation and heteroscedasticity

in italics. Columns 2-5: Standard Deviation of the block bootstrap in italics for. 200 replications used.

Records for unskilled displaced workers $1373 \mathrm{~N}$ : Total number of observations (individuals $\times$ records)

Table 3: Wage growth - Experience, Unskilled Workers

\section{Unskilled Workers}

Table 3 presents the results for the sample of unskilled workers (i.e. without an apprenticeship). The first column presents the experience profile obtained by OLS on the entire sample. The estimated returns to the first year of experience $(14.6 \%$ over a year) are large. This result is the same as the second regression based on the first job record of all those starting a new job (as in Topel 1991). When we consider the estimates based on the displaced workers only, but with no endogeneity/selection correction (in the third column), we find that the first year estimated returns fall to $8.7 \%{ }^{37}$ This implies that a large part of the first year increase in wages for unskilled workers is due to job search and improved matches. This is consistent with our results in the descriptive section, which suggest that among the unskilled, movers on average improve their wage with the first job change.

The fourth column illustrates the impact of adding the residuals but using the entire sample of job movers as in column 2. This ignores the bias that may be induced by the role of search in improving wages. The effect of adding these residuals compared to columns 1 and 2 is to reduce the returns to experience for later years, suggesting that the observed

\footnotetext{
${ }^{37}$ In Table 16 in Appendix D we provide the number of observations by experience level for the displacement sample.
} 
growth in later years can be attributed to the stronger labour market attachment of more able workers or workers with higher returns.

The final column presents results based on our approach; the residual terms are included and only the records relating to the first post-displacement job are used. The estimates of the coefficients on the residuals are presented in Table 15 of Appendix D. ${ }^{38}$ The residual terms based on bootstrap critical values are significant at the $0 \%$ level. Therefore the differences in the estimated coefficients obtained when the residuals are included, compared to those in column 3, are jointly significant. In addition a Wu-Hausman test comparing the experience coefficients presented in column 5 to those obtained by OLS in column 1 rejects equality at $1.4 \%$.

Now the first year returns are estimated to be $9.9 \%$, much lower than the original first year return from column 1. Comparing across columns we see that this is the effect of using displaced workers. Differences are also apparent in later years, where the results in the final column imply a flatter experience profile. Comparing the first to the last column, our final results imply that for the unskilled workers wage growth due to experience declines rapidly and falls to zero by five years. In fact the returns in column 5 are not significant beyond two years of experience. By contrast, the OLS returns are large and significant throughout, with a longer term return of $1.6 \%$.

Comparing the results of columns five with those of columns three and four we see that both the selection/endogeneity correction and the use of the displaced sample contribute to the differences from OLS. Columns 2 and 3 or 4 and 5 indicate that much of the early returns to experience can be attributed to improved matches, which is consistent with the fact that movers improve their wage. While comparing 4 and 5 where we add the residual terms, it is evident that endogeneity of experience (due to endogenous participation choices) is also an important issue at longer levels of experience (as also indicated by the significance of the residuals).

\footnotetext{
${ }^{38}$ Since the sample of displaced workers is relatively small, particularly for the unskilled workers, we have imposed the restriction that the coefficients on the residual terms are equal between the skilled and unskilled workers, a restriction we test and cannot reject. This does not impose that the resulting selection effects are the same since this also depends on the distribution of residual terms for the skilled and the unskilled.
} 


\section{Skilled Workers}

When estimating the model for the skilled workers, we include the period of apprenticeship in experience, tenure and sector tenure. The duration of apprenticeship varies usually between two and three years. The first return to experience that we can measure for the sample of skilled workers relates to the growth of wages following the second year of experience. ${ }^{39}$

We display results for the skilled workers in Table 4. For this group, the estimates based on the displaced sample with no endogeneity/selection correction (column 3) imply higher returns to experience in the second year than the estimates based either on the entire sample (1), or on the entire sample of new job starters (2). This is different from our findings for unskilled workers and is compatible with the fact that movers are negatively selected among the skilled workers, as we show in our descriptive section 3.1. In column 4 we report the results of including the residual terms but estimating the model on the entire sample of new job starts (as in column 2) and the results are very similar. In the final column, we use the displaced sample and include the residual terms to control for endogeneity/selection. Selection/endogeneity correction matters less for the skilled workers, as far as the returns to experience is concerned, which reflects the fact that the skilled workers have fewer and shorter spells out of work. The Wu-Hausman test comparing the experience coefficients in columns 1 and 5 has a p-value of $15 \%$.

To summarise, our findings suggest that wages for the unskilled workers grow significantly in the first two years of work, due to learning by doing. Thereafter unskilled workers enjoy little or no returns to experience. Skilled workers have lower wage growth initially - a result that may be attributed to the fact that they have received much of their general skills during their formal training period. However, other than for the unskilled wages continue to grow due to experience throughout the period of the life-cycle that we observe, at a relatively low but significant rate of $1.2 \%$.

\footnotetext{
${ }^{39}$ We do not model wages during apprenticeship.
} 


\begin{tabular}{|c|c|c|c|c|c|}
\hline & \multicolumn{3}{|c|}{$\overline{\mathrm{OLS}}$} & \multicolumn{2}{|c|}{ Control Function Estimator } \\
\hline & Whole Sample & All new Jobs & $\begin{array}{c}\text { New Jobs After } \\
\text { Displacement }\end{array}$ & All new jobs & $\begin{array}{c}\text { New Jobs after } \\
\text { Displacement }\end{array}$ \\
\hline \multicolumn{6}{|l|}{ Experience } \\
\hline \multirow[t]{2}{*}{ two years } & 0.047 & 0.042 & 0.067 & 0.054 & 0.068 \\
\hline & 0.0036 & 0.0045 & 0.019 & 0.0047 & 0.019 \\
\hline \multirow[t]{2}{*}{ three years } & 0.060 & 0.056 & 0.056 & 0.061 & 0.062 \\
\hline & 0.0022 & 0.0038 & 0.016 & 0.0039 & 0.014 \\
\hline \multirow[t]{2}{*}{ four years } & 0.067 & 0.039 & 0.060 & 0.070 & 0.062 \\
\hline & 0.0020 & 0.0050 & 0.015 & 0.0046 & 0.017 \\
\hline \multirow[t]{2}{*}{ five years +} & 0.021 & 0.017 & 0.022 & 0.013 & 0.012 \\
\hline & 0.0006 & 0.0016 & 0.0046 & 0.0014 & 0.004 \\
\hline $\mathrm{N}$ & 204543 & 57005 & 3639 & 57005 & 3639 \\
\hline $\begin{array}{l}\text { Column 1: } \mathrm{A} \\
\text { in italics. } \mathrm{Co} \\
\text { Records of } \mathrm{sl}\end{array}$ & $\begin{array}{l}\text { nptotic standard } \\
\text { ans 2-5: Standar } \\
\text { d displaced wor }\end{array}$ & $\begin{array}{l}\text { rors accounting } \\
\text { eviation of the } \\
3639 \text {. N: Tota }\end{array}$ & $\begin{array}{l}\text { or serial correlatic } \\
\text { lock bootstrap in } \\
\text { aumber of observa }\end{array}$ & $\begin{array}{l}\text { d heteroscedas } \\
\text { cs for. } 200 \text { repl } \\
\text { s (individuals } \times\end{array}$ & $\begin{array}{l}\text { city } \\
\text { cations used. } \\
\text { ecords) }\end{array}$ \\
\hline
\end{tabular}

Table 4: Wage growth - Experience, Skilled Workers

\section{Returns to sector tenure}

We now turn to the returns to remaining in the same sector. The results here are obtained from the same regressions as those for the returns to experience. The columns in the tables correspond. We have fitted a linear spline providing an annual return for the first five years and an annual return thereafter.

Based on the OLS results reported in Table 5, columns 1, the return to sector tenure is about $0.9 \%$ for skilled workers. For the unskilled, it is $2.2 \%$ in the first four years, and basically zero subsequently. When we consider the results based on our approach (column 5) we obtain that the returns to sector tenure are $1.0 \%$ for the skilled workers in the first five years and zero thereafter.

For the unskilled workers the returns are also now low and insignificant; combined with the results from the returns to experience this suggests that there is not much wage growth from learning by doing for the unskilled, at least as far as transferable skills are concerned. Finally, when we ignore sector tenure the returns to experience remain more or less unaffected. These results are consistent with the fact that job change is very frequently associated with sector change (see Table 2) since it does not seem particularly costly to change sector.

So far we have assumed that sector switches following displacement, and having controlled for the endogeneity of job acceptance and experience, can be taken as exogenous. To test 


\begin{tabular}{|c|c|c|c|c|c|}
\hline & \multicolumn{3}{|c|}{ OLS } & \multicolumn{2}{|c|}{ Control Function Estimator } \\
\hline & Whole Sample & All New Jobs & $\begin{array}{c}\text { New Jobs After } \\
\text { Displacement }\end{array}$ & All new jobs & $\begin{array}{c}\text { New Jobs after } \\
\text { Displacement }\end{array}$ \\
\hline \multicolumn{6}{|l|}{ Sector Tenure } \\
\hline \multicolumn{6}{|c|}{ Skilled } \\
\hline \multirow[t]{2}{*}{$<5$ Years } & 0.0088 & 0.014 & 0.0098 & 0.010 & 0.010 \\
\hline & 0.0007 & 0.00086 & 0.0029 & 0.001 & 0.003 \\
\hline \multirow{2}{*}{$\geq 5$ Years } & 0.0070 & 0.012 & 0.0054 & 0.012 & 0.006 \\
\hline & 0.00091 & 0.0018 & 0.0042 & 0.002 & 0.004 \\
\hline \multicolumn{6}{|c|}{ Unskilled } \\
\hline \multirow[t]{2}{*}{$<5$ Years } & 0.022 & 0.028 & 0.0049 & 0.023 & 0.003 \\
\hline & 0.0022 & 0.0026 & 0.0078 & 0.003 & 0.007 \\
\hline \multirow[t]{2}{*}{$\geq 5$ Years } & 0.0015 & 0.0007 & 0.014 & -0.003 & 0.022 \\
\hline & 0.0024 & 0.0045 & 0.010 & 0.006 & 0.013 \\
\hline
\end{tabular}

Table 5: Wage growth - Sector Tenure, Unskilled and Skilled

for this, we follow Neal (1995) and use as an instrument for sector tenure (and hence sector switches) the pre-displacement sector size. The idea is that the larger the sector, the more likely it is that a worker will find a job in the sector he left. In fact this instrument is highly significant in the sector tenure reduced form, with a p-value of zero. The test for the hypothesis of exogeneity of sector tenure consists of testing that we can exclude the sector tenure residual from the wage equation. This is easily accepted with a p-value of $77 \%$.

\section{The Returns to Firm Tenure}

In Table 6 we present the estimates for the annual returns to firm tenure for both groups of workers. As for sector tenure we have fitted a linear spline providing an annual return for the first five years and an annual return thereafter. The results in columns 1,4 and 5 are based on levels. Results in columns 2 and 3 are based on within firm wage growth as in Topel (1991). In this case we have regressed the within firm wage growth (differences in logs of wages over time) on tenure indicators, after subtracting the growth implied by experience and sector tenure shown in column 2 of Tables 3,4 and 5 respectively. In column 2 we use the entire sample and in column three the jobs that started post-displacement. 


\begin{tabular}{|c|c|c|c|c|c|}
\hline & \multicolumn{3}{|c|}{$\overline{\text { OLS }}$} & \multicolumn{2}{|c|}{ Control Function Estimator } \\
\hline & Whole Sample & All New Jobs & $\begin{array}{c}\text { New Jobs After } \\
\text { Displacement }\end{array}$ & All New Jobs & $\begin{array}{c}\text { New Jobs after } \\
\text { Displacement }\end{array}$ \\
\hline \multicolumn{6}{|l|}{ Tenure } \\
\hline \multicolumn{6}{|c|}{ Skilled } \\
\hline \multirow[t]{2}{*}{$\leq 5$ Years } & 0.012 & -0.009 & -0.0004 & 0.017 & 0.024 \\
\hline & 0.0007 & 0.0009 & 0.0045 & 0.0009 & 0.004 \\
\hline \multirow[t]{2}{*}{$>5$ Years } & -0.003 & -0.020 & 0.011 & 0.022 & 0.017 \\
\hline & 0.001 & 0.0019 & 0.014 & 0.004 & 0.012 \\
\hline \multicolumn{6}{|c|}{ Unskilled } \\
\hline \multirow[t]{2}{*}{$\leq 5$ Years } & 0.014 & -0.014 & -0.022 & 0.025 & 0.040 \\
\hline & 0.0022 & 0.0019 & 0.0074 & 0.0027 & 0.010 \\
\hline \multirow[t]{2}{*}{$>5$ Years } & -0.003 & -0.018 & -0.058 & 0.036 & 0.011 \\
\hline & 0.0027 & 0.004 & 0.020 & 0.006 & 0.019 \\
\hline
\end{tabular}

Table 6: Wage growth - Tenure, Unskilled and Skilled

From the levels OLS regression we find that for the skilled workers the returns to tenure are very low (being 1.2\% for the first five years and $0 \%$ thereafter). When we estimate the model based on within firm wage growth on all jobs, without controlling for endogeneity of the mobility decision (as in Topel, 1991), we find negative returns. This negative estimate is probably a result of bias induced by the fact that stayers are individuals who in the previous period had a better wage outcome within the firm than average. With low returns to tenure, this selection effect can dominate and make the overall return negative. Using the same method as in column 2, but only on the jobs following displacement cannot correct such a downward bias. When we control for the endogeneity of the mobility decision we find a $2.4 \%$ annual return to tenure for the skilled workers in the first five years and $1.7 \%$ thereafter (column 5). The coefficients of the residuals for the tenure equation are reported in Appendix D and are highly significant ( $\mathrm{p}$-value of 0 ), which implies that the differences in the coefficients on tenure when we include the residuals are jointly significant. The WuHausman test comparing the OLS returns to tenure in column 1 with those in column 5 has a p-value of $0.1 \%$, strongly rejecting equality. 
For the unskilled, the OLS returns are $1.4 \%$ for the first five years and zero thereafter. But based on the results of column 5 the unskilled have relatively high returns to tenure of $4 \%$ a year for the first five years in the firm. However, the returns beyond five years are much lower (1.1\%) and insignificant. The results between column 1 and 5 are significantly different with a p-value for the Wu-Hausman test of $1.5 \%$.

The increase in the returns to tenure may represent a reallocation of life-cycle growth from experience to tenure, since the returns to experience decline quite substantially when we correct for selection and search. Since the returns to tenure are estimated after the returns to experience we can check to see how much of the increase in the returns to tenure is due to this shifting of wage growth from experience to tenure and how much is due to the correction for selective departures. To do this we re-estimate the returns to tenure using OLS on the post-displacement sample. However, we first adjust wages for experience based on the estimates in column 5, Tables 3 and 4 . We obtain the following results: Skilled workers tenure $<5$ years 0.028 (se 0.004); skilled workers tenure $\geqslant 5$ years -0.006 (0.007); unskilled workers tenure $<5$ years 0.045 (se 0.009); unskilled workers tenure $\geqslant 5$ years $-0.026(0.013)$. Thus the increase in the returns to tenure for the early years seem to be driven by the decline in the returns to experience. Although correcting for selection in firm mobility reduces somewhat the early returns to tenure, the main effects of selection are for higher levels of tenure. The increase in the estimated returns to tenure when we correct for selection is consistent with a matching story, where individuals with a high individual effect in the return to tenure have a stronger incentive to move and match with a better firm if the improvement in the match is high enough to counteract the accumulated returns to tenure. To see this suppose that the match specific return to tenure consists of an individual effect multiplied by a firm effect (say $\nu_{i f t}=\phi_{i} \theta_{f}$ ). Given the costs of moving the returns to improving the match will be higher for those with a higher individual effect $\phi_{i}$.

We have also tested whether further curvature is required for the later years by including a quadratic term in experience, sector tenure and tenure for each skill group . The test for the exclusion of these extra quadratic terms has a p-value of $18 \%$. Moreover, none of the conclusions are altered. The full set of results for the control function estimator post- 


\begin{tabular}{ll}
\hline \hline \multicolumn{2}{c}{ Apprenticeship } \\
\hline All Closures & Old Firms \\
-0.05 & -0.006 \\
0.008 & 0.01 \\
\hline \hline
\end{tabular}

Table 7: Difference in the proportion of apprentices in firms which close down compared to all firms

displacement are presented in Table 19 of Appendix C.

Thus, there is strong evidence for positive returns to tenure, which are higher for the unskilled. The way German firms operate seems to reward loyalty. For the unskilled this seems to an important source of wage growth. The implication for policy is that subsidised placements (from wage subsidy programs say) would have to be made with a view of securing long term employment in the firm taking up such workers, since a large part of human capital accumulation does not seem to be transferable.

\subsection{Robustness Checks}

As stated in the assumptions of the model the validity of the results rely on the displaced workers being a random sample of all workers, conditional on the observables. This is an identifying assumption and cannot be tested. However we provide some circumstantial evidence using observable indicators. In the first column of Table 7 we show the difference in the proportion of apprentices among the population, and the firms that close down. This shows that firms that close down have about 5 percentage points fewer apprentices (from an average of 78\%). In Table 8, under the "All Closures" columns, we consider the difference in experience (conditional on age) between workers who join firms which will close down in our sample and workers who join any firm. The differences are mostly insignificant and very small. The largest difference is 0.13 of a year (or 6.8 weeks), and it is barely significant.

Among firms which close down there will be a disproportionate number of younger firms. These may be likely to hire less experienced workers since they are more mobile. Thus we repeat the comparison by concentrating on workers in firms that started up before 1980 . The difference in the proportion of apprentices for firms that will close down and all other 


\begin{tabular}{clllll}
\hline \hline \multicolumn{2}{c}{ All Workers } & \multicolumn{2}{c}{ Skilled } & \multicolumn{2}{c}{ Unskilled } \\
\hline All Closures & Old Firms & All Closures & Old Firms & All Closures & Old Firms \\
\hline-0.04 & 0.09 & 0.009 & 0.11 & -0.13 & 0.05 \\
0.03 & 0.04 & 0.03 & 0.04 & 0.06 & 0.09 \\
\hline Asymptotic Standard errors in italics. & & & \\
\hline \hline
\end{tabular}

Table 8: Difference at the date of entry in the years of experience of workers who join firms which close down, compared to workers who join any firm

\begin{tabular}{l|cc|cc}
\hline \hline & \multicolumn{2}{|c}{ Skilled } & \multicolumn{2}{c}{ Unskilled } \\
\hline & Population & $\begin{array}{c}\text { Firms that } \\
\text { will close }\end{array}$ & Population & $\begin{array}{c}\text { Firms that } \\
\text { will close }\end{array}$ \\
\hline Experience & 0.0371 & 0.0502 & 0.050 & 0.0718 \\
& $0.000^{r}$ & 0.0062 & 0.001 & 0.0102 \\
Sector Tenure & 0.0116 & 0.0115 & 0.0164 & 0.0180 \\
& 0.0006 & 0.0044 & 0.0016 & 0.0134 \\
\hline \multicolumn{7}{l}{ Asymptotic standard errors in italics. } \\
\hline
\end{tabular}

Table 9: Relationship of experience and sector tenure to wages in the population of firms and the firms that will close down in two years or more

firms is reported in the "Old Firms" column in Table 7, and it now drops to zero. As far as differences in experience are concerned the picture remains the same and indicates that there are no important differences between the workers in firms that will close down and the population (see "Old Firms" columns in table 8).

Finally we carry out a further simple experiment to check whether there are likely to be systematic differences in the relationship between experience, sector tenure and wages in the firms that will close down. We run a regression of log wages on experience and sector tenure for individuals starting new jobs. We compare this to the results we obtain when we confine attention to firms that will close down in two years or more. We focus on sector tenure since this seems to decline substantially when we condition on displacement firms. The results are reported in Table 9.These show that there are no significant differences in the relationship between experience and sector tenure with wages, between firms that will close down and other firms.

Thus workers in firms that are observed to close down are very similar to the whole population of young workers in our data set. However there are potential sources of non randomness of the displaced workers that these comparisons may not pick up. We thus 
consider two robustness checks.

The definition of the closure sample

In our data we know whether a firm closes down, independently of when the worker left, since we have direct access to a data set reporting firm size over a 17 year period for any firm which employed any worker in our sample. Up to now we have defined the population of displaced workers due to firm closure as the set of workers who left the firm which closed down within one year of their departure. Using a narrow window to define a worker displaced due to closure makes it more likely that the worker is in fact displaced because of an imminent closure. On the other hand, if the closure was anticipated by the management or by the worker, we may end up with a selected sample of workers (both in terms of observables and unobservables). This selection may have opposing effects: Firms may lay off less productive workers first, or the best workers may leave the firm before the closure. Taking a wider window mitigates this problem, but increases the risk that workers are included who moved for reasons other than closure.

In Table 10 we present results for the returns to experience for the skilled and unskilled based on the broader definition of closure. This defines as displaced any worker who left a firm that closed down within two years of their departure. The number of displaced workers with this definition increases from 3639 to 4589 for the skilled and from 1373 to 1796 for the unskilled. The regressions include the residuals, and they are comparable to the last column of Tables 3 (unskilled workers) and 4 (skilled workers).

The estimated initial returns for the skilled and unskilled workers are lower now. However, the difference is insignificant with a p-value for this difference of $50 \%$ for the skilled and $58 \%$ for the unskilled. All other returns are very similar and overall the differences are completely insignificant.

In the first column of Table 11, we also report the results for firm tenure for this definition of firm closure. The returns to tenure for the first five years remain unchanged vis a vis our 


\begin{tabular}{l|cc}
\hline \hline \multicolumn{2}{c}{ Skilled } & Unskilled \\
\hline \hline Experience & & $\mathbf{0 . 0 7 3}$ \\
& - & 0.031 \\
One year & - & $\mathbf{0 . 0 7 4}$ \\
two years & $\mathbf{0 . 0 5 2}$ & 0.032 \\
& 0.017 & $\mathbf{0 . 0 3 5}$ \\
three years & $\mathbf{0 . 0 5 6}$ & 0.032 \\
& 0.014 & $\mathbf{0 . 0 3 9}$ \\
four years & $\mathbf{0 . 0 6 3}$ & 0.029 \\
& 0.016 & $\mathbf{- 0 . 0 0 4}$ \\
five years + & $\mathbf{0 . 0 1 0}$ & 0.010 \\
\multicolumn{3}{l}{ N.Obs. } \\
\hline Standard Deviation of the block bootstrap in italics.
\end{tabular}

Table 10: Wage growth - Experience, Broader definition of closure

preferred results in the last column of Table 6 . The tenure returns beyond five years do increase bu they are not well determined

Thus the results are not sensitive to the precise way of defining displaced workers, although if we estimate the model on all movers we get significantly different results, as shown in the previous sections.

Is there evidence of bias due to self-selection by firm closure probability?

One reason that the closure sample may be non-random is that workers may self-select into firms based on any information relating to their closure probability. This assumption is important: Workers with higher unobserved returns to tenure would avoid firms more likely to close down, since they suffer a larger loss from closure. This would lead to a downward bias in the estimated average returns to tenure in the estimates we presented.

Our data provides information that allows us to present some evidence about this: As we have seen, young firms are more likely to close down (see figure 3). If workers with high returns to tenure were trying to avoid firms with high closure probability they should avoid employment in younger firms (all else being equal). Thus, we re-estimate our model based on the firms that were in existence before 1980 and subsequently closed down in our 


\begin{tabular}{l|cc}
\hline \hline Tenure & $\begin{array}{c}\text { Broad Definition } \\
\text { of Closure }\end{array}$ & Older Firms \\
\hline Skilled, $<5$ Years & $\mathbf{0 . 0 2 6}$ & $\mathbf{0 . 0 1 5}$ \\
& 0.0038 & 0.005 \\
\hline Skilled, $\geq 5$ Years & $\mathbf{0 . 0 2 6}$ & $\mathbf{0 . 0 0 3 2}$ \\
& 0.010 & 0.016 \\
\hline & 0.040 & $\mathbf{0 . 0 2 7}$ \\
\hline \hline & 0.008 & 0.009 \\
\hline Unskilled $<5$ Years & $\mathbf{0 . 0 2 5}$ & $\mathbf{- 0 . 0 2 3}$ \\
& 0.017 & 0.024 \\
\hline Unskilled, $\geq 5$ Years & \multicolumn{2}{l}{} \\
\hline \multicolumn{2}{l}{ Standard Deviation of the block bootstrap in italics. } \\
\hline \hline
\end{tabular}

Table 11: Wage growth - Tenure, Unskilled and Skilled, Robustness Checks

sample period. This leads to a drop in the sample of displaced workers by about $40 \%$. If such self-selection was an important phenomenon we should expect the returns to tenure to increase when using this sample, if indeed the returns to tenure are heterogeneous.

The results on the returns to tenure using workers displaced from older firms are presented in the second column of Table 11. These estimates show that the returns to tenure do not increase when using the sample of workers who were displaced following the closure of an older firm; in fact they decrease. Hence from these results there is no indication that selfselection by probability of closure has led to an underestimate of the returns to tenure. This reinforces our view that the use of the displacement sample is a valid way to proceed. The returns to experience are also similar and we do not report them for the sake of brevity.

\section{Concluding Remarks}

In this paper we analyse wage growth for workers in Germany. We focus on two groups: Those with apprenticeship training (skilled workers), and those with no post-secondary school education or formal training (unskilled workers).

The framework for our analysis is a model with match specific effects as well as heterogeneous returns to experience, firm tenure and sector tenure. We discuss a way of identifying and estimating this model based on displaced workers. The sample we consider is unique, in 
that we observe an accurate calendar of all job transitions from the beginning of the workers' careers. This has led us to consider workers up to the age of 35. As earlier studies have shown, this is the period of the most rapid wage growth.

Wages of the skilled workers grow with experience and the profile is concave, with growth starting at $7 \%$ early on, and falling to $1.2 \%$ a year beyond four years. The returns to staying in the same sector are about $1 \%$ a year but they decline after five years, while the returns to staying in the same firm are about $2.5 \%$ a year again declining after five years.

Wages of the unskilled workers only grow for the first two to three years of labour market experience. Experience related growth falls to zero following that. Their return to sector tenure are close to zero and statistically insignificant. However, unskilled workers seem to benefit from returns to firm tenure which are about $4 \%$ a year for the first five years but decline to an insignificant $1.1 \%$ thereafter. Thus, while the aquisition of transferable skills seem to be important for the wage growth of skilled workers early on in their career, unskilled workers benefit primarily from being attached to a particular firm. An important implication of this is for the success of temporary interventions in the labour market. Programmes that seek to improve employability of the unskilled via general work experience are likely to be less successful than programmes that attempt to match a worker with a firm, possibly by an initial period of a job subsidy, at least in Germany.

\section{Appendix A: The selection process into new jobs}

To see what the selection issue is and how exogenous displacements can help identify the returns to experience, we set up a mobility model for individuals. For the purpose of notational simplicity, we ignore here sector tenure, and we only consider one education level; we therefore drop the index $a$. Thus assume that individuals are risk neutral and denote by $u_{i f t}$ the set of unobservables $m_{i f t}, v_{i f t}$ and $\eta_{i t}$, where $i$ denotes individuals, $f$ the firm or job, and $t$ the time period. The value of a job is denoted by $V_{t}^{J}\left(T_{i t}^{G}, T_{i f t}^{F}, r_{t} \mid u_{i f t}\right)$. At the start tenure is zero $\left(T_{i f t}^{F}=0\right)$. We assume that a working individual receives an alternative offer from a firm $f^{\prime}$. The value of unemployment $V_{t}^{U}\left(T_{i t}^{G}, w_{i l}, d_{i t} \mid \eta_{i t}\right)$ depends on benefits $B_{i t}$, which in general will depend on the previous wage $\left(w_{i l}\right)$ and on unemployment duration $\left(d_{i t}\right)$. Hence 
$B_{i t}=B_{i t}\left(w_{i l}, d_{i t}\right)$. At the start of the unemployment spell duration will be zero.

Denote the value of the current job by

$$
\begin{gathered}
V_{t}^{J}\left(T_{i t}^{G}, T_{i t}^{f}, r_{t} \mid u_{i f t}\right)=w_{i f t}+ \\
\delta E_{t} \max \left[V_{t+1}^{J}\left(T_{i t}^{G}+1, T_{i f t}^{F}+1, r_{t+1} \mid u_{i f t+1}\right), V_{t+1}^{J}\left(T_{i t}^{G}+1,0, r_{t+1} \mid u_{i f^{\prime} t+1}\right),\right. \\
\left.V_{t+1}^{U}\left(T_{i t}^{G}+1, w_{i l}, 0, r_{t+1} \mid \eta_{i t}\right)\right] .
\end{gathered}
$$

The value of unemployment is

$$
\begin{gathered}
V_{t}^{U}\left(T_{i t}^{G}, w_{i l}, d_{i t}, r_{t} \mid \eta_{i t}\right)=B_{i t}+ \\
\delta E_{t} \max \left[V_{t+1}^{J}\left(T_{i t}^{G}, 0, r_{t+1} \mid u_{i f^{\prime \prime} t+1}\right), V_{t+1}^{U}\left(T_{i t}^{G}, w_{i l}, d_{i t}+1, r_{t+1} \mid \eta_{i t}\right)\right]
\end{gathered}
$$

Expectations are taken over future realisations of $u_{i f t}$ and $u_{i f^{\prime} t}$ conditional on the current value of $u_{i f t}$ and the other state variables (where $f$ and $f^{\prime}$ represent alternative firms).

Now consider the set of individuals observed starting a new job. They consist of two groups: First, those moving from an old job $f$ to a new one $f^{\prime}$. Second, those who quit (or were layed off) in period $s<t$ and have now received an acceptable job offer. The former satisfy the condition $V_{t}^{J}\left(T_{i t}^{G}, 0, r_{t} \mid u_{i f^{\prime} t}\right)>\max \left\{V_{t}^{J}\left(T_{i t}^{G}, T_{i f t}^{F}, r_{t} \mid u_{i f t}\right), V_{t}^{U}\left(T_{i t}^{G}, w_{i t}, 0, r_{t} \mid \eta_{i t}\right)\right\}$ denoted for short by $N J>0$. The latter satisfy two conditions: $V_{s}^{U}\left(T_{i s}^{G}, w_{i s}, 0, r_{s} \mid \eta_{i t}\right)>$ $\max \left\{V_{s}^{J}\left(T_{i s}^{G}, T_{i f s}^{F}, r_{s} \mid u_{i f s}\right), V_{s}^{J}\left(T_{i s}^{G}, 0, r_{s} \mid u_{i f^{\prime} s}\right)\right\}$ denoted by $U_{s}>0$ and $V_{t}^{J}\left(T_{i s}^{G}, 0, r_{t} \mid u_{i f t}\right)>$ $V_{t}^{U}\left(T_{i s}^{G}, w_{i s}, t-s, r_{t} \mid \eta_{i t}\right)$ denoted by $N J^{U}>0$. The latter group preferred unemployment to their previous job and an alternative job offer; at duration $t-s$ they obtained a job more acceptable than unemployment valued at duration $t-s$.

Now consider the expected value of wages $\left(\ln w_{i f}\right)$ for individuals who start a new job in firm $f$, for a given level of experience $\left(T_{i t}^{G}\right)$ and for given value of the observable characteristics $z_{i t}$.

$$
\begin{aligned}
& E\left(\ln w_{i f t} \mid T_{i t}^{G}, N J_{t}>0 \text { or }\left[U_{s}>0 \text { and } N J_{t}^{U}>0\right], t, z_{i t}\right)= \\
& \ln r_{t}+\left[\alpha+E\left(\eta_{i t} \mid T_{i t}^{G}, N J_{t}>0 \text { or }\left[U_{s}>0 \text { and } N J_{t}^{U}>0\right], t, z_{i t}\right)\right] T_{i t}^{G} \\
& +E\left(m_{i f t} \mid T_{i t}^{G}, N J_{t}>0 \text { or }\left[U_{s}>0 \text { and } N J_{t}^{U}>0\right], t, z_{i t}\right)
\end{aligned}
$$

The expression $\alpha+E\left(\eta_{i t} \mid T_{i t}^{G},\left[N J_{t}>0\right.\right.$, or $\left[U_{s}>0\right.$ and $\left.\left.N J_{t}^{U}>0\right] t, z_{i t}\right)$ is the average return to experience in the population of those starting a new job, while $E\left(m_{i f t} \mid T_{i t}^{G}, N J_{t}>0\right.$ or $\left[U_{s}>0\right.$ and $\left.\left.N J_{t}^{U}>0\right], t, z_{i t}\right)$ is the average match quality of these persons. The average 
return to experience which we want to estimate is $\alpha$. However modelling the dependence of $\eta_{i t}$ and $m_{i f t}$ for new job starts is complicated by the fact that these individuals are selected by multiple ways; consequently this selection cannot be expressed by a single index as in the Heckman (1974) selection model. Now consider workers who are displaced for a completely exogenous reason. For them the selection $N J_{t}>0$ and $U_{s}>0$ are irrelevant. Consequently

the selection terms become $\left[\alpha+E\left(\eta_{i t} \mid T_{i t}^{G}, N J_{t}^{U}>0, t, z_{i t}\right)\right]$ and $E\left(m_{i f t} \mid T_{i t}^{G}, N J_{t}^{U}>0, t, z_{i t}\right)$. The dependence of the conditional expectations on $N J_{t}^{U}>0$ reflects the job acceptance strategy of the unemployed and can be modelled as the standard selection into work, approximated by a single index, as in Heckman (1974). The conditioning on experience $\left(T_{i t}^{G}\right)$ reflects the fact that the unobservables may be serially correlated, and hence may affect past employment decisions and thus experience

\section{Appendix B: The Institutional Background in Germany}

\section{Wage Setting}

Unlike the US, there is no general, government imposed minimum wage in Germany. Instead, there is an elaborate system of tariff contracts, which specify minimum wages according to occupation, sector, region, and some personal characteristics. These minimum wages are determined by (annual) wage bargaining between unions and employer federations (or single employers).

Bargaining takes place on industry and regional level. Although in principle tariff agreements between an employer (or an employer association) and a union cover only employees who are union members, in practise the union status of the employee is irrelevant. The tariff contracts act as sector specific minimum wages for those firms that are members of employer associations, or that negotiate directly with the union. Not all firms are bound to the tariff agreements, however. Firms which are not in the employer's association do not have to pay tariff wages. In 1995, about 83 percent of all workers were employed in firms that were bound by tariff agreements (see Dustmann and Schoenberg 2002 for details).

\section{Job Security}

The German dismissal regulations concern protection from dismissal, advanced notice, 
as well as severance pay requirements.

The general dismissal protection regulations foresee that all dismissals of employees who are employed for more than 6 months without interruption, and which are initiated by the employer, are invalid if they are socially unacceptable. Dismissals must therefore be justified by the employer. Acceptable reasons for dismissal include rationalisation, macroeconomic shocks, absenteeism, illness etc.

The advanced notice period in Germany varies according to seniority and, before 1993, blue or a white collar status of the worker. Furthermore, there may be particular industry regulations as well as firm-worker specific agreements. In general, the advanced notice regulations foresee 4 weeks of advanced notice for blue collar workers who have been employed for at least 5 years, and 12 weeks for white collar workers. After 20 years of employment with the same firm, these periods rise to 12 weeks and 24 weeks for blue and white collar workers respectively (see Buttler et al., 1992).

\section{The Education and Apprenticeship System}

The German Apprenticeship System (GAS) is a vocational training programme which combines on the job training, provided by the firm, with school education, provided by the state.

The roots of the apprenticeship system can be traced back to the middle ages, when the craft guilds regulated journeymanship type training schemes, and issued training certificates. Today, more than 60 percent of each cohort in Germany goes through the apprenticeship system (see Soskice, 1994). In 1990, there were about 370 recognised apprenticeship occupations. These occupations include both blue and white collar professions, and cover many professions which require college attendance in the UK and the US (as, for instance, accountant etc.).

Apprenticeship training schemes last between 2 and 3.5 years. During this time, apprentices attend on average 1 - 2 days a week a vocational state school, where they acquire general knowledge, as well as knowledge which is specific to their occupation. For the remaining days, they are on on-the-job training schemes within the firm. Qualified personnel is responsible for the apprentice, and allocates apprentices to particular tasks. Larger firms 


\begin{tabular}{l|ccc}
\hline \hline \multicolumn{4}{c}{ Sector Allocation } \\
\hline & All & Skilled & Unskilled \\
\hline Agriculture & 1.80 & 1.72 & 2.10 \\
Energy, mining, water industry & 2.62 & 2.45 & 3.21 \\
Chemical industry & 7.21 & 6.93 & 8.23 \\
Metal industry, machines & 13.83 & 14.09 & 12.88 \\
Electro technical industry, automobiles & 13.38 & 14.19 & 10.37 \\
Optical industry, fine mechanics & 3.81 & 3.51 & 4.91 \\
Wood, printing, paper & 6.08 & 5.97 & 6.50 \\
Leather, textiles, food & 5.36 & 5.23 & 5.83 \\
Construction, carpentry & 12.65 & 12.53 & 13.07 \\
Trade & 12.35 & 12.92 & 10.26 \\
Traffic, news & 5.36 & 5.22 & 5.88 \\
Credit and insurance & 2.72 & 3.23 & 0.86 \\
Services & 7.82 & 7.04 & 10.71 \\
Charities & 1.79 & 1.76 & 1.94 \\
Public services & 3.22 & 3.21 & 3.23 \\
\hline Total & 100.00 & 100.00 & 100.00 \\
\hline \hline
\end{tabular}

Table 12: Percentage working in each sector in our estimation data set

\begin{tabular}{lcccc}
\hline \hline & \multicolumn{2}{c}{ Unskilled } & \multicolumn{2}{c}{ Skilled } \\
\hline & Coef & t rat & Coef & t rat \\
\hline Number of Job: 2 & 0.0277 & 6.574 & -0.0188 & -11.473 \\
Number of Job: 3 & 0.0014 & 0.290 & -0.0437 & -21.367 \\
Number of Job: 4 & -0.0419 & -7.016 & -0.0795 & -30.620 \\
Number of Job: 5 & -0.0730 & -10.310 & -0.1003 & -29.140 \\
Number of Job: 6 & -0.1067 & -12.714 & -0.1206 & -26.722 \\
Number of Job: 7 & -0.1371 & -13.526 & -0.1624 & -26.940 \\
Number of Job: 8 & -0.1841 & -15.277 & -0.2325 & -29.601 \\
\hline All regressions include age and time dummies \\
\hline \hline
\end{tabular}

Table 13: Log Wages and Job Number, Germany IAB

run also specific classes or seminars for apprentices.

\section{Appendix C: Sector employment allocation, Job mobility, wages and wage growth}

The following are regressions of log wages on job number, age dummies, and time dummies for Germany and the US. Table 13 does not include fixed effects; table 14 does include fixed effects. 


\begin{tabular}{lcccc}
\hline \hline & \multicolumn{2}{c}{ Unskilled } & \multicolumn{2}{c}{ Skilled } \\
\hline & Coeff & t ratio & Coeff & t ratio \\
\hline Number of Job: 2 & 0.1292 & 29.473 & 0.0611 & 37.386 \\
Number of Job: 3 & 0.1542 & 28.327 & 0.0821 & 38.689 \\
Number of Job: 4 & 0.1580 & 24.219 & 0.0817 & 30.597 \\
Number of Job: 5 & 0.1434 & 18.965 & 0.0861 & 25.834 \\
Number of Job: 6 & 0.1297 & 14.835 & 0.0843 & 20.327 \\
Number of Job: 7 & 0.1220 & 12.025 & 0.0646 & 12.443 \\
Number of Job: 8 & 0.1017 & 8.727 & 0.0228 & 3.531 \\
\hline All regressions include age and time dummies \\
\hline \hline
\end{tabular}

Table 14: Log Wages and Job Number, Germany IAB, Fixed Effects

Appendix D: The reduced form results and the coefficients of the residuals. 


\begin{tabular}{|c|c|c|c|c|}
\hline & \multicolumn{2}{|c|}{ Experience } & \multicolumn{2}{|c|}{ Tenure } \\
\hline & Coeff & StdE & Coeff & StdE \\
\hline$v^{P}$ & -0.022 & 0.0370 & -0.036 & 0.0032 \\
\hline$v^{P} \times c$ & 0.0179 & 0.0066 & 0.0198 & 0.006 \\
\hline$v^{P} \times T^{G}$ & -0.0012 & 0.012 & -0.014 & 0.0081 \\
\hline$v^{P} \times T^{G} \times c$ & -0.0010 & 0.0011 & -0.00002 & 0.0008 \\
\hline$v^{P} \times T^{S}$ & -0.0116 & 0.0087 & -0.0021 & 0.0075 \\
\hline$v^{P} \times T^{S} \times c$ & 0.0010 & 0.0009 & -0.0004 & 0.0008 \\
\hline$v^{P} \times T^{F}$ & & & -0.013 & 0.018 \\
\hline$v^{P} \times T^{F} \times c$ & & & 0.00022 & 0.0016 \\
\hline$v^{G}$ & -0.0315 & 0.0162 & -0.035 & 0.0152 \\
\hline$v^{G} \times c$ & 0.0024 & 0.0017 & 0.0059 & 0.0020 \\
\hline$v^{G} \times T^{G}$ & 0.0090 & 0.0038 & 0.0057 & 0.0035 \\
\hline$v^{G} \times T^{G} \times c$ & -0.0004 & 0.0003 & -0.0004 & 0.0003 \\
\hline$v^{G} \times T^{S}$ & 0.0028 & 0.0037 & 0.0021 & 0.034 \\
\hline$v^{G} \times T^{S} \times c$ & -0.0003 & 0.0003 & -0.0002 & 0.0003 \\
\hline$v^{G} \times T^{F}$ & & & 0.0054 & 0.0076 \\
\hline$v^{G} \times T^{F} \times c$ & & & -0.0010 & 0.0006 \\
\hline$v^{T}$ & & & 0.0070 & 0.0055 \\
\hline$v^{T} \times c$ & & & -0.0052 & 0.0021 \\
\hline$v^{T} \times T^{G}$ & & & 0.0001 & 0.0026 \\
\hline$v^{T} \times T^{G} \times c$ & & & 0.0005 & 0.0002 \\
\hline$v^{T} \times T^{S}$ & & & 0.0024 & 0.0013 \\
\hline$v^{T} \times T^{S} \times c$ & & & -0.00014 & 0.00013 \\
\hline$v^{T} \times T^{F}$ & & & -0.011 & 0.0035 \\
\hline$v^{T} \times T^{F} \times c$ & & & 0.00082 & 0.00027 \\
\hline \multirow{2}{*}{\multicolumn{5}{|c|}{$\begin{array}{lcc}\text { p-value for joint Sign. } & 0 \% & 0 \% \\
\text { Bootstrap standard errors and critical values. } & 200 \text { replications }\end{array}$}} \\
\hline & & & & \\
\hline Notation & \multicolumn{2}{|c|}{ Equation 6} & \multicolumn{2}{|c|}{ Equations 9-12 } \\
\hline
\end{tabular}

Table 15: Impact of residuals on the wage equation with selection correction - displaced sample.

\begin{tabular}{lcc}
\hline \hline & $\begin{array}{c}\text { Cell Size in Post Displacement Records } \\
\text { Experience }\end{array}$ & Unskilled \\
\hline 0 & Skilled & 339 \\
1 & - & 216 \\
2 & 448 & 185 \\
3 & 931 & 148 \\
4 & 611 & 128 \\
5 & 397 & 75 \\
6 & 334 & 67 \\
7 & 253 & 49 \\
$8+$ & 663 & 122 \\
\hline For skilled workers experience includes time spent in apprenticeship. We \\
observe skilled workers once apprenticeship is over. The level of experience \\
at which we first observe them depends on the length of apprenticeship. \\
\hline \hline
\end{tabular}

Table 16: Cell Sizes by experience for the displaced sample 


\begin{tabular}{|c|c|c|c|c|c|c|}
\hline & \multicolumn{2}{|c|}{ Participation } & \multicolumn{2}{|c|}{ Experience } & \multicolumn{2}{|c|}{ Tenure } \\
\hline & Coef & $\overline{\text { StdE }}$ & Coef & $\overline{\text { StdE }}$ & Coef & StdE \\
\hline age & 0.0425 & 0.0060 & 0.217 & 0.077 & 0.388 & 0.079 \\
\hline$c_{i t}$ & 0.678 & 0.0247 & 0.5635 & 0.0604 & 0.439 & 0.064 \\
\hline$c_{i t} \times a g e$ & -0.019 & 0.0007 & -0.0071 & 0.0039 & -0.018 & 0.004 \\
\hline Lower Secondary & 0.1550 & 0.0143 & 0.5357 & 0.1220 & 0.38 & 0.094 \\
\hline School unknown & 0.0172 & 0.0165 & -0.1899 & 0.1382 & -0.63 & 0.108 \\
\hline age 18 & 0.0124 & 0.0126 & -0.3428 & 0.1030 & -0.568 & 0.105 \\
\hline age 19 & -0.0072 & 0.0171 & -0.6038 & 0.1805 & -0.972 & 0.184 \\
\hline age 20 & 0.1082 & 0.0239 & -1.05 & 0.2593 & -1.50 & 0.263 \\
\hline age 21 & 0.0673 & 0.030 & -1.291 & 0.3391 & -1.78 & 0.344 \\
\hline age 22 & 0.1192 & 0.0373 & -1.890 & 0.4154 & -2.20 & 0.426 \\
\hline age 23 & 0.1273 & 0.0433 & -2.329 & 0.493 & -2.61 & 0.510 \\
\hline age 24 & 0.099 & 0.0497 & -2.851 & 0.5723 & -2.98 & 0.592 \\
\hline age 25 & 0.1363 & 0.0565 & -3.430 & 0.6528 & -3.46 & 0.684 \\
\hline age 26 & 0.1002 & 0.0625 & -4.026 & 0.7337 & -3.66 & 0.77 \\
\hline age 27 & 0.1254 & 0.0700 & -4.499 & 0.8156 & -3.96 & 0.873 \\
\hline age 28 & 0.0523 & 0.0772 & -4.968 & 0.9008 & -4.18 & 0.982 \\
\hline age 29 & 0.028 & 0.0852 & -5.278 & 0.9920 & -4.21 & 1.06 \\
\hline age 30 & 0.0013 & 0.092 & -4.675 & 1.065 & -3.25 & 1.1 \\
\hline age 31 & 0.0007 & 0.1040 & -3.947 & 1.146 & -2.1 & 1.12 \\
\hline age 32 & 0.1835 & 0.1124 & -1.65 & 1.225 & 0.651 & 1.38 \\
\hline age 33 & 0.0455 & 0.143 & -0.6215 & 1.250 & 0.828 & 1.55 \\
\hline age 34 & -0.2497 & 0.1669 & -0.2204 & 1.08 & 0.409 & 1.54 \\
\hline$c_{i t} \times$ age 18 & -0.1358 & 0.0127 & 0.1785 & 0.0223 & 0.209 & 0.024 \\
\hline$c_{i t} \times$ age 19 & -0.1761 & 0.0116 & 0.2525 & 0.0255 & 0.241 & 0.028 \\
\hline$c_{i t} \times$ age 20 & -0.242 & 0.0116 & 0.3666 & 0.0297 & 0.31 & 0.031 \\
\hline$c_{i t} \times$ age 21 & -0.2312 & 0.0108 & 0.3541 & 0.0336 & 0.289 & 0.035 \\
\hline$c_{i t} \times$ age 22 & -0.2289 & 0.0101 & 0.4274 & 0.0363 & 0.311 & 0.039 \\
\hline$c_{i t} \times$ age 23 & -0.2142 & 0.0096 & 0.459 & 0.0400 & 0.334 & 0.044 \\
\hline$c_{i t} \times$ age 24 & -0.1950 & 0.0091 & 0.5014 & 0.0435 & 0.356 & 0.047 \\
\hline$c_{i t} \times$ age 25 & -0.1850 & 0.0086 & 0.5446 & 0.0475 & 0.399 & 0.053 \\
\hline$c_{i t} \times$ age 26 & -0.163 & 0.0083 & 0.5740 & 0.0516 & 0.396 & 0.058 \\
\hline$c_{i t} \times$ age 27 & -0.1488 & 0.008 & 0.5885 & 0.0560 & 0.411 & 0.063 \\
\hline$c_{i t} \times$ age 28 & -0.1242 & 0.0077 & 0.6074 & 0.0605 & 0.413 & 0.069 \\
\hline$c_{i t} \times$ age 29 & -0.1060 & 0.0076 & 0.6091 & 0.0649 & 0.40 & 0.072 \\
\hline$c_{i t} \times$ age 30 & -0.0866 & 0.0076 & 0.5282 & 0.0680 & 0.306 & 0.077 \\
\hline$c_{i t} \times$ age 31 & -0.0706 & 0.0078 & 0.432 & 0.0715 & 0.202 & 0.07 \\
\hline$c_{i t} \times$ age 32 & -0.0657 & 0.0078 & 0.2288 & 0.0763 & -0.015 & 0.087 \\
\hline$c_{i t} \times$ age 33 & -0.039 & 0.0095 & 0.1208 & 0.0766 & -0.035 & 0.092 \\
\hline$c_{i t} \times$ age 34 & -0.0020 & 0.0104 & 0.0375 & 0.0647 & -0.020 & 0.093 \\
\hline Observations & \multicolumn{2}{|c|}{47998} & \multicolumn{2}{|c|}{47998} & \multicolumn{2}{|c|}{55882} \\
\hline R-squared & \multicolumn{2}{|c|}{0.16} & \multicolumn{2}{|c|}{0.77} & \multicolumn{2}{|c|}{0.28} \\
\hline P-Value for age dummies & \multicolumn{2}{|c|}{0.00} & \multicolumn{2}{|c|}{0.00} & \multicolumn{2}{|c|}{0.00} \\
\hline P-Value for age $\times c_{i t}$ & \multicolumn{2}{|c|}{0.0} & \multicolumn{2}{|c|}{0.0} & \multicolumn{2}{|c|}{0.0} \\
\hline \multicolumn{7}{|c|}{$\begin{array}{l}\text { Standard Errors in italics, allowing for heteroskedasticity and serial correlation. } \\
\text { Default education group: Higher Secondary. Youngest age is } 16 \text {. All regressions include } \\
\text { time dummies. Experience and tenure are measured in years including fractions of a year; } \\
\text { Participation .is measured in fractions of a year worked. The number of observations } \\
\text { include non-work spells.in the case of experience and tenure. For tenure there may be } \\
\text { multiple records per year. }\end{array}$} \\
\hline
\end{tabular}

Table 17: Reduced forms, unskilled workers 


\begin{tabular}{|c|c|c|c|c|c|c|}
\hline & \multicolumn{2}{|c|}{ Participation } & \multicolumn{2}{|c|}{ Experience } & \multicolumn{2}{|c|}{ Tenure } \\
\hline & Coef & $\overline{\text { StdE }}$ & Coef & 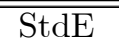 & Coef & $\overline{\mathrm{StdE}}$ \\
\hline age & 0.0173 & 0.0039 & 0.433 & 0.0593 & 0.314 & 0.077 \\
\hline$c_{i t}$ & -0.0102 & 0.0507 & 1.55 & 0.0963 & -0.409 & 0.2064 \\
\hline$c_{i t} \times a g e$ & -0.0000 & 0.0014 & -0.036 & 0.0043 & 0.007 & 0.0072 \\
\hline Lower Secondary & 0.012 & 0.0052 & 0.355 & 0.0592 & 0.44 & 0.087 \\
\hline School unknown & -0.1069 & 0.0073 & -0.095 & 0.0698 & -1.2 & 0.097 \\
\hline age 20 & -0.1272 & 0.0251 & -0.428 & 0.0655 & -0.569 & 0.1230 \\
\hline age 21 & -0.1767 & 0.0246 & -0.846 & 0.1223 & -0.896 & 0.1802 \\
\hline age 22 & -0.2004 & 0.0246 & -1.32 & 0.1808 & -1.33 & 0.2487 \\
\hline age 23 & -0.1777 & 0.0257 & -1.82 & 0.2397 & -1.74 & 0.3218 \\
\hline age 24 & -0.1255 & 0.0273 & -2.29 & 0.2988 & -2.07 & 0.3976 \\
\hline age 25 & -0.1021 & 0.0296 & -2.72 & 0.3580 & -2.29 & 0.4752 \\
\hline age 26 & -0.1152 & 0.0320 & -3.17 & 0.4165 & -2.56 & 0.5528 \\
\hline age 27 & -0.1053 & 0.0349 & -3.61 & 0.4756 & -2.81 & 0.6325 \\
\hline age 28 & -0.095 & 0.0380 & -4.07 & 0.5341 & -3.19 & 0.7129 \\
\hline age 29 & -0.0981 & 0.0419 & -4.43 & 0.5945 & -2.98 & 0.7931 \\
\hline age 30 & -0.0680 & 0.0455 & -4.70 & 0.6517 & -1.82 & 0.8746 \\
\hline age 31 & -0.0783 & 0.0494 & -4.96 & 0.7068 & -1.21 & 0.9477 \\
\hline age 32 & -0.0747 & 0.0521 & -5.16 & 0.7615 & -0.815 & 1.02 \\
\hline age 33 & -0.1559 & 0.0633 & -4.70 & 0.798 & -0.948 & 1.038 \\
\hline age 34 & -0.1476 & 0.067 & -3.13 & 0.7177 & -1.17 & 0.947 \\
\hline$c_{i t} \times$ age 20 & 0.0420 & 0.0220 & -0.007 & 0.02 & 0.40 & 0.0802 \\
\hline$c_{i t} \times a g e 21$ & 0.0404 & 0.0206 & -0.034 & 0.0246 & 0.43 & 0.0755 \\
\hline$c_{i t} \times a g e 22$ & 0.0518 & 0.0190 & -0.015 & 0.0247 & 0.473 & 0.0710 \\
\hline$c_{i t} \times \operatorname{age} 23$ & 0.0428 & 0.0176 & 0.040 & 0.0255 & 0.511 & 0.0673 \\
\hline$c_{i t} \times a g e 24$ & 0.0263 & 0.016 & 0.087 & 0.0269 & 0.525 & 0.0644 \\
\hline$c_{i t} \times a g e 25$ & 0.0197 & 0.0147 & 0.128 & 0.0290 & 0.515 & 0.0625 \\
\hline$c_{i t} \times a g e 26$ & 0.0203 & 0.0133 & 0.172 & 0.0314 & 0.51 & 0.0610 \\
\hline$c_{i t} \times a g e 27$ & 0.0177 & 0.0119 & 0.220 & 0.0343 & 0.519 & 0.0607 \\
\hline$c_{i t} \times \operatorname{age} 28$ & 0.0150 & 0.0106 & 0.266 & 0.0373 & 0.529 & 0.0612 \\
\hline$c_{i t} \times a g e 29$ & 0.0140 & 0.0093 & 0.299 & 0.0409 & 0.468 & 0.0628 \\
\hline$c_{i t} \times a g e 30$ & 0.0101 & 0.0080 & 0.322 & 0.0443 & 0.308 & 0.065 \\
\hline$c_{i t} \times a g e 31$ & 0.0095 & 0.0068 & 0.345 & 0.0476 & 0.207 & 0.0670 \\
\hline$c_{i t} \times$ age 32 & 0.0086 & 0.0057 & 0.369 & 0.0509 & 0.154 & 0.0707 \\
\hline$c_{i t} \times a g e 33$ & 0.0136 & 0.0053 & 0.333 & 0.0531 & 0.14 & 0.0699 \\
\hline$c_{i t} \times$ age 34 & 0.0116 & 0.004 & 0.219 & 0.0476 & 0.122 & 0.0626 \\
\hline Observations & \multicolumn{2}{|c|}{181206} & \multicolumn{2}{|c|}{181206} & \multicolumn{2}{|c|}{204503} \\
\hline R-squared & \multicolumn{2}{|c|}{0.067} & \multicolumn{2}{|c|}{0.83} & \multicolumn{2}{|c|}{0.14} \\
\hline P-Value for as & \multicolumn{2}{|c|}{0.0} & \multicolumn{2}{|c|}{0.0} & \multicolumn{2}{|c|}{0.0} \\
\hline P-Value for age $\times c_{i t}$ & \multicolumn{2}{|c|}{0.0} & & 0 & \multicolumn{2}{|c|}{0.0} \\
\hline Youngest age is $17 . \mathrm{O}$ & & & & & & \\
\hline
\end{tabular}

Table 18: Reduced forms, skilled workers 


\begin{tabular}{|c|c|c|c|c|c|c|c|}
\hline & \multicolumn{2}{|c|}{ Experience } & & \multicolumn{2}{|c|}{ Sector Tenure } & \multicolumn{2}{|c|}{ Tenure } \\
\hline & Skilled & Unskilled & & Skilled & Unskilled & Skilled & Unskilled \\
\hline \multirow[t]{2}{*}{ One Year } & & 0.102 & $\leq 5$ Years & 0.0097 & -0.015 & 0.032 & 0.068 \\
\hline & & 0.034 & & 0.0079 & 0.019 & 0.011 & 0.017 \\
\hline \multirow[t]{2}{*}{ two Year } & 0.083 & 0.084 & $>5$ Years & 0.007 & -0.063 & 0.032 & 0.11 \\
\hline & 0.021 & 0.038 & & 0.032 & 0.079 & 0.023 & 0.047 \\
\hline \multirow[t]{2}{*}{ three Years } & 0.083 & 0.033 & tenure $^{2}$ & -0.00002 & 0.0048 & -0.0020 & -0.0080 \\
\hline & 0.018 & 0.042 & & 0.0019 & 0.0046 & 0.0025 & 0.0036 \\
\hline \multirow[t]{2}{*}{ four Years } & 0.076 & 0.040 & & & & & \\
\hline & 0.020 & 0.050 & & & & & \\
\hline \multirow[t]{2}{*}{ five Years +} & 0.058 & -0.007 & & & & & \\
\hline & 0.028 & 0.057 & & & & & \\
\hline \multirow[t]{2}{*}{ experience $^{2}$} & -0.0029 & -0.0004 & & & & & \\
\hline & 0.0017 & 0.0035 & & & & & \\
\hline p-value* & \multicolumn{2}{|c|}{0.26} & & \multicolumn{2}{|c|}{0.51} & \multicolumn{2}{|c|}{0.085} \\
\hline \multicolumn{8}{|c|}{$\begin{array}{l}\text { Standard deviation of the block bootstrap in italics. }{ }^{*} \text { p-value corresponds to the two degree of freedom } \\
\text { test for excluding the quadratic terms in each part of the model. p-value of joint } 6 \text { degrees of freedom } \\
\text { test for excluding all quadratic terms is } 0.18 \text {. Experience, tenure and sector tenure measured in years. }\end{array}$} \\
\hline
\end{tabular}

Table 19: Results including a quadratic term - Control function Estimator - post displacement 


\section{References}

[1] Altonji J.G. and N. Williams (1996) "The Effects of Labor Market Experience, Job Seniority and Job Mobility on Wage growth", mimeo.

[2] Altonji J.G. and N. Williams (1997) "Do wages rise with seniority? A Reassessment", mimeo

[3] Altonji, J.G. and Shakotko, R.A. (1987) "Do Wages rise with Seniority?", Review of Economic Studies, 54, 437-459.

[4] Becker, G. (1993) "Human Capital", NBER, The Chicago University Press

[5] Bender, S., J. Hilzendegen, G. Rohwer and H. Rudolph (1996): "Die IAB Beshaeftigungsstichprobe 1975-1990", Beitraege zur Arbeitsmarkt- und Berufsforschung, BeitrAB 197, Nurnberg.

[6] Bender, S. C. Dustamnn, D. Margolis and C. Meghir (2002) "Worker Displacement in France and Germany, in Loosing work, Moving on", Peter J. Kuhn ed. Upjohn Institute, Michigan, pp 375-452.

[7] Ben-Porath, Y. (1967) "The Production of Human Capital and the Life Cycle of Earnings", Journal of Political Economy, 75, 352-365.

[8] Bjorklund, A. and R. Moffitt (1987) "The Estimation of Wage Gains and Welfare Gains in Self-selection", Review of Economics and Statistics, 69, $42-49$.

[9] Blinder, A. and Y. Weiss (1976) "Human Capital and Labor Supply: A Synthesis", Journal of Political Economy, Vol 84.3 pp. 449-472.

[10] Burda, M. and A. Mertens (2001) Wages and Worker Displacement in Germany Labour Economics 8, pp 15-41

[11] Buttler, F., W. Brandes, E. Dorndorf, W. Gaum, and U. Walwei (1992), "Flexibility and Job Security in the Federal Republik of Germany", Technical Report 1, SAM, working paper.

[12] Card, David (2001) "Estimating the Returns to Schooling: Progress on some Persistent Econometric Problems", Econometrica 69 pp 1127-60.

[13] Datta, S. (1995) "Building Trust", LSE, mimeo

[14] Dustmann, C. and U. Schoenberg (2002) "Training and Unions", UCL, mimeo

[15] Eckstein Zvi, and Kenneth Wolpin (1989) Dynamic Labour Force Participation of Married Women and Endogenous Work Experience, Review of Economic Studies Vol. 56.3

[16] Farber, H. S. (1994) "The Analysis of Interfirm Worker Mobility", Journal of Labor Economics, 12, 554-593 
[17] Farber H. S.(1983) "The Determination of the Union Status of Workers" Econometrica, Vol. 51, No. 5. pp. 1417-1438.

[18] Fitzenberger, Berndt and Claudia, Kurz (2002) New Insights on Earnings Trends Across Skill Groups and Industries in West Germany, Empirical Economics

[19] Florens, J.P., J. J. Heckman, C. Meghir and E. Vytlacil (2002) "Instrumental Variables, Local Instrumental Variables and Control Functions", mimeo UCL/IFS.

[20] Garen, John (1984) "The Returns to Schooling: A Selectivity Bias Approach with Continuous Choice Variables", Econometrica 52 pp 1199-1218.

[21] Gibbons, R. and L. Katz (1992) "Does unmeasured ability explain interindustry wage differentials?", Review of Economic Studies, 59, 515-535.

[22] Hall, Peter and Joel Horowitz (1996) Bootstrap Critical Values for Tests Based on Generalized-Method-of-Moments Estimators, Econometrica, Vol. 64, No. 4. July, pp. 891-916

[23] Harris, C. and L. Felli (1996) "Learning, Wage Dynamics, and Firm Specific Human Capital", Journal of Political Economy, 104, 838-868.

[24] Hashimoto, M. (1981) "Firm Specific Human Capital as a Shared investment", American Economic Review, Vol 71.3 pp 475-82

[25] Heckman, J.J. (1974) "Shadow Prices, Market Wages, and Labor Supply", Econometrica 42, 679-694.

[26] Heckman, J.J. (1979) "Selection Bias as a Specification Error", Econometrica $47,153-62$.

[27] Heckman, J.J. (1995) "Instrumental Variables: A Cautionary Tale", mimeo

[28] Heckman, James J. and Richard Robb (1985) Alternative Methods for Evaluating the Impact of Interventions, in Longitudinal Analysis of Labor Market Data Econometric Society Monograph Series no. 10 Heckman, J. J. and Burton Singer eds. Cambridge University Press, 156-245.

[29] Heckman, J.J. and G. Sedlacek (1985) "Heterogeneity, Aggregation and market Wage Functions: An Empirical model of Self-Selection in the Labor Market, Journal of Political Economy 93.6 pp. 1077-1125

[30] Heckman, J. J. and E .Vytlacil (1998) "Instrumental Variables Methods for the Correlated Random Coefficient Model: Estimating the Average Rate of Return to Schooling when the Return is Correlated with Schooling", University of Chicago, mimeo. 
[31] Horowitz, Joel (2000) "The Bootstrap" Forthcoming The Handbook of Econometrics.

[32] Imbens, G.W. and J.D. Angrist(1994) "Identification and Estimation of local Average Treatment Effects", Econometrica 62(2) 467-75

[33] Jovanovic, B. (1979) "Firm Specific Capital and Turnover", Journal of Political Economy 87, 1246-1260.

[34] Killingsworth, M. (1982) "Learning by Doing and Investment in Training: A Synthesis of two Rival Models of the Life Cycle", Review of Economic Studies, 49, 263-271.

[35] Kletzer, Lori G. (1989) "Returns to Seniority after Permanent Job Loss", American Economic Review Vol 79.3 June pp 536-43.

[36] Nagypal, Eva (2002) "Learning by Doing versus Learning about match quality: Can we tell them apart?" mimeo Northwestern University and University of Stockholm.

[37] Neal, D. (1995) "Industry-Specific Human Capital: Evidence from Displaced Workers", Journal of Labor Economics, 13, 653-677.

[38] Newey, Whitney, James Powell and Frank Vella (1999) "Nonparametric Estimation of Triangular Simulataneous Equations models" Econometrica Vol. 67 pp 565-604.

[39] Parent, D. (1995) "Industry-Specific Capital and the Wage Pofile: Evidence from the NLSY and the PSID", working paper No 795, Universite de Montreal, Centre de Recherche et Developement en Economique.

[40] Robin, J.M. and R. Smith (2000) "Tests of Rank", Econometric Theory 16 pp 151-75

[41] Rosen, S. (1972) "Learning and Experience in the Labor Market", Journal of Human Resources, 7, 336-342.

[42] Rosen, S. (1976) "A Theory of Life Earnings" The Journal of Political Economy, Vol. 84, No. 4, Part 2: Essays in Labor Economics in Honor of $\mathrm{H}$. Gregg Lewis. (Aug., 1976), pp. S45-S67.

[43] Scoones, David and Dan Bernhardt (1996) Promotion Turnover and Discretionary Human Capital Acquisition, mimeo

[44] Soskice, D. (1994) "Reconciling Markets and Institutions: The German Apprenticeship System", in Lynch (ed), Training and the Private Sector - International Comparisons, University of Chicago Press for NBER, Chicago.

[45] Topel, R.H. (1991) "Specific Capital, Mobility and Wages: Wages Rise with Job seniority", Journal of Political Economy, 99, 145-176. 
[46] Topel, R.H. and M.P Ward (1992) "Job Mobility and the Careers of Young Men", Quarterly Journal of Economics, 107, 439-479.

[47] Willis and Rosen (1979) "Education and self-selection" Journal of Political Economy Vol 87.5 part2 ppS7-S36 


\title{
Wages, Experience and Seniority*
}

\author{
Christian Dustmann and Costas Meghir \\ Institute for Fiscal Studies, University College London and CEPR
}

\author{
This Version: September 2003
}

\begin{abstract}
In this paper we study the sources of wage growth. We identify the contribution to such growth of general, sector specific and firm specific human capital. Our results are interpretable within the context of a model where the returns to human capital may be heterogeneous and where firms may offer different combinations of entry level wages and firm specific human capital development. We allow for the possibility that wages are match specific and that workers move jobs as a result of identifying a better match. To estimate the average returns to experience, sector tenure and firm specific tenure within this context, we develop an identification strategy which relies on the use of firm closures. Our data source is a new and unique administrative data set for Germany that includes complete work histories as well as individual characteristics. We find positive returns to experience and firm tenure for skilled workers. The returns to experience for unskilled workers are small and insignificant after two years of experience. Their returns to sector tenure are also zero. However their returns to firm tenure are substantial.
\end{abstract}

*We thank three anonymous referees and the editor James Dow for useful comments and suggestions. Discussions with Joe Altonji, Orazio Attanasio, James Banks, Richard Blundell, Ken Burdett, Lorraine Dearden, Jim Heckman, Derek Neal, Gillian Paull, Jean-Mark Robin, Uta Schoenberg, Chris Taber and Yoram Weiss proved particularly useful in developing this paper. We would also like to thank participants in seminars at Universities of Aarhus, (Denmark), Chicago, Copenhagen, Essex (UK), IIES (Sweden), Northwestern, Pennsylvania, Pompeu Fabra (Barcelona), as well as the EUI (Florence) and ECARE (Brussells), for stimulating comments. We thank the ESRC centre for the analysis of Fiscal Policy and the Anglo German foundation for funding the project. We also thank the IAB for letting us use the data and Stefan Bender for his invaluable help with it. We remain responsible for all errors and interpretations. Correspondence: c.dustmann@ucl.ac.uk and c.meghir@ucl.ac.uk 


\section{Introduction}

In this paper we study the growth of wages of young workers in Germany. Knowing the extent and reasons for individual wage growth over the lifecycle is important for a number of areas in Economics. Just to mention two examples: First, it is a key element to understanding and designing active labour market programmes. Many such programmes offer temporary (and often subsidised) work opportunities. Examples are the New Deal in the UK and the Swedish programmes as well as a number of programmes in Germany. These programmes are based on the assumption that general skills are sufficiently enhanced while working, so as to render the workers employable without a wage subsidy. Thus the success of these programs depends on how skills improve on the job for the target population, and whether this skill enhancement is transferable across jobs. Second, it is a key to understanding the benefits and costs of job mobility. This in turn matters for a number of policy issues, including the design of pension policies, relating for example to final salary schemes.

As a result of this widespread interest, a large body of empirical research has focused on obtaining estimates for the returns of experience and seniority. ${ }^{1}$ Our study uses a new and unique administrative data set with a number of features that are important for our analysis and allow us to avoid many problems encountered in earlier work in this field. In our model wages grow due to learning by doing, which may be heterogeneous across individuals. Moreover, since firms offer different career profiles and because we allow for match specific effects on wages, investments take the form of searching for the firm with the most desirable learning by doing characteristics (career structure). ${ }^{2}$

Thus the framework we present leads to a wage equation, which depends on the number of periods the individual has worked (experience), the time spent in the sector (sector tenure) and the time spent in the firm (tenure). The impacts of these factors is allowed to be

\footnotetext{
${ }^{1}$ See Altonji and Shakotko (1987), Topel (1991), Topel and Ward (1992), Altonji and Williams (1996), Altonji and Williams (1997), Neal (1995) and Parent (1995) among others.

${ }^{2}$ In general the acquisition of human capital on the job may be a result of decisions to invest as well as purely learning by doing. Examples of models with explicit investment in Human Capital are Ben Porath (1967), Rosen (1976), Blinder and Weiss, (1976) and Jovanovic (1979), amongst others. Examples of models where learning is a by product of work are given in Rosen (1972). Killingsworth (1982) presents a model unifying the features of the earlier literature.
} 
heterogeneous across individuals, which leads to a correlated random coefficients model for wages. Random coefficient models are not new of course. The Willis and Rosen (1979) model on the returns to education and the Heckman and Sedlacek (1985) model of self selection to the labour market (based on Roy), are early empirical examples. Heckman and Robb (1985) discuss the estimation of such models in the context of evaluation of treatment effects and Bjorklund and Moffitt (1987) apply these ideas to the estimation of the returns to training in Sweden. More recently Imbens and Angrist (1994) and Heckman (1995) consider the interpretability of instrumental variable estimation in the context of random coefficient models.

We discuss how the population average returns to experience and tenure can be identified given individual and firm behaviour. Our approach is partly based on using displaced workers due to firm closure, thus allowing us to distinguish wage growth due to learning by doing from wage growth due to endogenous job mobility, which leads to improved job matches. ${ }^{3}$ However we recognise that even for displaced workers both the fact that they accepted a new job as well as experience itself are endogenous at job entry. We use age as an excluded instrument to allow for such endogeneity by developing an estimator based on the control function approach of Heckman and Robb (1985), and allowing for heterogeneous returns to experience, sector tenure and firm tenure. ${ }^{4}$

Our data allows us to observe all transitions that take place between jobs and between work and unemployment from the start of the worker's labour market career. All wage observations relate to a particular job and are not averaged across jobs; thus when an individual changes employment we observe the new wage at which he is appointed. Because the data is administrative, there is practically no attrition and most probably much less measurement error than that in questionnaire based survey data. In addition, for any firm that closed down and employed any of our workers within our observation window, we know the year of closure.

\footnotetext{
${ }^{3}$ Displaced workers have been used before to control for selection due to unobserved heterogeneity. Examples include Kletzer (1989) and Gibbons and Katz (1992). Kletzer also includes among the exogenously displaced individuals those fired from firms that continue as a going concern.

${ }^{4}$ The approach we follow is parametric and is similar to Heckman and Vytlacil (1998). General nonparametric identification issues in these models are discussed in Florens et al (2002).
} 
From the overall data base, we extract a sample of workers entering the labour market between 1975 to 1995. The oldest worker in our sample is 35. The use of such a young sample has the advantage that we can focus on the age group where most of the job mobility and life-cycle wage growth takes place. Since this data base came into existence in 1975, our sample selection ensures that we choose those cohorts for which the complete labour market history of all individuals is observed.

Our analysis is carried out separately for skilled individuals who have received formal vocational training (apprenticeship) and for those who have not - the unskilled. This reveals important differences between the groups, which is key to the design of policy such as active labour market programmes.

We find that the returns to experience for the skilled workers can be substantial. In the first two years of work, following formal training, wages grow at $7 \%$ and then at $6 \%$ a year. The returns decline thereafter, but even in the longer run experience leads to a wage growth of $1.2 \%$ a year. For the unskilled workers there are substantial returns in the first two years (10\% and $8 \%$ ) but they become effectively zero beyond three years of work. In addition to this growth due to experience, the wages of unskilled workers also grow early on via improved job matches achieved by job mobility; this, however, is not an important source of growth for the skilled workers. The returns to remaining in the same sector (sector or industry tenure) are $1 \%$ a year for skilled workers and basically zero for the unskilled. On the other hand the returns to remaining with the same employer (tenure) for the unskilled workers are quite high for the first 5 years ( $4 \%$ a year) but zero thereafter, despite the fact that we control for sector tenure. Skilled workers have lower returns to tenure $(2.4 \%)$. Thus in Germany unskilled workers benefit most by finding a good match and remaining with it. An implication is that if a labour market program is to be effective for the unskilled it will have to make sure placements are long-lasting. For skilled workers human capital is transferable and tenure is not as important. This may be due to the nature of the apprenticeship system. A series of sensitivity tests demonstrate the robustness of these results to alternative definitions of displacement.

The paper proceeds as follows: In the next section we present a theoretical framework, 
where we describe the model and discuss identification of the parameters of interest under different theoretical assumptions. This is followed by a section where we describe the data and the sample we use, and provide descriptive features of job mobility and wage growth for young workers in Germany. We then present our empirical results. Finally, we summarise our findings and their implications in the concluding section.

\section{Theoretical framework}

Human capital is composed of transferable skills, sector specific skills and firm specific skills. Workers are assumed to obtain the returns to the first two and to share the returns to the latter, based on the proportion invested for its acquisition by the worker relative to the firm. ${ }^{5}$ Thus define by $H_{i f t}^{a}$ that part of human capital for which worker $i$ with education type $a$, working in firm $f$ during period $t$ gets paid for. This is related to the number of periods the workers has worked in firm $f\left(T_{i f t}^{F}\right)$, in sector $s\left(T_{i t}^{S}\right)$ and overall $\left(T_{i t}^{G}\right)$ by the function

$$
\ln H_{i f t}^{a}=g\left(T_{i t}^{G} \mid a_{i}\right)+\eta_{i t} T_{i t}^{G}+s\left(T_{i t}^{S} \mid a_{i}\right)+\varepsilon_{i t} T_{i t}^{S}+f\left(T_{i f t}^{F} \mid a_{i}\right)+\nu_{i f t} T_{i f t}^{F}+m_{i f t}
$$

where $g\left(T_{i t}^{G} \mid a_{i}\right)+\eta_{i t} T_{i t}^{G}$ is general transferable human capital, $s\left(T_{i t}^{S} \mid a_{i}\right)+\varepsilon_{i t} T_{i t}^{S}$ is human capital specific to the sector, and $f\left(T_{i f t}^{F} \mid a_{i}\right)+\nu_{i f t} T_{i f t}^{F}$ is firm specific human capital whose return is enjoyed by the worker. The term $\eta_{i t}$ reflects individual specific returns to general experience. The terms $m_{i f t}$ and $\nu_{i f t}$ reflect the match specific productivity and career structure. Thus the value of a match (given experience and tenure) is characterised by a firm/worker specific component of the wage level $m_{i f t}$ and growth $\nu_{i f t}$. We expect these to be negatively correlated in equilibrium. ${ }^{6}$ Finally, $a_{i}$ is the educational category of individual $i$. Note that the random returns may be persistent over time or even fixed for each individual.

We assume learning by doing is passive and takes place within a job. The individual can

\footnotetext{
${ }^{5}$ See Becker (1993). Equilibrium models that explain why workers get rewarded for specific training and the way the costs and the returns are shared have been developed under many different assumptions. Some examples include Hashimoto (1981), Datta (1995), Scoones and Bernhardt (1996) and Harris and Felli (1996).

${ }^{6}$ No restrictions are imposed on the way that the unobservables $\eta_{i t}, \varepsilon_{i t}, m_{i f t}$ and $\nu_{i f t}$ are correlated. Also note that the firm's willingness to hire the worker or otherwise is reflected in the overall value of the match. Given the pay that this implies it is then up to the worker to take the job or not. See Farber (1983) for an alternative where there may be excess supply of workers, in his case to union jobs.
} 
choose the firm with the desired career profile, the sector in which he works and whether to work or not in a particular period.

In our empirical analysis we distinguish between two skill categories: Those with apprenticeship education $\left(a_{i}=1\right)$ and those without $\left(a_{i}=0\right)$. The market price for human capital of type $a$ is $r_{t}^{a}$. The observed wage of individual $i$ in time period $t$ and of skill level $a$ is $w_{i t}=r_{t}^{a} H_{i f t}^{a} e^{e_{i t}}$ where $e_{i t}$ represents either measurement error and/or transitory shocks to human capital. ${ }^{7}$ The log wage for an individual $i$ in period $t$ can be written as:

$$
\begin{aligned}
\ln w_{i t}= & \ln r_{t}^{a}+g\left(T_{i t}^{G} \mid a_{i}\right)+s\left(T_{i t}^{S} \mid a_{i}\right)+f\left(T_{i f t}^{F} \mid a_{i}\right) \\
& +\eta_{i t} T_{i t}^{G}+\varepsilon_{i t} T_{i t}^{S}+\nu_{i f t} T_{i f t}^{F}+m_{i f t}+e_{i t} .
\end{aligned}
$$

Draws of the match specific effects $\left(u_{i f t}=\left\{m_{i f t}, \nu_{i f t}\right\}\right)$ will in general be correlated across firms, due to individual unobserved characteristics. Preferred draws of $u_{i f t}$ will drive mobility. $^{8}$

\subsection{Identifying the return to experience}

Comparing the wages of workers with different levels of experience is known to provide biased results for the returns to experience (see for example, Altonji and Shakotko, 1986, Topel, 1991 and Altonji and Williams, 1996) for at least two reasons. First, because some of the differences may be attributed to better matches achieved by workers who have been in the labour market longer. Second, because high ability workers are likely to have a stronger labour market attachment and hence end up with more experience. In our model, there is a further source of a potential bias in the estimation of the average returns to experience: Workers with higher returns to experience are likely to spend less time out of the labour market, because for them the opportunity cost of not working is higher. This will lead to a positive correlation of the returns to experience $\eta_{i t}$ with experience $T_{i t}^{G}$.

The dynamic selection induced by this process will generally distort the returns to experience, and it is difficult to model (see Eckstein and Wolpin, 1989). Topel (1991) suggests estimating the returns to experience by using the wages of those starting a new job and who

\footnotetext{
${ }^{7}$ The subscript $f$ is used to emphasise that certain variables on the right hand side depend on the firm. For simplicity of notation however, we drop the firm subscript from the wage rate.

${ }^{8}$ Farber (1994) among others provides interesting evidence on the importance of matching for mobility.
} 
therefore have zero tenure. However, workers who start a new job are a mixture of workers who are improving on their previous wage, workers who have been fired from an ongoing firm, and workers who have been displaced because the firm actually closed down, all of whom find the current offer more attractive than unemployment.

We resolve this problem by using only those workers who start a new job following a displacement caused by the closure of a firm. ${ }^{9}$ We will term these displaced workers. In Appendix A we show why exogenous displacement can simplify the problem. The basic intuition is simple: If, as we assume, firm closure is exogenous conditional on our observables, then workers who have thus been displaced are a random sample of the workforce and are not selected into new jobs on the basis of their past choices, but just on whether this job offer is preferable to unemployment. Thus our approach identifies the returns to experience by comparing the wages of workers with different levels of experience, who start a new job following displacement.

Of course even for this sample there is still the well known ability bias problem (experience is correlated with the permanent part of the unobservables), and the problem that only those displaced workers receiving good enough offers will take up employment. ${ }^{10}$ We solve these endogeneity/selection problems by using age effects as exclusion restrictions, combined with a control function estimator on the displaced sample, where we use residuals from an experience and participation reduced form to allow for the endogenous job acceptance and experience. ${ }^{11}$

In what follows, we state a set of assumptions that justify our approach and present the estimation procedure we use.

\footnotetext{
${ }^{9}$ This strategy is based on a number of assumptions, which we list below. Gibbons and Katz (1992) also argue that displaced workers can be used to control for selection in a matching context. They apply their strategy in a bid to explain inter-industry wage differentials.

${ }^{10} \mathrm{By}$ ability bias we refer to the bias generated by the tendency of individuals who are more productive, or have a higher return to experience, to spend more time in employment and hence be more experienced for any given level of potential experience.

${ }^{11}$ See Heckman and Robb (1985).
} 


\subsection{Assumptions}

Our approach for estimating the average returns to experience for the workforce population is based on the following assumptions:

A.1 Workers cannot predict a closure before joining the firm. Moreover, they cannot predict a closure when working in the firm if the closure is more than a year away.

Assumption A.1 ensures that there is no self-selection of a particular type of worker (in terms of unobserved characteristics) into firms that are subsequently observed to close down. Since we can predict firm closure in terms of certain observables, we can carry out a sensitivity analysis. In particular, we compare the results we obtain using all closures, to those obtained using closures of older firms only, which have much lower exit rates. We develop this idea at the end of the empirical section.

There may also be selection of workers leaving the firm before closure. In our data we know whether a firm closed down, independently of whether the worker remained employed by it. Hence, we can define a displaced worker as someone who left a firm which closed down in $\mathrm{x}$ amount of time following his departure, where $\mathrm{x}$ is chosen by us. A.1 assumes there are no selective departures related to the closure earlier than a year before the event. In the empirical section we develop a sensitivity test, based on alternative definitions of this time window. In particular, we consider a worker as displaced if the firm closes down within different periods of his departure, and we compare the results.

A.2 Workers and firms have full information on the quality of the match.

Assumption A.2 excludes learning about the quality of the match so as to simplify the interpretation of the results. ${ }^{12}$

A.3 Exclusion restriction: For the population of young displaced workers $\left(D_{i t}=1\right)$ the unobservables in the wage equation are mean independent of age, conditional on exogenous observable characteristics $X_{i t}$ (including school education, apprenticeship status, and time).

\footnotetext{
${ }^{12}$ In the presence of learning about the quality of the match it may not be possible to disentangle the growth of wages due to an increase in productivity from growth due to increased remuneration as the quality of the match is revealed. See Nagypal (2002) for a recent attempt to distinguish learning by doing from learning about match quality.
} 
Thus,

$$
\begin{gathered}
E\left(\eta_{i t} \mid a g e_{i t}, X_{i t}, D_{i t}=1\right)=E\left(\varepsilon_{i t} \mid a g e_{i t}, X_{i t}, D_{i t}=1\right)=0 \\
E\left(\nu_{i f t} \mid a g e_{i t}, X_{i t}, D_{i t}=1\right)=E\left(m_{i f t}+e_{i t} \mid a g e_{i t}, X_{i t}, D_{i t}=1\right)=0
\end{gathered}
$$

This assumption ensures that age does not affect wage offers facing exogenously displaced individuals with the same observables. ${ }^{13}$ This assumption may not be true in the overall sample since the quality of matches may improve with age because older workers will have been sampling jobs for longer. The key point of this assumption is that post displacement, workers have lost all earlier match advantages that would have been achieved through search (search capital) and that workers have to start afresh. As a result, being an older or younger worker (within the relatively narrow age range we consider - remember that workers are less than 35 years old) does not in itself confer any advantage in obtaining a better match post-displacement. Implicit also in this assumption is the exclusion of cohort effects from wages. $^{14}$

We also require a condition that ensures that the instruments we use can explain participation and experience and also induce independent variation in the two predictions. Our requirement is that age has an impact on participation in the labour market. We expect this to be the case since labour market attachment changes with age for a variety of reasons, including family formation, housing, better job matches etc.

The instruments will also have explanatory power for experience since actual experience is the sum of past employment outcomes. If age effects on participation are sufficiently nonlinear this exclusion restriction provides all the necessary identifying information. In practice this is the case. In addition, we can also exploit the fact that the impact of age changes with potential experience by using age/potential experience interactions as instruments. Since potential experience is age minus years of education in practice this amounts to using age/education interactions as additional instruments. This leads us to the rank condition, which can be stated as: ${ }^{15}$

\footnotetext{
${ }^{13}$ Since the conditional mean of the unobservables is assumed to be equal to zero, which is their unconditional population mean, these orthogonality conditions identify the population mean of the returns to experience.

${ }^{14}$ Note that age + cohort $=$ year. Since the model also includes time effects, including cohort and time would be the same as including age, at least linearly.

${ }^{15}$ For a recent application of a similar idea see Blundell, Duncan and Meghir (1998) and for the theory of
} 
A.4 Rank condition: Define by $\vartheta^{G}$ the vector coefficients on all excluded instruments in the experience reduced form and by $\vartheta^{P}$ the vector of coefficients of these same variables in the participation reduced form. The rank condition of identification requires that the matrix $\left[\begin{array}{ll}\vartheta^{G} & \vartheta^{P}\end{array}\right]$ has rank 2.

We present a formal test of the rank condition, which is easily satisfied in our data.

The exclusion restriction and the rank condition are not sufficient for identifying average returns in models with heterogeneous returns which may be correlated with the endogenous variables. ${ }^{16}$ In addition we require the following control function assumptions that define how the mean of the unobservables relate to experience $\left(T^{G}\right)$, sector tenure $\left(T^{S}\right)$ and job acceptance following a closure $(P)$.

A.5 For the sample of displaced workers $\left(D_{i t}=1\right)$ starting a new job ${ }^{17}$ following a firm closure, we assume that:

$$
\begin{gathered}
E\left(m_{i f t}+e_{i t} \mid a g e_{i t}, X_{i t}, D_{i t}=1, P_{i t}=1, T_{i t}^{G}, T_{i t}^{S}, T_{i f t}^{F}=0\right)=\delta^{G}\left(c_{i t}\right) v_{i t}^{G}+\delta^{P}\left(c_{i t}\right) v_{i t}^{P}, \\
E\left(\eta_{i t} \mid a g e_{i t}, X_{i t}, D_{i t}=1, P_{i t}=1, T_{i t}^{G}, T_{i t}^{S}, T_{i f t}^{F}=0\right)=\gamma^{G}\left(c_{i t}\right) v_{i t}^{G}+\gamma^{P}\left(c_{i t}\right) v_{i t}^{P}, \\
E\left(\varepsilon_{i t} \mid a g e_{i t}, X_{i t}, D_{i t}=1, P_{i t}=1, T_{i t}^{G}, T_{i t}^{S}, T_{i f t}^{F}=0\right)=\kappa^{G}\left(c_{i t}\right) v_{i t}^{G}+\kappa^{P}\left(c_{i t}\right) v_{i t}^{P},
\end{gathered}
$$

where $P_{i t}=1$ represents those accepting a new job following displacement, $c_{i t}$ is potential experience $^{18}$, and $v_{i t}^{G}=T_{i t}^{G}-E\left(T_{i t}^{G} \mid a g e_{i t}, X_{i t}\right)$, and $v_{i t}^{P}=P_{i t}-E\left(P_{i t} \mid a g e_{i t}, X_{i t}\right)$ are residuals from an experience and participation reduced form. The control function assumption is familiar from standard selection models (e.g. Heckman, 1979). A sufficient (but not necessary) condition for this assumption to hold is that the instrument is independent of the errors. Subject to the exclusion restrictions A.3 and the rank condition A.4, this control function assumption allows us to identify the average return to experience and sector tenure based on rank tests see Robin and Smith (2000).

${ }^{16}$ See Garen (1984), Heckman and Robb (1985), Heckman and Vytlacil (1999), Card (2001) and Florens et al. (2002).

${ }^{17}$ All these workers have zero tenure at that point.

${ }^{18}$ Potential experience is the number of years that the person could have worked for pay since the end of full time education. Since $X$ includes education and we also condition on age, $c_{i t}$ is implicitly included in the set of conditioning variables. 
the wage obtained following displacement. We allow the coefficients (the $\delta$ 's, $\gamma$ 's and $\kappa$ 's) to depend on potential experience $c_{i t}$ because the distribution of experience will vary with the number of years that the individual has been in the labour market. For example, a person with 5 years of potential experience can have no more than 5 years of actual experience. Moreover, as implied by (3) and (4), the above formulation recognises that past and present employment outcomes may depend on the returns to experience $\left(\eta_{i t}\right)$, and sector tenure $\left(\varepsilon_{i t}\right)$.

Assumption A.5 implies that conditional on experience, job acceptance following displacement and the other observable characteristics, a sector tenure residual is not required. We provide a test of this exogeneity assumption, which turns out to be easily acceptable in our data. This is not surprising, since we allow for the returns to sector tenure to affect the mobility and work decisions (see equation 4). We discuss the test in the empirical section.

Finally, note that identification does not rely on linearity of the control function. There are two key elements in the identification of the average treatment effect using the control function estimator. ${ }^{19}$ First an instrument which is continuous or takes on many discrete values. In a non-parametric setting this instrument must satisfy a generalised rank condition which implies that it can explain any function of the endogenous variable. Second, that the dependence of the conditional mean of the unobservables given the endogenous variables and the instrument is only a function of the residuals $v^{P}$ and $v^{G}$ and not of the endogenous variable and the instrument separately. Florens, Heckman, Meghir and Vytlacil (2002) develop arguments relating to the non-parametric identifiability of models with heterogeneous impacts of continuous variables such as experience or tenure.

We do not impose any arbitrary functional form assumptions on the residuals that would force them to have independent variation. The residuals originate from simple linear regressions. We just require the testable rank condition A.4 to be satisfied. Finally note that there are further structural restrictions linking participation and experience but we do not exploit these here.

\footnotetext{
${ }^{19}$ See also Newey, Powell and Vella (1999).
} 


\subsection{Implementation of the estimation method}

To implement this estimation approach, we start by estimating reduced forms for participation, and for experience at the beginning of the current period. These are estimated on all individuals (independently of their current or past work status) using Ordinary Least Squares (OLS). A separate reduced form is estimated for each skill group. The experience reduced form for each skill group $a$ (apprentices and non-apprentices) is

$$
T_{i t}^{G}=\alpha_{0}^{a G}+\alpha_{1}^{a G} a g e_{i t}+\alpha_{2}^{a G} c_{i t}+\alpha_{3}^{a G} a g e_{i t} \times c_{i t}+a d_{i t}^{\prime} \alpha_{4}^{a G}+\left(a d_{i t} \times c_{i t}\right)^{\prime} \alpha_{5}^{a G}+x_{i t}^{\prime} \xi^{a G}+v_{i t}^{G} .
$$

The variables $a d$ are age indicators. ${ }^{20}$ The $x$ variables are the year indicators and the level of school education. The variable $c_{i t}$ is potential experience of individual $i$ in calendar period $t$. We also estimate a reduced form participation equation (job acceptance), which has the same form. Having estimated the reduced forms, we compute the respective residuals $\hat{v}_{i t}^{G}$ and $\hat{v}_{i t}^{P}$.

The next step involves writing wages as $\ln w_{i t}=E\left(\ln w_{i t} \mid a g e_{i t}, X_{i t}, D_{i t}=1, P_{i t}=\right.$ $\left.1, T_{i t}^{G}, T_{i t}^{S}, T_{i f t}^{F}=0\right)+e_{i t}^{*}$, by applying the assumptions (2), (3) and (4) when taking the conditional expectation of wages in (1). We assume that the parameters on the residual terms in (2) and (3) $\left(\delta^{G}\left(c_{i t}\right), \delta^{P}\left(c_{i t}\right), \gamma^{G}\left(c_{i t}\right), \gamma^{P}\left(c_{i t}\right), \kappa^{G}\left(c_{i t}\right), \kappa^{P}\left(c_{i t}\right)\right)$ are linear in potential experience. ${ }^{21}$ Thus we obtain the following regression that can be estimated using ordinary least squares on the subsample of those starting a new job following displacement:

$$
\begin{aligned}
\ln w_{i t}=\ln r_{t}^{a}+g\left(T_{i t}^{G} \mid a_{i}\right)+s\left(T_{i t}^{S} \mid a_{i}\right)+x_{i t}^{\prime} \gamma^{a} & +\delta_{1}^{G} \hat{v}_{i t}^{G}+\delta_{2}^{G} c_{i t} \hat{v}_{i t}^{G}+\delta_{1}^{P} \hat{v}_{i t}^{P}+\delta_{2}^{P} c_{i t} \hat{v}_{i t}^{P} \\
& +\gamma_{1}^{G} T_{i t}^{G} \hat{v}_{i t}^{G}+\gamma_{2}^{G} c_{i t} T_{i t}^{G} \hat{v}_{i t}^{G} \\
& +\gamma_{1}^{P} T_{i t}^{G} \hat{v}_{i t}^{P}+\gamma_{2}^{P} c_{i t} T_{i t}^{G} \hat{v}_{i t}^{P} \\
& +\kappa_{1}^{G} T_{i t}^{S} \hat{v}_{i t}^{G}+\kappa_{2}^{G} c_{i t} T_{i t}^{S} \hat{v}_{i t}^{G} \\
& +\kappa_{1}^{P} T_{i t}^{S} \hat{v}_{i t}^{P}+\kappa_{2}^{P} c_{i t} T_{i t}^{S} \hat{v}_{i t}^{P}+e_{i t}^{*}
\end{aligned}
$$

\footnotetext{
${ }^{20}$ To test for non-linearities, we test for the exclusion of the age dummies, given the inclusion of the linear age term.

${ }^{21}$ For example, $\delta^{G}\left(c_{i t}\right)=\delta_{1}^{G}+\delta_{2}^{G} c_{i t}$.
} 
Any estimator that includes the control functions (residual terms) will be referred to as a control function estimator.

The specification of $g\left(T_{i t}^{G} \mid a_{i}\right)$ and $s\left(T_{i t}^{S} \mid a_{i}\right)$ is stated in the empirical section. The interactions of these residuals with experience $T_{i t}^{G}$ and sector tenure $T_{i t}^{S}$ control for self selection due to heterogeneous returns to experience and sector tenure. Finally, as explained above, the relationship of these residuals to the unobservables in wages are likely to be changing with potential experience $c_{i t}{ }^{22}$ We allow for this by interacting all terms with $c_{i t}$.

\subsection{Estimating the return to tenure}

In estimating the returns to tenure, we use wages in jobs that follow firm closures. This is necessary because the existence of match specific returns to tenure may imply the accumulation of search capital which may be confused with returns to tenure. Consider wages adjusted for average growth due to experience and sector tenure. These are

$$
\widetilde{\ln w_{i t}}=\ln w_{i t}-\widehat{\ln r_{t}^{a}}-g \widehat{\left(T_{i t}^{G} \mid a_{i}\right)}-\widehat{s\left(T_{i t}^{S} \mid a_{i}\right)}
$$

where $\left.\widehat{\ln r_{t}^{a}}, g \widehat{\left(T_{i t}^{G} \mid a_{i}\right.}\right)$ and $\left.\widehat{s\left(T_{i t}^{S} \mid a_{i}\right.}\right)$ are the pre-estimated aggregate growth of wages and the experience and sector tenure components respectively.

The adjusted wage is then given by

$$
\widetilde{\ln w_{i t}}=f\left(T_{i t}^{F} \mid a_{i}\right)+\left[\eta_{i t} T_{i t}^{G}+\varepsilon_{i t} T_{i t}^{S}+\nu_{i f t} T_{i f t}^{F}+m_{i f t}+\tilde{e}_{i t}\right] .
$$

where $\tilde{e}_{i t}$ reflects estimation error from the first stage as well as the original error $e_{i t}$.

With heterogeneous returns and/or heterogeneity that varies over time first differencing does not help. Thus, to estimate the returns to tenure similar to the case of experience, we need to model $E\left[\eta_{i t} T_{i t}^{G}+\varepsilon_{i t} T_{i t}^{S}+\nu_{i f t} T_{i f t}^{F}+m_{i f t}+e_{i t} \mid a g e, T_{i t}^{G}, T_{i t}^{S}, T_{i f t}^{F}, c_{i t}\right]$. Relative to the case where tenure is zero, this expression includes an extra term $\left(\nu_{\text {ift }} T_{i f t}^{F}\right)$. Moreover we need to model the relationship between tenure and all the residual terms. Thus the

\footnotetext{
${ }^{22}$ If nothing else, the maximum number of years of experience increases with potential experience.
} 
assumptions we made earlier are updated to ${ }^{23}$

$$
\begin{aligned}
& E\left(m_{i f t}+e_{i t} \mid a g e_{i t}, X_{i t}, D_{i t}=1, P_{i t}=1, T_{i t}^{G}, T_{i t}^{S}, T_{i f t}^{F}\right)=\lambda^{G}\left(c_{i t}\right) v_{i t}^{G}+\lambda^{P}\left(c_{i t}\right) v_{i t}^{P}+\lambda^{T}\left(c_{i t}\right) v_{i t}^{T}, \\
& E\left(T_{i t}^{G} \eta_{i t} \mid a g e_{i t}, X_{i t}, D_{i t}=1, P_{i t}=1, T_{i t}^{G}, T_{i t}^{S}, T_{i f t}^{F}\right)=\left[\rho^{G}\left(c_{i t}\right) v_{i t}^{G}+\rho^{P}\left(c_{i t}\right) v_{i t}^{P}+\rho^{T}\left(c_{i t}\right) v_{i t}^{T}\right] T_{i t}^{G}, \\
& E\left(T_{i t}^{S} \varepsilon_{i t} \mid a g e_{i t}, X_{i t}, D_{i t}=1, P_{i t}=1, T_{i t}^{G}, T_{i t}^{S}, T_{i f t}^{F}\right)=\left[\theta^{G}\left(c_{i t}\right) v_{i t}^{G}+\theta^{P}\left(c_{i t}\right) v_{i t}^{P}+\theta^{T}\left(c_{i t}\right) v_{i t}^{T}\right] T_{i t}^{S}, \\
& E\left(T_{i t}^{F} \nu_{i f t} \mid a g e_{i t}, X_{i t}, D_{i t}=1, P_{i t}=1, T_{i t}^{G}, T_{i t}^{S}, T_{i f t}^{F}\right)=\left[\xi^{G}\left(c_{i t}\right) v_{i t}^{G}+\xi^{P}\left(c_{i t}\right) v_{i t}^{P}+\xi^{T}\left(c_{i t}\right) v_{i t}^{T}\right] T_{i t}^{F}
\end{aligned}
$$

where $v_{i t}^{T}$ is the residual from the tenure reduced form and where as before the coefficients of each of the residuals are linear functions of potential experience $\left(c_{i t}\right)$.

The tenure reduced form will be of the same form as (5). We expect age to affect mobility between jobs and hence tenure because mobility costs will be higher for older individuals due to family and housing among other things. Thus age effects and age interacted with potential experience should matter for tenure. More generally, identification relies on the matrix of coefficients on the age effects and age effects interacted with potential experience from the three reduced forms (participation, experience and tenure) having rank three. The rank condition is more demanding than for estimating the effects of experience alone. Thus overall the conditions for identifying the returns to tenure are more stringent than the conditions required for identifying the returns to experience. The rank condition is amply satisfied in the data even with the three reduced forms, as shown below. Identification is further aided by the fact that the returns to experience and sector tenure can be estimated at a first step, under weaker conditions by relying on the first job record, where tenure is zero (as discussed above).

Implementation of the estimator involves regressing the adjusted wage $\left(\widetilde{\ln w_{i t}}\right)$ on the function of tenure $\left(f\left(T_{i t}^{F} \mid a_{i}\right)\right)$ and on all pre-estimated residual terms shown in the equations above. The residuals are estimated based on linear reduced forms for experience, participa-

\footnotetext{
${ }^{23}$ Note that $D_{i t}=1$ means that the worker had been displaced in the job immediately preceding the current one.
} 
tion and tenure with the same specification as in equation (5).

\subsubsection{Standard errors and inference}

Our approach requires that the standard errors are corrected for generated regressor bias. We also need to account for serial correlation and heteroskedasticity, both of unknown form. Since computing the standard errors analytically can be very cumbersome in these circumstances we have used the block bootstrap where we treat each individual as a sampling unit, thus allowing for arbitrary serial correlation and heteroskedasticity. We bootstrap the entire estimation procedure thus allowing for the stage by stage nature of our estimator. This also allows us to evaluate whether there is any important small sample bias in our approach (see Hall and Horowitz, 1996 and Horowitz, 2000). ${ }^{24}$ Moreover, many of the test statistics we present use bootstrap critical values. To the extent that the tests are pivotal ( i.e. their asymptotic distribution does not depend on unknown parameters), this will provide small sample refinements. Otherwise this procedure is equivalent to using the asymptotic distribution.

\section{The Data}

The data we use is a 1 percent sample from the German Social Security records (IAB data), which has been supplemented by information from the official unemployment records. We only consider male workers in West Germany. This data is available for the years 1975-1995 (see Bender et al. 1996 for details). Over this period, it records for each worker the exact date of any change to a new job or to (and from) unemployment. Furthermore, it contains an obligatory yearly entry for each worker. Thus an accurate calendar of labour market status is provided with minimal, if any, measurement error for each worker. It further provides information about whether a worker is on an apprenticeship training scheme.

Wages are recorded in the following fashion. If the worker does not change firm over the calendar year, the average daily wage is recorded over this period. If the worker changes jobs, the record includes the average daily wage for the period from the start of the calendar

\footnotetext{
${ }^{24}$ Fitzenberger and Kurz (2002) provide a recent application in the use of the block bootstrap in the context of estimating wage equations.
} 
year (or the start of the spell, whichever is more recent) to the date of termination of employment at the firm. Then we obtain an average daily wage from the beginning of the new employment spell to the end of the calendar year (or to the end of the employment spell, whichever comes sooner). Hence the wage information always relates to a single firm, and never covers more than one calendar year. We deflate wages by the German consumer price index. In addition, we use data on age, educational qualifications and industry. Thus the data allows us to construct very accurate work and earnings histories. The accuracy of our work history information contrasts with information based on recall and individual based responses (such as the US NLSY and PSID or the UK BHPS).

The data does not cover the entire German labour force, as the self employed and civil servants do not pay social security contributions, and are therefore excluded. Moreover, as with many administrative data sets, the data is top coded. In our analysis, we consider only young individuals who went through apprenticeship training, and individuals who did not receive any further training after school. Top coding hardly affects the wages of workers in these groups. $^{25}$

The data base contains also information on the firm in which each worker is employed. Using separate information on the firm we can link in the year that the firm started and closed down. When the firm has many establishments the data refers to one establishment and not to a whole firm. However, for simplicity we just use the term firm throughout.

\section{The Sample}

From this data base, we construct a sample of young male workers whom we observe from the entry to the labour force onwards. To ensure that we do not miss out early employment spells, we restrict our sample to workers who were not older than 15 in 1975 (which is the minimum compulsory full time schooling age).

We distinguish between two levels of qualification: workers who go through an apprenticeship training scheme early on in their careers, and workers who do not acquire any further formal training after school (which could be a high school degree with 13 years of schooling,

\footnotetext{
${ }^{25}$ Less than 1 percent of our sample population experience a right censoring later in their career.
} 
or a lower secondary degree with 9-10 years of schooling), or who drop out of the training scheme. We refer to these two samples as the skilled and the unskilled sample. The longest labour market history in our data set is 19 years, and the shortest 2 years. Our final sample consists of 25649 skilled workers, with 204458 employment records, and 7264 unskilled workers, with 55924 employment records. ${ }^{26}$

\subsection{A descriptive analysis of wage growth and job mobility}

We provide some information on the institutional background, the education system and wage setting in Germany in appendix B. ${ }^{27}$ In this section, we describe the basic features of job mobility and wage growth in our sample.

\section{Mobility}

In figure 1, we illustrate job mobility for the first 10 years of labour market experience, where we brake down our sample into the two different educational categories. The figure shows that mobility is lower for better educated workers throughout. After 10 years, an unskilled worker has held 3.4 jobs on average, while a skilled worker has held 2.8 jobs. The figure also shows that the average number of jobs held in Germany increases only during the first 4 to 5 years, and flattens out afterwards. These numbers confirm that mobility in Germany is relatively low; this contrasts to the US for example where, on average, workers hold their 7th job after 10 years of labour market experience (see Topel and Ward, 1992).

In Table 2 we show the percentage of job moves that result in a job within the same sector and in a different sector. Table 12 in Appendix C provides the list of the 15 sectors we consider and the proportion of workers in our sample employed in each over the entire time period we consider. Here it emerges that the majority of moves between firms involves a change in sector. However, when it comes to the moves caused by closure the proportion staying in the same sector rises. Thus among those making a decision to move between firms a large proportion also decides to change sector. This is consistent with the low number of

\footnotetext{
${ }^{26}$ We delete the few individuals who have one or more part time spells.

${ }^{27}$ Bender et al. (2002), Burda and Mertens (2001) and Fitzenberger and Kurz (2002) provide additional descriptive evidence on the German labour market.
} 


\begin{tabular}{l|c|c|}
\hline \hline Six Month periods & Skilled & Unskilled \\
\hline Job to Job & $49.1 \%$ & $30.8 \%$ \\
$0-1$ & $23.9 \%$ & $30.5 \%$ \\
$1-2$ & $12.6 \%$ & $15.8 \%$ \\
$2-3$ & $7.5 \%$ & $9.9 \%$ \\
$3-4$ & $1.5 \%$ & $3.8 \%$ \\
$4-5$ & $2.0 \%$ & $4.1 \%$ \\
$5+$ & $3.4 \%$ & $5.1 \%$ \\
\hline \hline
\end{tabular}

Table 1: Time to a new job following displacement (six month periods)

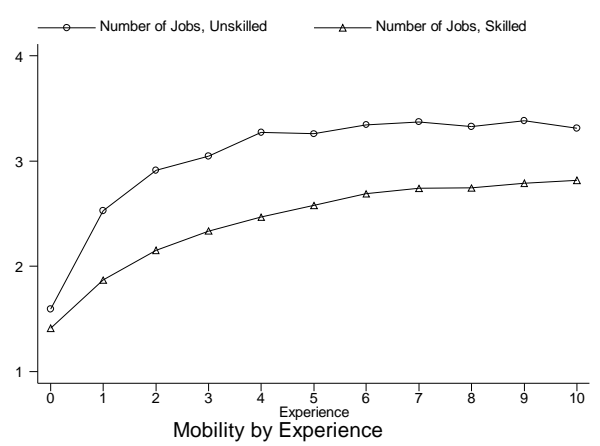

Figure 1: Average number of jobs by years of experience

moves we observe and such mobility may be an important part of job or career "shopping" activity by young workers.

In Table 1 we show the time taken by the displaced to find new jobs. A large proportion move to a new job with no interruption, which probably reflects the advance notice that workers get in Germany (see Appendix B). This is less true for the unskilled workers, who overall have longer spells out of work.

\begin{tabular}{|c|c|c|c|}
\hline \multicolumn{4}{|l|}{ Mobility within and across sectors } \\
\hline & All & Skilled & Unskilled \\
\hline \% Job Termination to New firm, Same Sector & 38.5 & 41.4 & 31.0 \\
\hline \% Job Termination to New firm, New Sector & 61.5 & 58.6 & 69.0 \\
\hline \% Job Termination to New firm, Same Sector (after Displacement) & 44.9 & 47.6 & 39.3 \\
\hline \% Job Termination to New firm, New Sector (after Displacement) & 55.1 & 52.4 & 60.7 \\
\hline
\end{tabular}

Table 2: Percentage of Job Terminations within/across sectors 


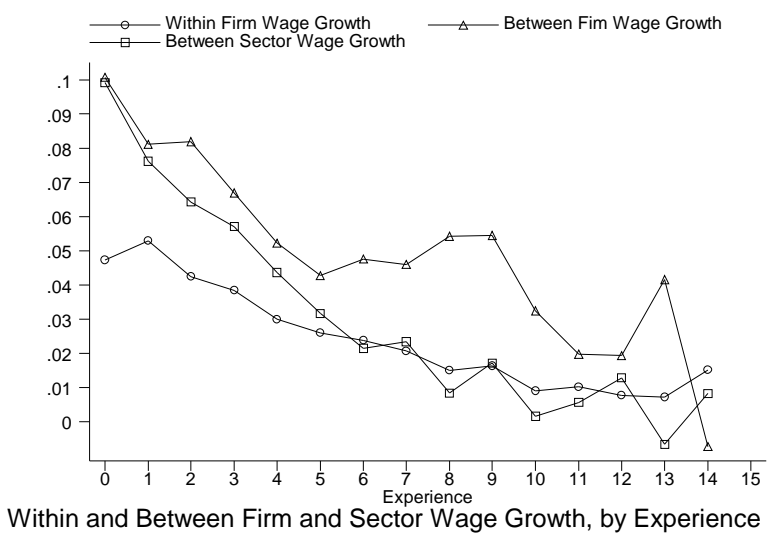

Figure 2:

\section{Between and Within Job Wage Growth}

Figure 2 displays wage growth for workers within firm, between firms of the same sector and between firms of different sectors, against experience. Within job average annual wage growth is lower than between job average wage growth. The difference in within and between job wage growth declines with experience. This may reflect a higher variance of accepted job offers for movers early in the career when workers have not sorted into their best match yet. Between sector wage growth is initially similar to between job wage growth, but declines more rapidly with experience.

Overall average within job wage growth in the first 4 years in the labour market is 4.2 percent, which compares to 7.6 percent for between job wage growth, and 6.8 percent for between job and between sector wage growth. ${ }^{28}$ We also find that the realised gains from moving decline with the number of jobs the individual has held. ${ }^{29}$ This is consistent with the idea that the scope for improvement of a match declines eventually.

\footnotetext{
${ }^{28}$ Within firm wage growth is the annual growth in wages for those staying in the same firm. Between firm wage growth is equal to the difference in log wages between the new firm and the old firm. Between sector wage growth is calculated over those who change sector when they change firm.

${ }^{29}$ This is in line with Topel and Ward (1992), who find for the US that between job wage growth declines with experience. However, they establish a far larger between job wage growth: $12 \%$ for the first 10 years of labour market experience, as compared to $1.75 \%$ within jobs.
} 
Wages, Wage Growth, and the Number of Jobs

Our descriptive analysis suggests that job movers obtain wage gains, as predicted by search theory. However, this does not imply that, on average, job movers have higher wages than non-movers. To investigate this, we regress log wages on dummies for the number of the jobs the individual has held to date (first job, second job etc.), as well as on age and year dummies. ${ }^{30}$ These estimates indicate that workers who have held more jobs have lower wages. When braking this down by skill level we see that the phenomenon is particularly strong for the skilled workers. Those among the unskilled who have held two jobs have the highest wages on average. Wages decline thereafter with more jobs.

When we run the same regression of wages on the number of jobs, including individual fixed effects, the number of jobs is positively associated with wages for all education groups. ${ }^{31}$ Hence, although it seems that movers among the skilled workers are negatively selected, job mobility does lead to wage gains on average for all groups. Moreover, the unskilled with a few (but not too many) job moves seem to be the most productive.

\section{The Firms}

An important component of our identification strategy is information about the closure of the firm in which the worker is employed. In our data we observe establishments, which we always refer to as firms. In multi-establishment firms closure refers to the closure of one of these.

We discussed the assumptions we need to make about selection of workers in these firms above. In figure 3 we plot the survivor function for the firms that came into existence after 1978. The annual exit rates are quite high initially, and they steadily decline. Only just over $60 \%$ of firms observed to start up survive beyond 15 years.

In figure 4, we show the evolution of average employment for German firms known to close down. We distinguish between 3 different categories, according to their age at closure (point 0 on the $\mathrm{x}$-axis in the graph); s1, s2 and s3 refer to firms ehich died 6,11 and 16 years of age respectively. The fourth category ( $\mathrm{s} 0$ ) includes all firms which were founded before

\footnotetext{
${ }^{30}$ See Table 13 in Appendix C, where we report the results for the first eight jobs.

${ }^{31}$ See Table 14 in Appendix C.
} 


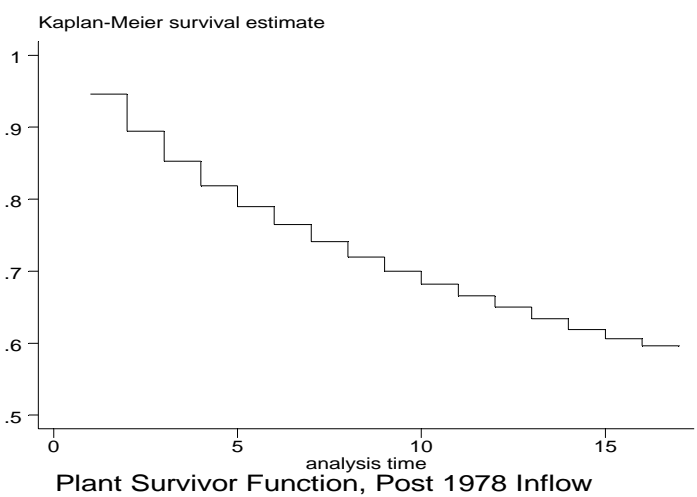

Figure 3:

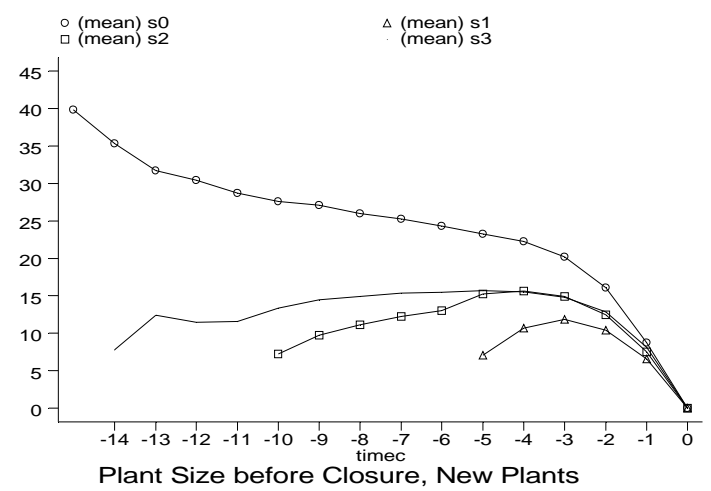

Figure 4: 
1978 (the first year for which firm information is available). ${ }^{32}$ The first obvious drop in employment in firms that will eventually close down is between years minus two and minus one.

As we discuss above, selective firing or quits may impact on the average quality of the workforce in the firm. In fact, we find that the wages of the unskilled workers who remain in the firm within less than a year of its closure are lower by $10 \%$ on average than the average wage of the workforce observed a year earlier (see figure 5, where the upper graph refers to skilled workers, and the lower one to unskilled workers; time zero is the year of closure). This may partly reflects wage drops, and partly composition effects. For the skilled, the drop is only about 1-2\%. Post closure the unskilled seem to recover immediately all wage losses. Moreover, wage growth is higher for that sample for one more year. This may be linked to the fact that post closure these workers become more mobile to recover the lost search capital and may also indicate returns to tenure. ${ }^{33}$

These graphs indicate that selective departures from firms that will close down may start as early as two years before closure. This motivates our robustness check where we define displaced workers in two ways: workers who leave a firm that closes down within one year of their departure and workers who leave a firm that closes down within two years of their departure. We discuss differences between workers displaced due to firm closure and all others in a later section when we carry out sensitivity analysis for our results.

\section{Estimation of the wage equation}

\subsection{The reduced forms}

There are three reduced forms in our model: one for experience (the accumulation of past participation decisions), one for current participation, and one for tenure. Experience is

\footnotetext{
${ }^{32}$ The s0 graph in (4) has to be interpreted with care since its gradient is partly due to the change in the age composition of firms. Thus the breakdown by cohort (s1,s2 and s3) is made so as to avoid the composition effects that are induced by the fact that young firms are both smaller and more likely to close down. The differences in firm size across the lines reflect a different age of each group.

${ }^{33}$ It is worth emphasising that our estimates of wage growth never rely on comparisons pre and post displacement. The graph on the evolution of wages pre and post displacement provide a graphic explanation as to why such comparison may be misleading.
} 


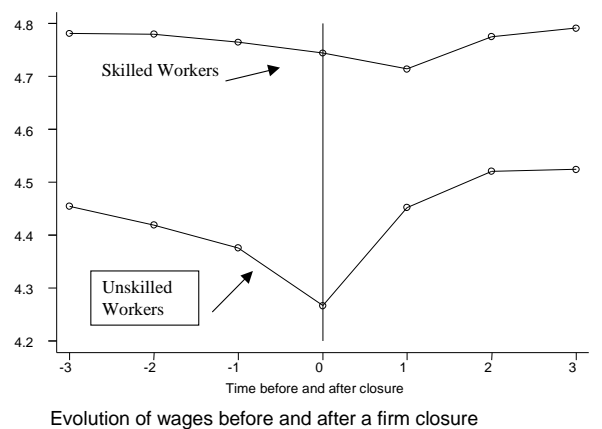

Figure 5:

defined as the number of years (including fractions of a year) worked up to now. To deal with the incredible amount of detail in the data we define current participation as the fraction of the calendar year in employment. ${ }^{34}$ Tenure is defined as the number of years (including fractions of a year) worked in the current firm. The reduced forms include age indicators, potential experience, and interactions (see equation 5), as well as initial education and time effects, and they are estimated separately for apprentices and non-apprentices. All reduced forms are estimated on the entire sample and not only on the sample of displaced workers, to improve precision. They are presented in Appendix D.

In all reduced forms the age dummies as well as the age dummies interacted with potential experience are highly significant and have a p-value of zero, over and above the linear age and potential experience effects. This is necessary (but not sufficient) for the rank condition to be satisfied. Formally the rank condition requires that the rank of the matrix of the coefficients on the age dummies and the age dummies interacted with potential experience has its maximum value of three (i.e. as many as the reduced forms). Based on the eigen value test of Robin and Smith (2000) we tested the null hypotheses of rank 2 against that of three. $^{35}$ We used the bootstrap to derive critical values for the test. We found that the pvalue for this test was 0.0 for 300 replications for both skilled and unskilled workers decisively rejecting rank 2. In other words the rank condition $\mathbf{A . 4}$ as well as the more stringent one

\footnotetext{
${ }^{34} \mathrm{An}$ alternative would be to allocate a whole period of time such as a quarter or a year either to work or to unemployment.

${ }^{35}$ For another application and discussion, see for example Blundell, Duncan and Meghir, 1998.
} 
required to identify the returns to tenure are easily satisfied in our data.

We have also estimated the model excluding the interactions between potential experience and age dummies. The rank condition was again satisfied with a p-value of zero and the estimates of the wage equation were very similar to the ones we present here, with marginally lower precision.

\subsection{The Returns to Experience, Sector Tenure and Firm Tenure}

All wage equations include as conditioning variables indicators for education, as well as annual time effects. The results from the block bootstrap suggests that the small sample bias in all the estimates we present is negligible. Moreover confidence intervals based on the normal distribution using the standard error computed using the bootstrap were basically identical to the ones obtained from the percentiles of the bootstrap. ${ }^{36}$

Throughout we consider 5 different estimation methods: OLS on the whole sample; OLS for the sample of those starting a new job (as in Topel, 1991); OLS on the sample of those starting a job post displacement; our control function approach using the entire sample of new jobs and including the residual terms for endogeneity/selection correction; our control function approach which includes the same residual terms but uses only the first post displacement record.

\section{The returns to experience}

Experience is modelled as a set of annual experience indicators for the first four years of experience and a linear experience effect beyond that. All coefficients are interpreted as the effect of experience on annual growth of wages at different experience levels. All regressions include sector tenure. Results on sector and firm tenure are discussed in later sections.

\footnotetext{
${ }^{36}$ In whatever follows we will compare the skilled to the unskilled workers. The differences between the two groups should not be interpreted necessarily as causal; they may well be due to the unobserved characteristics of individuals choosing the alternative careers.
} 


\begin{tabular}{|c|c|c|c|c|c|}
\hline & \multicolumn{3}{|c|}{ OLS } & \multicolumn{2}{|c|}{ Control Function Estimator } \\
\hline & Whole sample & All New Jobs & $\begin{array}{c}\text { New Jobs after } \\
\text { Displacement }\end{array}$ & All New Jobs & $\begin{array}{c}\text { New Jobs after } \\
\text { Displacement }\end{array}$ \\
\hline \multicolumn{6}{|l|}{ Experience } \\
\hline \multirow[t]{2}{*}{ One year } & 0.146 & 0.146 & 0.087 & 0.17 & 0.099 \\
\hline & 0.0056 & 0.010 & 0.037 & 0.01 & 0.035 \\
\hline \multirow[t]{2}{*}{ two years } & 0.082 & 0.059 & 0.085 & 0.060 & 0.082 \\
\hline & 0.0057 & 0.012 & 0.039 & 0.012 & 0.038 \\
\hline \multirow[t]{2}{*}{ three years } & 0.064 & 0.029 & 0.045 & 0.032 & 0.029 \\
\hline & 0.0057 & 0.013 & 0.036 & 0.012 & 0.036 \\
\hline \multirow[t]{2}{*}{ four years } & 0.043 & 0.034 & 0.041 & 0.021 & 0.033 \\
\hline & 0.0055 & 0.012 & 0.030 & 0.015 & 0.032 \\
\hline \multirow[t]{2}{*}{ five years +} & 0.016 & 0.014 & 0.015 & 0.0012 & -0.004 \\
\hline & 0.0016 & 0.003 & 0.0063 & 0.0038 & 0.01 \\
\hline $\mathrm{N}$ & 55953 & 18923 & 1373 & 18923 & 1373 \\
\hline
\end{tabular}

Column 1: Asymptotic standard errors acounting for serial correlation and heteroscedasticity

in italics. Columns 2-5: Standard Deviation of the block bootstrap in italics for. 200 replications used.

Records for unskilled displaced workers $1373 \mathrm{~N}$ : Total number of observations (individuals $\times$ records)

Table 3: Wage growth - Experience, Unskilled Workers

\section{Unskilled Workers}

Table 3 presents the results for the sample of unskilled workers (i.e. without an apprenticeship). The first column presents the experience profile obtained by OLS on the entire sample. The estimated returns to the first year of experience $(14.6 \%$ over a year) are large. This result is the same as the second regression based on the first job record of all those starting a new job (as in Topel 1991). When we consider the estimates based on the displaced workers only, but with no endogeneity/selection correction (in the third column), we find that the first year estimated returns fall to $8.7 \%{ }^{37}$ This implies that a large part of the first year increase in wages for unskilled workers is due to job search and improved matches. This is consistent with our results in the descriptive section, which suggest that among the unskilled, movers on average improve their wage with the first job change.

The fourth column illustrates the impact of adding the residuals but using the entire sample of job movers as in column 2. This ignores the bias that may be induced by the role of search in improving wages. The effect of adding these residuals compared to columns 1 and 2 is to reduce the returns to experience for later years, suggesting that the observed

\footnotetext{
${ }^{37}$ In Table 16 in Appendix D we provide the number of observations by experience level for the displacement sample.
} 
growth in later years can be attributed to the stronger labour market attachment of more able workers or workers with higher returns.

The final column presents results based on our approach; the residual terms are included and only the records relating to the first post-displacement job are used. The estimates of the coefficients on the residuals are presented in Table 15 of Appendix D. ${ }^{38}$ The residual terms based on bootstrap critical values are significant at the $0 \%$ level. Therefore the differences in the estimated coefficients obtained when the residuals are included, compared to those in column 3, are jointly significant. In addition a Wu-Hausman test comparing the experience coefficients presented in column 5 to those obtained by OLS in column 1 rejects equality at $1.4 \%$.

Now the first year returns are estimated to be $9.9 \%$, much lower than the original first year return from column 1. Comparing across columns we see that this is the effect of using displaced workers. Differences are also apparent in later years, where the results in the final column imply a flatter experience profile. Comparing the first to the last column, our final results imply that for the unskilled workers wage growth due to experience declines rapidly and falls to zero by five years. In fact the returns in column 5 are not significant beyond two years of experience. By contrast, the OLS returns are large and significant throughout, with a longer term return of $1.6 \%$.

Comparing the results of columns five with those of columns three and four we see that both the selection/endogeneity correction and the use of the displaced sample contribute to the differences from OLS. Columns 2 and 3 or 4 and 5 indicate that much of the early returns to experience can be attributed to improved matches, which is consistent with the fact that movers improve their wage. While comparing 4 and 5 where we add the residual terms, it is evident that endogeneity of experience (due to endogenous participation choices) is also an important issue at longer levels of experience (as also indicated by the significance of the residuals).

\footnotetext{
${ }^{38}$ Since the sample of displaced workers is relatively small, particularly for the unskilled workers, we have imposed the restriction that the coefficients on the residual terms are equal between the skilled and unskilled workers, a restriction we test and cannot reject. This does not impose that the resulting selection effects are the same since this also depends on the distribution of residual terms for the skilled and the unskilled.
} 


\section{Skilled Workers}

When estimating the model for the skilled workers, we include the period of apprenticeship in experience, tenure and sector tenure. The duration of apprenticeship varies usually between two and three years. The first return to experience that we can measure for the sample of skilled workers relates to the growth of wages following the second year of experience. ${ }^{39}$

We display results for the skilled workers in Table 4. For this group, the estimates based on the displaced sample with no endogeneity/selection correction (column 3) imply higher returns to experience in the second year than the estimates based either on the entire sample (1), or on the entire sample of new job starters (2). This is different from our findings for unskilled workers and is compatible with the fact that movers are negatively selected among the skilled workers, as we show in our descriptive section 3.1. In column 4 we report the results of including the residual terms but estimating the model on the entire sample of new job starts (as in column 2) and the results are very similar. In the final column, we use the displaced sample and include the residual terms to control for endogeneity/selection. Selection/endogeneity correction matters less for the skilled workers, as far as the returns to experience is concerned, which reflects the fact that the skilled workers have fewer and shorter spells out of work. The Wu-Hausman test comparing the experience coefficients in columns 1 and 5 has a p-value of $15 \%$.

To summarise, our findings suggest that wages for the unskilled workers grow significantly in the first two years of work, due to learning by doing. Thereafter unskilled workers enjoy little or no returns to experience. Skilled workers have lower wage growth initially - a result that may be attributed to the fact that they have received much of their general skills during their formal training period. However, other than for the unskilled wages continue to grow due to experience throughout the period of the life-cycle that we observe, at a relatively low but significant rate of $1.2 \%$.

\footnotetext{
${ }^{39}$ We do not model wages during apprenticeship.
} 


\begin{tabular}{|c|c|c|c|c|c|}
\hline & \multicolumn{3}{|c|}{$\overline{\mathrm{OLS}}$} & \multicolumn{2}{|c|}{ Control Function Estimator } \\
\hline & Whole Sample & All new Jobs & $\begin{array}{c}\text { New Jobs After } \\
\text { Displacement }\end{array}$ & All new jobs & $\begin{array}{c}\text { New Jobs after } \\
\text { Displacement }\end{array}$ \\
\hline \multicolumn{6}{|l|}{ Experience } \\
\hline \multirow[t]{2}{*}{ two years } & 0.047 & 0.042 & 0.067 & 0.054 & 0.068 \\
\hline & 0.0036 & 0.0045 & 0.019 & 0.0047 & 0.019 \\
\hline \multirow[t]{2}{*}{ three years } & 0.060 & 0.056 & 0.056 & 0.061 & 0.062 \\
\hline & 0.0022 & 0.0038 & 0.016 & 0.0039 & 0.014 \\
\hline \multirow[t]{2}{*}{ four years } & 0.067 & 0.039 & 0.060 & 0.070 & 0.062 \\
\hline & 0.0020 & 0.0050 & 0.015 & 0.0046 & 0.017 \\
\hline \multirow[t]{2}{*}{ five years +} & 0.021 & 0.017 & 0.022 & 0.013 & 0.012 \\
\hline & 0.0006 & 0.0016 & 0.0046 & 0.0014 & 0.004 \\
\hline $\mathrm{N}$ & 204543 & 57005 & 3639 & 57005 & 3639 \\
\hline $\begin{array}{l}\text { Column 1: } \mathrm{A} \\
\text { in italics. } \mathrm{Co} \\
\text { Records of } \mathrm{sl}\end{array}$ & $\begin{array}{l}\text { nptotic standard } \\
\text { ans 2-5: Standar } \\
\text { d displaced wor }\end{array}$ & $\begin{array}{l}\text { rors accounting } \\
\text { eviation of the } \\
3639 \text {. N: Tota }\end{array}$ & $\begin{array}{l}\text { or serial correlatic } \\
\text { lock bootstrap in } \\
\text { aumber of observa }\end{array}$ & $\begin{array}{l}\text { d heteroscedas } \\
\text { cs for. } 200 \text { repl } \\
\text { s (individuals } \times\end{array}$ & $\begin{array}{l}\text { city } \\
\text { cations used. } \\
\text { ecords) }\end{array}$ \\
\hline
\end{tabular}

Table 4: Wage growth - Experience, Skilled Workers

\section{Returns to sector tenure}

We now turn to the returns to remaining in the same sector. The results here are obtained from the same regressions as those for the returns to experience. The columns in the tables correspond. We have fitted a linear spline providing an annual return for the first five years and an annual return thereafter.

Based on the OLS results reported in Table 5, columns 1, the return to sector tenure is about $0.9 \%$ for skilled workers. For the unskilled, it is $2.2 \%$ in the first four years, and basically zero subsequently. When we consider the results based on our approach (column 5) we obtain that the returns to sector tenure are $1.0 \%$ for the skilled workers in the first five years and zero thereafter.

For the unskilled workers the returns are also now low and insignificant; combined with the results from the returns to experience this suggests that there is not much wage growth from learning by doing for the unskilled, at least as far as transferable skills are concerned. Finally, when we ignore sector tenure the returns to experience remain more or less unaffected. These results are consistent with the fact that job change is very frequently associated with sector change (see Table 2) since it does not seem particularly costly to change sector.

So far we have assumed that sector switches following displacement, and having controlled for the endogeneity of job acceptance and experience, can be taken as exogenous. To test 


\begin{tabular}{|c|c|c|c|c|c|}
\hline & \multicolumn{3}{|c|}{ OLS } & \multicolumn{2}{|c|}{ Control Function Estimator } \\
\hline & Whole Sample & All New Jobs & $\begin{array}{c}\text { New Jobs After } \\
\text { Displacement }\end{array}$ & All new jobs & $\begin{array}{c}\text { New Jobs after } \\
\text { Displacement }\end{array}$ \\
\hline \multicolumn{6}{|l|}{ Sector Tenure } \\
\hline \multicolumn{6}{|c|}{ Skilled } \\
\hline \multirow[t]{2}{*}{$<5$ Years } & 0.0088 & 0.014 & 0.0098 & 0.010 & 0.010 \\
\hline & 0.0007 & 0.00086 & 0.0029 & 0.001 & 0.003 \\
\hline \multirow{2}{*}{$\geq 5$ Years } & 0.0070 & 0.012 & 0.0054 & 0.012 & 0.006 \\
\hline & 0.00091 & 0.0018 & 0.0042 & 0.002 & 0.004 \\
\hline \multicolumn{6}{|c|}{ Unskilled } \\
\hline \multirow[t]{2}{*}{$<5$ Years } & 0.022 & 0.028 & 0.0049 & 0.023 & 0.003 \\
\hline & 0.0022 & 0.0026 & 0.0078 & 0.003 & 0.007 \\
\hline \multirow[t]{2}{*}{$\geq 5$ Years } & 0.0015 & 0.0007 & 0.014 & -0.003 & 0.022 \\
\hline & 0.0024 & 0.0045 & 0.010 & 0.006 & 0.013 \\
\hline
\end{tabular}

Table 5: Wage growth - Sector Tenure, Unskilled and Skilled

for this, we follow Neal (1995) and use as an instrument for sector tenure (and hence sector switches) the pre-displacement sector size. The idea is that the larger the sector, the more likely it is that a worker will find a job in the sector he left. In fact this instrument is highly significant in the sector tenure reduced form, with a p-value of zero. The test for the hypothesis of exogeneity of sector tenure consists of testing that we can exclude the sector tenure residual from the wage equation. This is easily accepted with a p-value of $77 \%$.

\section{The Returns to Firm Tenure}

In Table 6 we present the estimates for the annual returns to firm tenure for both groups of workers. As for sector tenure we have fitted a linear spline providing an annual return for the first five years and an annual return thereafter. The results in columns 1,4 and 5 are based on levels. Results in columns 2 and 3 are based on within firm wage growth as in Topel (1991). In this case we have regressed the within firm wage growth (differences in logs of wages over time) on tenure indicators, after subtracting the growth implied by experience and sector tenure shown in column 2 of Tables 3,4 and 5 respectively. In column 2 we use the entire sample and in column three the jobs that started post-displacement. 


\begin{tabular}{|c|c|c|c|c|c|}
\hline & \multicolumn{3}{|c|}{$\overline{\text { OLS }}$} & \multicolumn{2}{|c|}{ Control Function Estimator } \\
\hline & Whole Sample & All New Jobs & $\begin{array}{c}\text { New Jobs After } \\
\text { Displacement }\end{array}$ & All New Jobs & $\begin{array}{c}\text { New Jobs after } \\
\text { Displacement }\end{array}$ \\
\hline \multicolumn{6}{|l|}{ Tenure } \\
\hline \multicolumn{6}{|c|}{ Skilled } \\
\hline \multirow[t]{2}{*}{$\leq 5$ Years } & 0.012 & -0.009 & -0.0004 & 0.017 & 0.024 \\
\hline & 0.0007 & 0.0009 & 0.0045 & 0.0009 & 0.004 \\
\hline \multirow[t]{2}{*}{$>5$ Years } & -0.003 & -0.020 & 0.011 & 0.022 & 0.017 \\
\hline & 0.001 & 0.0019 & 0.014 & 0.004 & 0.012 \\
\hline \multicolumn{6}{|c|}{ Unskilled } \\
\hline \multirow[t]{2}{*}{$\leq 5$ Years } & 0.014 & -0.014 & -0.022 & 0.025 & 0.040 \\
\hline & 0.0022 & 0.0019 & 0.0074 & 0.0027 & 0.010 \\
\hline \multirow[t]{2}{*}{$>5$ Years } & -0.003 & -0.018 & -0.058 & 0.036 & 0.011 \\
\hline & 0.0027 & 0.004 & 0.020 & 0.006 & 0.019 \\
\hline
\end{tabular}

Table 6: Wage growth - Tenure, Unskilled and Skilled

From the levels OLS regression we find that for the skilled workers the returns to tenure are very low (being 1.2\% for the first five years and $0 \%$ thereafter). When we estimate the model based on within firm wage growth on all jobs, without controlling for endogeneity of the mobility decision (as in Topel, 1991), we find negative returns. This negative estimate is probably a result of bias induced by the fact that stayers are individuals who in the previous period had a better wage outcome within the firm than average. With low returns to tenure, this selection effect can dominate and make the overall return negative. Using the same method as in column 2, but only on the jobs following displacement cannot correct such a downward bias. When we control for the endogeneity of the mobility decision we find a $2.4 \%$ annual return to tenure for the skilled workers in the first five years and $1.7 \%$ thereafter (column 5). The coefficients of the residuals for the tenure equation are reported in Appendix D and are highly significant ( $\mathrm{p}$-value of 0 ), which implies that the differences in the coefficients on tenure when we include the residuals are jointly significant. The WuHausman test comparing the OLS returns to tenure in column 1 with those in column 5 has a p-value of $0.1 \%$, strongly rejecting equality. 
For the unskilled, the OLS returns are $1.4 \%$ for the first five years and zero thereafter. But based on the results of column 5 the unskilled have relatively high returns to tenure of $4 \%$ a year for the first five years in the firm. However, the returns beyond five years are much lower (1.1\%) and insignificant. The results between column 1 and 5 are significantly different with a p-value for the Wu-Hausman test of $1.5 \%$.

The increase in the returns to tenure may represent a reallocation of life-cycle growth from experience to tenure, since the returns to experience decline quite substantially when we correct for selection and search. Since the returns to tenure are estimated after the returns to experience we can check to see how much of the increase in the returns to tenure is due to this shifting of wage growth from experience to tenure and how much is due to the correction for selective departures. To do this we re-estimate the returns to tenure using OLS on the post-displacement sample. However, we first adjust wages for experience based on the estimates in column 5, Tables 3 and 4 . We obtain the following results: Skilled workers tenure $<5$ years 0.028 (se 0.004); skilled workers tenure $\geqslant 5$ years -0.006 (0.007); unskilled workers tenure $<5$ years 0.045 (se 0.009); unskilled workers tenure $\geqslant 5$ years $-0.026(0.013)$. Thus the increase in the returns to tenure for the early years seem to be driven by the decline in the returns to experience. Although correcting for selection in firm mobility reduces somewhat the early returns to tenure, the main effects of selection are for higher levels of tenure. The increase in the estimated returns to tenure when we correct for selection is consistent with a matching story, where individuals with a high individual effect in the return to tenure have a stronger incentive to move and match with a better firm if the improvement in the match is high enough to counteract the accumulated returns to tenure. To see this suppose that the match specific return to tenure consists of an individual effect multiplied by a firm effect (say $\nu_{i f t}=\phi_{i} \theta_{f}$ ). Given the costs of moving the returns to improving the match will be higher for those with a higher individual effect $\phi_{i}$.

We have also tested whether further curvature is required for the later years by including a quadratic term in experience, sector tenure and tenure for each skill group . The test for the exclusion of these extra quadratic terms has a p-value of $18 \%$. Moreover, none of the conclusions are altered. The full set of results for the control function estimator post- 


\begin{tabular}{ll}
\hline \hline \multicolumn{2}{c}{ Apprenticeship } \\
\hline All Closures & Old Firms \\
-0.05 & -0.006 \\
0.008 & 0.01 \\
\hline \hline
\end{tabular}

Table 7: Difference in the proportion of apprentices in firms which close down compared to all firms

displacement are presented in Table 19 of Appendix C.

Thus, there is strong evidence for positive returns to tenure, which are higher for the unskilled. The way German firms operate seems to reward loyalty. For the unskilled this seems to an important source of wage growth. The implication for policy is that subsidised placements (from wage subsidy programs say) would have to be made with a view of securing long term employment in the firm taking up such workers, since a large part of human capital accumulation does not seem to be transferable.

\subsection{Robustness Checks}

As stated in the assumptions of the model the validity of the results rely on the displaced workers being a random sample of all workers, conditional on the observables. This is an identifying assumption and cannot be tested. However we provide some circumstantial evidence using observable indicators. In the first column of Table 7 we show the difference in the proportion of apprentices among the population, and the firms that close down. This shows that firms that close down have about 5 percentage points fewer apprentices (from an average of 78\%). In Table 8, under the "All Closures" columns, we consider the difference in experience (conditional on age) between workers who join firms which will close down in our sample and workers who join any firm. The differences are mostly insignificant and very small. The largest difference is 0.13 of a year (or 6.8 weeks), and it is barely significant.

Among firms which close down there will be a disproportionate number of younger firms. These may be likely to hire less experienced workers since they are more mobile. Thus we repeat the comparison by concentrating on workers in firms that started up before 1980 . The difference in the proportion of apprentices for firms that will close down and all other 


\begin{tabular}{clllll}
\hline \hline \multicolumn{2}{c}{ All Workers } & \multicolumn{2}{c}{ Skilled } & \multicolumn{2}{c}{ Unskilled } \\
\hline All Closures & Old Firms & All Closures & Old Firms & All Closures & Old Firms \\
\hline-0.04 & 0.09 & 0.009 & 0.11 & -0.13 & 0.05 \\
0.03 & 0.04 & 0.03 & 0.04 & 0.06 & 0.09 \\
\hline Asymptotic Standard errors in italics. & & & \\
\hline \hline
\end{tabular}

Table 8: Difference at the date of entry in the years of experience of workers who join firms which close down, compared to workers who join any firm

\begin{tabular}{l|cc|cc}
\hline \hline & \multicolumn{2}{|c}{ Skilled } & \multicolumn{2}{c}{ Unskilled } \\
\hline & Population & $\begin{array}{c}\text { Firms that } \\
\text { will close }\end{array}$ & Population & $\begin{array}{c}\text { Firms that } \\
\text { will close }\end{array}$ \\
\hline Experience & 0.0371 & 0.0502 & 0.050 & 0.0718 \\
& $0.000^{r}$ & 0.0062 & 0.001 & 0.0102 \\
Sector Tenure & 0.0116 & 0.0115 & 0.0164 & 0.0180 \\
& 0.0006 & 0.0044 & 0.0016 & 0.0134 \\
\hline \multicolumn{7}{l}{ Asymptotic standard errors in italics. } \\
\hline
\end{tabular}

Table 9: Relationship of experience and sector tenure to wages in the population of firms and the firms that will close down in two years or more

firms is reported in the "Old Firms" column in Table 7, and it now drops to zero. As far as differences in experience are concerned the picture remains the same and indicates that there are no important differences between the workers in firms that will close down and the population (see "Old Firms" columns in table 8).

Finally we carry out a further simple experiment to check whether there are likely to be systematic differences in the relationship between experience, sector tenure and wages in the firms that will close down. We run a regression of log wages on experience and sector tenure for individuals starting new jobs. We compare this to the results we obtain when we confine attention to firms that will close down in two years or more. We focus on sector tenure since this seems to decline substantially when we condition on displacement firms. The results are reported in Table 9.These show that there are no significant differences in the relationship between experience and sector tenure with wages, between firms that will close down and other firms.

Thus workers in firms that are observed to close down are very similar to the whole population of young workers in our data set. However there are potential sources of non randomness of the displaced workers that these comparisons may not pick up. We thus 
consider two robustness checks.

The definition of the closure sample

In our data we know whether a firm closes down, independently of when the worker left, since we have direct access to a data set reporting firm size over a 17 year period for any firm which employed any worker in our sample. Up to now we have defined the population of displaced workers due to firm closure as the set of workers who left the firm which closed down within one year of their departure. Using a narrow window to define a worker displaced due to closure makes it more likely that the worker is in fact displaced because of an imminent closure. On the other hand, if the closure was anticipated by the management or by the worker, we may end up with a selected sample of workers (both in terms of observables and unobservables). This selection may have opposing effects: Firms may lay off less productive workers first, or the best workers may leave the firm before the closure. Taking a wider window mitigates this problem, but increases the risk that workers are included who moved for reasons other than closure.

In Table 10 we present results for the returns to experience for the skilled and unskilled based on the broader definition of closure. This defines as displaced any worker who left a firm that closed down within two years of their departure. The number of displaced workers with this definition increases from 3639 to 4589 for the skilled and from 1373 to 1796 for the unskilled. The regressions include the residuals, and they are comparable to the last column of Tables 3 (unskilled workers) and 4 (skilled workers).

The estimated initial returns for the skilled and unskilled workers are lower now. However, the difference is insignificant with a p-value for this difference of $50 \%$ for the skilled and $58 \%$ for the unskilled. All other returns are very similar and overall the differences are completely insignificant.

In the first column of Table 11, we also report the results for firm tenure for this definition of firm closure. The returns to tenure for the first five years remain unchanged vis a vis our 


\begin{tabular}{l|cc}
\hline \hline \multicolumn{2}{c}{ Skilled } & Unskilled \\
\hline \hline Experience & & $\mathbf{0 . 0 7 3}$ \\
& - & 0.031 \\
One year & - & $\mathbf{0 . 0 7 4}$ \\
two years & $\mathbf{0 . 0 5 2}$ & 0.032 \\
& 0.017 & $\mathbf{0 . 0 3 5}$ \\
three years & $\mathbf{0 . 0 5 6}$ & 0.032 \\
& 0.014 & $\mathbf{0 . 0 3 9}$ \\
four years & $\mathbf{0 . 0 6 3}$ & 0.029 \\
& 0.016 & $\mathbf{- 0 . 0 0 4}$ \\
five years + & $\mathbf{0 . 0 1 0}$ & 0.010 \\
\multicolumn{3}{l}{ N.Obs. } \\
\hline Standard Deviation of the block bootstrap in italics.
\end{tabular}

Table 10: Wage growth - Experience, Broader definition of closure

preferred results in the last column of Table 6 . The tenure returns beyond five years do increase bu they are not well determined

Thus the results are not sensitive to the precise way of defining displaced workers, although if we estimate the model on all movers we get significantly different results, as shown in the previous sections.

Is there evidence of bias due to self-selection by firm closure probability?

One reason that the closure sample may be non-random is that workers may self-select into firms based on any information relating to their closure probability. This assumption is important: Workers with higher unobserved returns to tenure would avoid firms more likely to close down, since they suffer a larger loss from closure. This would lead to a downward bias in the estimated average returns to tenure in the estimates we presented.

Our data provides information that allows us to present some evidence about this: As we have seen, young firms are more likely to close down (see figure 3). If workers with high returns to tenure were trying to avoid firms with high closure probability they should avoid employment in younger firms (all else being equal). Thus, we re-estimate our model based on the firms that were in existence before 1980 and subsequently closed down in our 


\begin{tabular}{l|cc}
\hline \hline Tenure & $\begin{array}{c}\text { Broad Definition } \\
\text { of Closure }\end{array}$ & Older Firms \\
\hline Skilled, $<5$ Years & $\mathbf{0 . 0 2 6}$ & $\mathbf{0 . 0 1 5}$ \\
& 0.0038 & 0.005 \\
\hline Skilled, $\geq 5$ Years & $\mathbf{0 . 0 2 6}$ & $\mathbf{0 . 0 0 3 2}$ \\
& 0.010 & 0.016 \\
\hline & 0.040 & $\mathbf{0 . 0 2 7}$ \\
\hline \hline & 0.008 & 0.009 \\
\hline Unskilled $<5$ Years & $\mathbf{0 . 0 2 5}$ & $\mathbf{- 0 . 0 2 3}$ \\
& 0.017 & 0.024 \\
\hline Unskilled, $\geq 5$ Years & \multicolumn{2}{l}{} \\
\hline \multicolumn{2}{l}{ Standard Deviation of the block bootstrap in italics. } \\
\hline \hline
\end{tabular}

Table 11: Wage growth - Tenure, Unskilled and Skilled, Robustness Checks

sample period. This leads to a drop in the sample of displaced workers by about $40 \%$. If such self-selection was an important phenomenon we should expect the returns to tenure to increase when using this sample, if indeed the returns to tenure are heterogeneous.

The results on the returns to tenure using workers displaced from older firms are presented in the second column of Table 11. These estimates show that the returns to tenure do not increase when using the sample of workers who were displaced following the closure of an older firm; in fact they decrease. Hence from these results there is no indication that selfselection by probability of closure has led to an underestimate of the returns to tenure. This reinforces our view that the use of the displacement sample is a valid way to proceed. The returns to experience are also similar and we do not report them for the sake of brevity.

\section{Concluding Remarks}

In this paper we analyse wage growth for workers in Germany. We focus on two groups: Those with apprenticeship training (skilled workers), and those with no post-secondary school education or formal training (unskilled workers).

The framework for our analysis is a model with match specific effects as well as heterogeneous returns to experience, firm tenure and sector tenure. We discuss a way of identifying and estimating this model based on displaced workers. The sample we consider is unique, in 
that we observe an accurate calendar of all job transitions from the beginning of the workers' careers. This has led us to consider workers up to the age of 35. As earlier studies have shown, this is the period of the most rapid wage growth.

Wages of the skilled workers grow with experience and the profile is concave, with growth starting at $7 \%$ early on, and falling to $1.2 \%$ a year beyond four years. The returns to staying in the same sector are about $1 \%$ a year but they decline after five years, while the returns to staying in the same firm are about $2.5 \%$ a year again declining after five years.

Wages of the unskilled workers only grow for the first two to three years of labour market experience. Experience related growth falls to zero following that. Their return to sector tenure are close to zero and statistically insignificant. However, unskilled workers seem to benefit from returns to firm tenure which are about $4 \%$ a year for the first five years but decline to an insignificant $1.1 \%$ thereafter. Thus, while the aquisition of transferable skills seem to be important for the wage growth of skilled workers early on in their career, unskilled workers benefit primarily from being attached to a particular firm. An important implication of this is for the success of temporary interventions in the labour market. Programmes that seek to improve employability of the unskilled via general work experience are likely to be less successful than programmes that attempt to match a worker with a firm, possibly by an initial period of a job subsidy, at least in Germany.

\section{Appendix A: The selection process into new jobs}

To see what the selection issue is and how exogenous displacements can help identify the returns to experience, we set up a mobility model for individuals. For the purpose of notational simplicity, we ignore here sector tenure, and we only consider one education level; we therefore drop the index $a$. Thus assume that individuals are risk neutral and denote by $u_{i f t}$ the set of unobservables $m_{i f t}, v_{i f t}$ and $\eta_{i t}$, where $i$ denotes individuals, $f$ the firm or job, and $t$ the time period. The value of a job is denoted by $V_{t}^{J}\left(T_{i t}^{G}, T_{i f t}^{F}, r_{t} \mid u_{i f t}\right)$. At the start tenure is zero $\left(T_{i f t}^{F}=0\right)$. We assume that a working individual receives an alternative offer from a firm $f^{\prime}$. The value of unemployment $V_{t}^{U}\left(T_{i t}^{G}, w_{i l}, d_{i t} \mid \eta_{i t}\right)$ depends on benefits $B_{i t}$, which in general will depend on the previous wage $\left(w_{i l}\right)$ and on unemployment duration $\left(d_{i t}\right)$. Hence 
$B_{i t}=B_{i t}\left(w_{i l}, d_{i t}\right)$. At the start of the unemployment spell duration will be zero.

Denote the value of the current job by

$$
\begin{gathered}
V_{t}^{J}\left(T_{i t}^{G}, T_{i t}^{f}, r_{t} \mid u_{i f t}\right)=w_{i f t}+ \\
\delta E_{t} \max \left[V_{t+1}^{J}\left(T_{i t}^{G}+1, T_{i f t}^{F}+1, r_{t+1} \mid u_{i f t+1}\right), V_{t+1}^{J}\left(T_{i t}^{G}+1,0, r_{t+1} \mid u_{i f^{\prime} t+1}\right),\right. \\
\left.V_{t+1}^{U}\left(T_{i t}^{G}+1, w_{i l}, 0, r_{t+1} \mid \eta_{i t}\right)\right] .
\end{gathered}
$$

The value of unemployment is

$$
\begin{gathered}
V_{t}^{U}\left(T_{i t}^{G}, w_{i l}, d_{i t}, r_{t} \mid \eta_{i t}\right)=B_{i t}+ \\
\delta E_{t} \max \left[V_{t+1}^{J}\left(T_{i t}^{G}, 0, r_{t+1} \mid u_{i f^{\prime \prime} t+1}\right), V_{t+1}^{U}\left(T_{i t}^{G}, w_{i l}, d_{i t}+1, r_{t+1} \mid \eta_{i t}\right)\right]
\end{gathered}
$$

Expectations are taken over future realisations of $u_{i f t}$ and $u_{i f^{\prime} t}$ conditional on the current value of $u_{i f t}$ and the other state variables (where $f$ and $f^{\prime}$ represent alternative firms).

Now consider the set of individuals observed starting a new job. They consist of two groups: First, those moving from an old job $f$ to a new one $f^{\prime}$. Second, those who quit (or were layed off) in period $s<t$ and have now received an acceptable job offer. The former satisfy the condition $V_{t}^{J}\left(T_{i t}^{G}, 0, r_{t} \mid u_{i f^{\prime} t}\right)>\max \left\{V_{t}^{J}\left(T_{i t}^{G}, T_{i f t}^{F}, r_{t} \mid u_{i f t}\right), V_{t}^{U}\left(T_{i t}^{G}, w_{i t}, 0, r_{t} \mid \eta_{i t}\right)\right\}$ denoted for short by $N J>0$. The latter satisfy two conditions: $V_{s}^{U}\left(T_{i s}^{G}, w_{i s}, 0, r_{s} \mid \eta_{i t}\right)>$ $\max \left\{V_{s}^{J}\left(T_{i s}^{G}, T_{i f s}^{F}, r_{s} \mid u_{i f s}\right), V_{s}^{J}\left(T_{i s}^{G}, 0, r_{s} \mid u_{i f^{\prime} s}\right)\right\}$ denoted by $U_{s}>0$ and $V_{t}^{J}\left(T_{i s}^{G}, 0, r_{t} \mid u_{i f t}\right)>$ $V_{t}^{U}\left(T_{i s}^{G}, w_{i s}, t-s, r_{t} \mid \eta_{i t}\right)$ denoted by $N J^{U}>0$. The latter group preferred unemployment to their previous job and an alternative job offer; at duration $t-s$ they obtained a job more acceptable than unemployment valued at duration $t-s$.

Now consider the expected value of wages $\left(\ln w_{i f}\right)$ for individuals who start a new job in firm $f$, for a given level of experience $\left(T_{i t}^{G}\right)$ and for given value of the observable characteristics $z_{i t}$.

$$
\begin{aligned}
& E\left(\ln w_{i f t} \mid T_{i t}^{G}, N J_{t}>0 \text { or }\left[U_{s}>0 \text { and } N J_{t}^{U}>0\right], t, z_{i t}\right)= \\
& \ln r_{t}+\left[\alpha+E\left(\eta_{i t} \mid T_{i t}^{G}, N J_{t}>0 \text { or }\left[U_{s}>0 \text { and } N J_{t}^{U}>0\right], t, z_{i t}\right)\right] T_{i t}^{G} \\
& +E\left(m_{i f t} \mid T_{i t}^{G}, N J_{t}>0 \text { or }\left[U_{s}>0 \text { and } N J_{t}^{U}>0\right], t, z_{i t}\right)
\end{aligned}
$$

The expression $\alpha+E\left(\eta_{i t} \mid T_{i t}^{G},\left[N J_{t}>0\right.\right.$, or $\left[U_{s}>0\right.$ and $\left.\left.N J_{t}^{U}>0\right] t, z_{i t}\right)$ is the average return to experience in the population of those starting a new job, while $E\left(m_{i f t} \mid T_{i t}^{G}, N J_{t}>0\right.$ or $\left[U_{s}>0\right.$ and $\left.\left.N J_{t}^{U}>0\right], t, z_{i t}\right)$ is the average match quality of these persons. The average 
return to experience which we want to estimate is $\alpha$. However modelling the dependence of $\eta_{i t}$ and $m_{i f t}$ for new job starts is complicated by the fact that these individuals are selected by multiple ways; consequently this selection cannot be expressed by a single index as in the Heckman (1974) selection model. Now consider workers who are displaced for a completely exogenous reason. For them the selection $N J_{t}>0$ and $U_{s}>0$ are irrelevant. Consequently

the selection terms become $\left[\alpha+E\left(\eta_{i t} \mid T_{i t}^{G}, N J_{t}^{U}>0, t, z_{i t}\right)\right]$ and $E\left(m_{i f t} \mid T_{i t}^{G}, N J_{t}^{U}>0, t, z_{i t}\right)$. The dependence of the conditional expectations on $N J_{t}^{U}>0$ reflects the job acceptance strategy of the unemployed and can be modelled as the standard selection into work, approximated by a single index, as in Heckman (1974). The conditioning on experience $\left(T_{i t}^{G}\right)$ reflects the fact that the unobservables may be serially correlated, and hence may affect past employment decisions and thus experience

\section{Appendix B: The Institutional Background in Germany}

\section{Wage Setting}

Unlike the US, there is no general, government imposed minimum wage in Germany. Instead, there is an elaborate system of tariff contracts, which specify minimum wages according to occupation, sector, region, and some personal characteristics. These minimum wages are determined by (annual) wage bargaining between unions and employer federations (or single employers).

Bargaining takes place on industry and regional level. Although in principle tariff agreements between an employer (or an employer association) and a union cover only employees who are union members, in practise the union status of the employee is irrelevant. The tariff contracts act as sector specific minimum wages for those firms that are members of employer associations, or that negotiate directly with the union. Not all firms are bound to the tariff agreements, however. Firms which are not in the employer's association do not have to pay tariff wages. In 1995, about 83 percent of all workers were employed in firms that were bound by tariff agreements (see Dustmann and Schoenberg 2002 for details).

\section{Job Security}

The German dismissal regulations concern protection from dismissal, advanced notice, 
as well as severance pay requirements.

The general dismissal protection regulations foresee that all dismissals of employees who are employed for more than 6 months without interruption, and which are initiated by the employer, are invalid if they are socially unacceptable. Dismissals must therefore be justified by the employer. Acceptable reasons for dismissal include rationalisation, macroeconomic shocks, absenteeism, illness etc.

The advanced notice period in Germany varies according to seniority and, before 1993, blue or a white collar status of the worker. Furthermore, there may be particular industry regulations as well as firm-worker specific agreements. In general, the advanced notice regulations foresee 4 weeks of advanced notice for blue collar workers who have been employed for at least 5 years, and 12 weeks for white collar workers. After 20 years of employment with the same firm, these periods rise to 12 weeks and 24 weeks for blue and white collar workers respectively (see Buttler et al., 1992).

\section{The Education and Apprenticeship System}

The German Apprenticeship System (GAS) is a vocational training programme which combines on the job training, provided by the firm, with school education, provided by the state.

The roots of the apprenticeship system can be traced back to the middle ages, when the craft guilds regulated journeymanship type training schemes, and issued training certificates. Today, more than 60 percent of each cohort in Germany goes through the apprenticeship system (see Soskice, 1994). In 1990, there were about 370 recognised apprenticeship occupations. These occupations include both blue and white collar professions, and cover many professions which require college attendance in the UK and the US (as, for instance, accountant etc.).

Apprenticeship training schemes last between 2 and 3.5 years. During this time, apprentices attend on average 1 - 2 days a week a vocational state school, where they acquire general knowledge, as well as knowledge which is specific to their occupation. For the remaining days, they are on on-the-job training schemes within the firm. Qualified personnel is responsible for the apprentice, and allocates apprentices to particular tasks. Larger firms 


\begin{tabular}{l|ccc}
\hline \hline \multicolumn{4}{c}{ Sector Allocation } \\
\hline & All & Skilled & Unskilled \\
\hline Agriculture & 1.80 & 1.72 & 2.10 \\
Energy, mining, water industry & 2.62 & 2.45 & 3.21 \\
Chemical industry & 7.21 & 6.93 & 8.23 \\
Metal industry, machines & 13.83 & 14.09 & 12.88 \\
Electro technical industry, automobiles & 13.38 & 14.19 & 10.37 \\
Optical industry, fine mechanics & 3.81 & 3.51 & 4.91 \\
Wood, printing, paper & 6.08 & 5.97 & 6.50 \\
Leather, textiles, food & 5.36 & 5.23 & 5.83 \\
Construction, carpentry & 12.65 & 12.53 & 13.07 \\
Trade & 12.35 & 12.92 & 10.26 \\
Traffic, news & 5.36 & 5.22 & 5.88 \\
Credit and insurance & 2.72 & 3.23 & 0.86 \\
Services & 7.82 & 7.04 & 10.71 \\
Charities & 1.79 & 1.76 & 1.94 \\
Public services & 3.22 & 3.21 & 3.23 \\
\hline Total & 100.00 & 100.00 & 100.00 \\
\hline \hline
\end{tabular}

Table 12: Percentage working in each sector in our estimation data set

\begin{tabular}{lcccc}
\hline \hline & \multicolumn{2}{c}{ Unskilled } & \multicolumn{2}{c}{ Skilled } \\
\hline & Coef & t rat & Coef & t rat \\
\hline Number of Job: 2 & 0.0277 & 6.574 & -0.0188 & -11.473 \\
Number of Job: 3 & 0.0014 & 0.290 & -0.0437 & -21.367 \\
Number of Job: 4 & -0.0419 & -7.016 & -0.0795 & -30.620 \\
Number of Job: 5 & -0.0730 & -10.310 & -0.1003 & -29.140 \\
Number of Job: 6 & -0.1067 & -12.714 & -0.1206 & -26.722 \\
Number of Job: 7 & -0.1371 & -13.526 & -0.1624 & -26.940 \\
Number of Job: 8 & -0.1841 & -15.277 & -0.2325 & -29.601 \\
\hline All regressions include age and time dummies \\
\hline \hline
\end{tabular}

Table 13: Log Wages and Job Number, Germany IAB

run also specific classes or seminars for apprentices.

\section{Appendix C: Sector employment allocation, Job mobility, wages and wage growth}

The following are regressions of log wages on job number, age dummies, and time dummies for Germany and the US. Table 13 does not include fixed effects; table 14 does include fixed effects. 


\begin{tabular}{lcccc}
\hline \hline & \multicolumn{2}{c}{ Unskilled } & \multicolumn{2}{c}{ Skilled } \\
\hline & Coeff & t ratio & Coeff & t ratio \\
\hline Number of Job: 2 & 0.1292 & 29.473 & 0.0611 & 37.386 \\
Number of Job: 3 & 0.1542 & 28.327 & 0.0821 & 38.689 \\
Number of Job: 4 & 0.1580 & 24.219 & 0.0817 & 30.597 \\
Number of Job: 5 & 0.1434 & 18.965 & 0.0861 & 25.834 \\
Number of Job: 6 & 0.1297 & 14.835 & 0.0843 & 20.327 \\
Number of Job: 7 & 0.1220 & 12.025 & 0.0646 & 12.443 \\
Number of Job: 8 & 0.1017 & 8.727 & 0.0228 & 3.531 \\
\hline All regressions include age and time dummies \\
\hline \hline
\end{tabular}

Table 14: Log Wages and Job Number, Germany IAB, Fixed Effects

Appendix D: The reduced form results and the coefficients of the residuals. 


\begin{tabular}{|c|c|c|c|c|}
\hline & \multicolumn{2}{|c|}{ Experience } & \multicolumn{2}{|c|}{ Tenure } \\
\hline & Coeff & StdE & Coeff & StdE \\
\hline$v^{P}$ & -0.022 & 0.0370 & -0.036 & 0.0032 \\
\hline$v^{P} \times c$ & 0.0179 & 0.0066 & 0.0198 & 0.006 \\
\hline$v^{P} \times T^{G}$ & -0.0012 & 0.012 & -0.014 & 0.0081 \\
\hline$v^{P} \times T^{G} \times c$ & -0.0010 & 0.0011 & -0.00002 & 0.0008 \\
\hline$v^{P} \times T^{S}$ & -0.0116 & 0.0087 & -0.0021 & 0.0075 \\
\hline$v^{P} \times T^{S} \times c$ & 0.0010 & 0.0009 & -0.0004 & 0.0008 \\
\hline$v^{P} \times T^{F}$ & & & -0.013 & 0.018 \\
\hline$v^{P} \times T^{F} \times c$ & & & 0.00022 & 0.0016 \\
\hline$v^{G}$ & -0.0315 & 0.0162 & -0.035 & 0.0152 \\
\hline$v^{G} \times c$ & 0.0024 & 0.0017 & 0.0059 & 0.0020 \\
\hline$v^{G} \times T^{G}$ & 0.0090 & 0.0038 & 0.0057 & 0.0035 \\
\hline$v^{G} \times T^{G} \times c$ & -0.0004 & 0.0003 & -0.0004 & 0.0003 \\
\hline$v^{G} \times T^{S}$ & 0.0028 & 0.0037 & 0.0021 & 0.034 \\
\hline$v^{G} \times T^{S} \times c$ & -0.0003 & 0.0003 & -0.0002 & 0.0003 \\
\hline$v^{G} \times T^{F}$ & & & 0.0054 & 0.0076 \\
\hline$v^{G} \times T^{F} \times c$ & & & -0.0010 & 0.0006 \\
\hline$v^{T}$ & & & 0.0070 & 0.0055 \\
\hline$v^{T} \times c$ & & & -0.0052 & 0.0021 \\
\hline$v^{T} \times T^{G}$ & & & 0.0001 & 0.0026 \\
\hline$v^{T} \times T^{G} \times c$ & & & 0.0005 & 0.0002 \\
\hline$v^{T} \times T^{S}$ & & & 0.0024 & 0.0013 \\
\hline$v^{T} \times T^{S} \times c$ & & & -0.00014 & 0.00013 \\
\hline$v^{T} \times T^{F}$ & & & -0.011 & 0.0035 \\
\hline$v^{T} \times T^{F} \times c$ & & & 0.00082 & 0.00027 \\
\hline \multirow{2}{*}{\multicolumn{5}{|c|}{$\begin{array}{lcc}\text { p-value for joint Sign. } & 0 \% & 0 \% \\
\text { Bootstrap standard errors and critical values. } & 200 \text { replications }\end{array}$}} \\
\hline & & & & \\
\hline Notation & \multicolumn{2}{|c|}{ Equation 6} & \multicolumn{2}{|c|}{ Equations 9-12 } \\
\hline
\end{tabular}

Table 15: Impact of residuals on the wage equation with selection correction - displaced sample.

\begin{tabular}{lcc}
\hline \hline & $\begin{array}{c}\text { Cell Size in Post Displacement Records } \\
\text { Experience }\end{array}$ & Unskilled \\
\hline 0 & Skilled & 339 \\
1 & - & 216 \\
2 & 448 & 185 \\
3 & 931 & 148 \\
4 & 611 & 128 \\
5 & 397 & 75 \\
6 & 334 & 67 \\
7 & 253 & 49 \\
$8+$ & 663 & 122 \\
\hline For skilled workers experience includes time spent in apprenticeship. We \\
observe skilled workers once apprenticeship is over. The level of experience \\
at which we first observe them depends on the length of apprenticeship. \\
\hline \hline
\end{tabular}

Table 16: Cell Sizes by experience for the displaced sample 


\begin{tabular}{|c|c|c|c|c|c|c|}
\hline & \multicolumn{2}{|c|}{ Participation } & \multicolumn{2}{|c|}{ Experience } & \multicolumn{2}{|c|}{ Tenure } \\
\hline & Coef & $\overline{\text { StdE }}$ & Coef & $\overline{\text { StdE }}$ & Coef & StdE \\
\hline age & 0.0425 & 0.0060 & 0.217 & 0.077 & 0.388 & 0.079 \\
\hline$c_{i t}$ & 0.678 & 0.0247 & 0.5635 & 0.0604 & 0.439 & 0.064 \\
\hline$c_{i t} \times a g e$ & -0.019 & 0.0007 & -0.0071 & 0.0039 & -0.018 & 0.004 \\
\hline Lower Secondary & 0.1550 & 0.0143 & 0.5357 & 0.1220 & 0.38 & 0.094 \\
\hline School unknown & 0.0172 & 0.0165 & -0.1899 & 0.1382 & -0.63 & 0.108 \\
\hline age 18 & 0.0124 & 0.0126 & -0.3428 & 0.1030 & -0.568 & 0.105 \\
\hline age 19 & -0.0072 & 0.0171 & -0.6038 & 0.1805 & -0.972 & 0.184 \\
\hline age 20 & 0.1082 & 0.0239 & -1.05 & 0.2593 & -1.50 & 0.263 \\
\hline age 21 & 0.0673 & 0.030 & -1.291 & 0.3391 & -1.78 & 0.344 \\
\hline age 22 & 0.1192 & 0.0373 & -1.890 & 0.4154 & -2.20 & 0.426 \\
\hline age 23 & 0.1273 & 0.0433 & -2.329 & 0.493 & -2.61 & 0.510 \\
\hline age 24 & 0.099 & 0.0497 & -2.851 & 0.5723 & -2.98 & 0.592 \\
\hline age 25 & 0.1363 & 0.0565 & -3.430 & 0.6528 & -3.46 & 0.684 \\
\hline age 26 & 0.1002 & 0.0625 & -4.026 & 0.7337 & -3.66 & 0.77 \\
\hline age 27 & 0.1254 & 0.0700 & -4.499 & 0.8156 & -3.96 & 0.873 \\
\hline age 28 & 0.0523 & 0.0772 & -4.968 & 0.9008 & -4.18 & 0.982 \\
\hline age 29 & 0.028 & 0.0852 & -5.278 & 0.9920 & -4.21 & 1.06 \\
\hline age 30 & 0.0013 & 0.092 & -4.675 & 1.065 & -3.25 & 1.1 \\
\hline age 31 & 0.0007 & 0.1040 & -3.947 & 1.146 & -2.1 & 1.12 \\
\hline age 32 & 0.1835 & 0.1124 & -1.65 & 1.225 & 0.651 & 1.38 \\
\hline age 33 & 0.0455 & 0.143 & -0.6215 & 1.250 & 0.828 & 1.55 \\
\hline age 34 & -0.2497 & 0.1669 & -0.2204 & 1.08 & 0.409 & 1.54 \\
\hline$c_{i t} \times$ age 18 & -0.1358 & 0.0127 & 0.1785 & 0.0223 & 0.209 & 0.024 \\
\hline$c_{i t} \times$ age 19 & -0.1761 & 0.0116 & 0.2525 & 0.0255 & 0.241 & 0.028 \\
\hline$c_{i t} \times$ age 20 & -0.242 & 0.0116 & 0.3666 & 0.0297 & 0.31 & 0.031 \\
\hline$c_{i t} \times$ age 21 & -0.2312 & 0.0108 & 0.3541 & 0.0336 & 0.289 & 0.035 \\
\hline$c_{i t} \times$ age 22 & -0.2289 & 0.0101 & 0.4274 & 0.0363 & 0.311 & 0.039 \\
\hline$c_{i t} \times$ age 23 & -0.2142 & 0.0096 & 0.459 & 0.0400 & 0.334 & 0.044 \\
\hline$c_{i t} \times$ age 24 & -0.1950 & 0.0091 & 0.5014 & 0.0435 & 0.356 & 0.047 \\
\hline$c_{i t} \times$ age 25 & -0.1850 & 0.0086 & 0.5446 & 0.0475 & 0.399 & 0.053 \\
\hline$c_{i t} \times$ age 26 & -0.163 & 0.0083 & 0.5740 & 0.0516 & 0.396 & 0.058 \\
\hline$c_{i t} \times$ age 27 & -0.1488 & 0.008 & 0.5885 & 0.0560 & 0.411 & 0.063 \\
\hline$c_{i t} \times$ age 28 & -0.1242 & 0.0077 & 0.6074 & 0.0605 & 0.413 & 0.069 \\
\hline$c_{i t} \times$ age 29 & -0.1060 & 0.0076 & 0.6091 & 0.0649 & 0.40 & 0.072 \\
\hline$c_{i t} \times$ age 30 & -0.0866 & 0.0076 & 0.5282 & 0.0680 & 0.306 & 0.077 \\
\hline$c_{i t} \times$ age 31 & -0.0706 & 0.0078 & 0.432 & 0.0715 & 0.202 & 0.07 \\
\hline$c_{i t} \times$ age 32 & -0.0657 & 0.0078 & 0.2288 & 0.0763 & -0.015 & 0.087 \\
\hline$c_{i t} \times$ age 33 & -0.039 & 0.0095 & 0.1208 & 0.0766 & -0.035 & 0.092 \\
\hline$c_{i t} \times$ age 34 & -0.0020 & 0.0104 & 0.0375 & 0.0647 & -0.020 & 0.093 \\
\hline Observations & \multicolumn{2}{|c|}{47998} & \multicolumn{2}{|c|}{47998} & \multicolumn{2}{|c|}{55882} \\
\hline R-squared & \multicolumn{2}{|c|}{0.16} & \multicolumn{2}{|c|}{0.77} & \multicolumn{2}{|c|}{0.28} \\
\hline P-Value for age dummies & \multicolumn{2}{|c|}{0.00} & \multicolumn{2}{|c|}{0.00} & \multicolumn{2}{|c|}{0.00} \\
\hline P-Value for age $\times c_{i t}$ & \multicolumn{2}{|c|}{0.0} & \multicolumn{2}{|c|}{0.0} & \multicolumn{2}{|c|}{0.0} \\
\hline \multicolumn{7}{|c|}{$\begin{array}{l}\text { Standard Errors in italics, allowing for heteroskedasticity and serial correlation. } \\
\text { Default education group: Higher Secondary. Youngest age is } 16 \text {. All regressions include } \\
\text { time dummies. Experience and tenure are measured in years including fractions of a year; } \\
\text { Participation .is measured in fractions of a year worked. The number of observations } \\
\text { include non-work spells.in the case of experience and tenure. For tenure there may be } \\
\text { multiple records per year. }\end{array}$} \\
\hline
\end{tabular}

Table 17: Reduced forms, unskilled workers 


\begin{tabular}{|c|c|c|c|c|c|c|}
\hline & \multicolumn{2}{|c|}{ Participation } & \multicolumn{2}{|c|}{ Experience } & \multicolumn{2}{|c|}{ Tenure } \\
\hline & Coef & $\overline{\text { StdE }}$ & Coef & 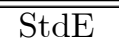 & Coef & $\overline{\mathrm{StdE}}$ \\
\hline age & 0.0173 & 0.0039 & 0.433 & 0.0593 & 0.314 & 0.077 \\
\hline$c_{i t}$ & -0.0102 & 0.0507 & 1.55 & 0.0963 & -0.409 & 0.2064 \\
\hline$c_{i t} \times a g e$ & -0.0000 & 0.0014 & -0.036 & 0.0043 & 0.007 & 0.0072 \\
\hline Lower Secondary & 0.012 & 0.0052 & 0.355 & 0.0592 & 0.44 & 0.087 \\
\hline School unknown & -0.1069 & 0.0073 & -0.095 & 0.0698 & -1.2 & 0.097 \\
\hline age 20 & -0.1272 & 0.0251 & -0.428 & 0.0655 & -0.569 & 0.1230 \\
\hline age 21 & -0.1767 & 0.0246 & -0.846 & 0.1223 & -0.896 & 0.1802 \\
\hline age 22 & -0.2004 & 0.0246 & -1.32 & 0.1808 & -1.33 & 0.2487 \\
\hline age 23 & -0.1777 & 0.0257 & -1.82 & 0.2397 & -1.74 & 0.3218 \\
\hline age 24 & -0.1255 & 0.0273 & -2.29 & 0.2988 & -2.07 & 0.3976 \\
\hline age 25 & -0.1021 & 0.0296 & -2.72 & 0.3580 & -2.29 & 0.4752 \\
\hline age 26 & -0.1152 & 0.0320 & -3.17 & 0.4165 & -2.56 & 0.5528 \\
\hline age 27 & -0.1053 & 0.0349 & -3.61 & 0.4756 & -2.81 & 0.6325 \\
\hline age 28 & -0.095 & 0.0380 & -4.07 & 0.5341 & -3.19 & 0.7129 \\
\hline age 29 & -0.0981 & 0.0419 & -4.43 & 0.5945 & -2.98 & 0.7931 \\
\hline age 30 & -0.0680 & 0.0455 & -4.70 & 0.6517 & -1.82 & 0.8746 \\
\hline age 31 & -0.0783 & 0.0494 & -4.96 & 0.7068 & -1.21 & 0.9477 \\
\hline age 32 & -0.0747 & 0.0521 & -5.16 & 0.7615 & -0.815 & 1.02 \\
\hline age 33 & -0.1559 & 0.0633 & -4.70 & 0.798 & -0.948 & 1.038 \\
\hline age 34 & -0.1476 & 0.067 & -3.13 & 0.7177 & -1.17 & 0.947 \\
\hline$c_{i t} \times$ age 20 & 0.0420 & 0.0220 & -0.007 & 0.02 & 0.40 & 0.0802 \\
\hline$c_{i t} \times a g e 21$ & 0.0404 & 0.0206 & -0.034 & 0.0246 & 0.43 & 0.0755 \\
\hline$c_{i t} \times a g e 22$ & 0.0518 & 0.0190 & -0.015 & 0.0247 & 0.473 & 0.0710 \\
\hline$c_{i t} \times \operatorname{age} 23$ & 0.0428 & 0.0176 & 0.040 & 0.0255 & 0.511 & 0.0673 \\
\hline$c_{i t} \times a g e 24$ & 0.0263 & 0.016 & 0.087 & 0.0269 & 0.525 & 0.0644 \\
\hline$c_{i t} \times a g e 25$ & 0.0197 & 0.0147 & 0.128 & 0.0290 & 0.515 & 0.0625 \\
\hline$c_{i t} \times a g e 26$ & 0.0203 & 0.0133 & 0.172 & 0.0314 & 0.51 & 0.0610 \\
\hline$c_{i t} \times a g e 27$ & 0.0177 & 0.0119 & 0.220 & 0.0343 & 0.519 & 0.0607 \\
\hline$c_{i t} \times \operatorname{age} 28$ & 0.0150 & 0.0106 & 0.266 & 0.0373 & 0.529 & 0.0612 \\
\hline$c_{i t} \times a g e 29$ & 0.0140 & 0.0093 & 0.299 & 0.0409 & 0.468 & 0.0628 \\
\hline$c_{i t} \times a g e 30$ & 0.0101 & 0.0080 & 0.322 & 0.0443 & 0.308 & 0.065 \\
\hline$c_{i t} \times a g e 31$ & 0.0095 & 0.0068 & 0.345 & 0.0476 & 0.207 & 0.0670 \\
\hline$c_{i t} \times$ age 32 & 0.0086 & 0.0057 & 0.369 & 0.0509 & 0.154 & 0.0707 \\
\hline$c_{i t} \times a g e 33$ & 0.0136 & 0.0053 & 0.333 & 0.0531 & 0.14 & 0.0699 \\
\hline$c_{i t} \times$ age 34 & 0.0116 & 0.004 & 0.219 & 0.0476 & 0.122 & 0.0626 \\
\hline Observations & \multicolumn{2}{|c|}{181206} & \multicolumn{2}{|c|}{181206} & \multicolumn{2}{|c|}{204503} \\
\hline R-squared & \multicolumn{2}{|c|}{0.067} & \multicolumn{2}{|c|}{0.83} & \multicolumn{2}{|c|}{0.14} \\
\hline P-Value for as & \multicolumn{2}{|c|}{0.0} & \multicolumn{2}{|c|}{0.0} & \multicolumn{2}{|c|}{0.0} \\
\hline P-Value for age $\times c_{i t}$ & \multicolumn{2}{|c|}{0.0} & & 0 & \multicolumn{2}{|c|}{0.0} \\
\hline Youngest age is $17 . \mathrm{O}$ & & & & & & \\
\hline
\end{tabular}

Table 18: Reduced forms, skilled workers 


\begin{tabular}{|c|c|c|c|c|c|c|c|}
\hline & \multicolumn{2}{|c|}{ Experience } & & \multicolumn{2}{|c|}{ Sector Tenure } & \multicolumn{2}{|c|}{ Tenure } \\
\hline & Skilled & Unskilled & & Skilled & Unskilled & Skilled & Unskilled \\
\hline \multirow[t]{2}{*}{ One Year } & & 0.102 & $\leq 5$ Years & 0.0097 & -0.015 & 0.032 & 0.068 \\
\hline & & 0.034 & & 0.0079 & 0.019 & 0.011 & 0.017 \\
\hline \multirow[t]{2}{*}{ two Year } & 0.083 & 0.084 & $>5$ Years & 0.007 & -0.063 & 0.032 & 0.11 \\
\hline & 0.021 & 0.038 & & 0.032 & 0.079 & 0.023 & 0.047 \\
\hline \multirow[t]{2}{*}{ three Years } & 0.083 & 0.033 & tenure $^{2}$ & -0.00002 & 0.0048 & -0.0020 & -0.0080 \\
\hline & 0.018 & 0.042 & & 0.0019 & 0.0046 & 0.0025 & 0.0036 \\
\hline \multirow[t]{2}{*}{ four Years } & 0.076 & 0.040 & & & & & \\
\hline & 0.020 & 0.050 & & & & & \\
\hline \multirow[t]{2}{*}{ five Years +} & 0.058 & -0.007 & & & & & \\
\hline & 0.028 & 0.057 & & & & & \\
\hline \multirow[t]{2}{*}{ experience $^{2}$} & -0.0029 & -0.0004 & & & & & \\
\hline & 0.0017 & 0.0035 & & & & & \\
\hline p-value* & \multicolumn{2}{|c|}{0.26} & & \multicolumn{2}{|c|}{0.51} & \multicolumn{2}{|c|}{0.085} \\
\hline \multicolumn{8}{|c|}{$\begin{array}{l}\text { Standard deviation of the block bootstrap in italics. }{ }^{*} \text { p-value corresponds to the two degree of freedom } \\
\text { test for excluding the quadratic terms in each part of the model. p-value of joint } 6 \text { degrees of freedom } \\
\text { test for excluding all quadratic terms is } 0.18 \text {. Experience, tenure and sector tenure measured in years. }\end{array}$} \\
\hline
\end{tabular}

Table 19: Results including a quadratic term - Control function Estimator - post displacement 


\section{References}

[1] Altonji J.G. and N. Williams (1996) "The Effects of Labor Market Experience, Job Seniority and Job Mobility on Wage growth", mimeo.

[2] Altonji J.G. and N. Williams (1997) "Do wages rise with seniority? A Reassessment", mimeo

[3] Altonji, J.G. and Shakotko, R.A. (1987) "Do Wages rise with Seniority?", Review of Economic Studies, 54, 437-459.

[4] Becker, G. (1993) "Human Capital", NBER, The Chicago University Press

[5] Bender, S., J. Hilzendegen, G. Rohwer and H. Rudolph (1996): "Die IAB Beshaeftigungsstichprobe 1975-1990", Beitraege zur Arbeitsmarkt- und Berufsforschung, BeitrAB 197, Nurnberg.

[6] Bender, S. C. Dustamnn, D. Margolis and C. Meghir (2002) "Worker Displacement in France and Germany, in Loosing work, Moving on", Peter J. Kuhn ed. Upjohn Institute, Michigan, pp 375-452.

[7] Ben-Porath, Y. (1967) "The Production of Human Capital and the Life Cycle of Earnings", Journal of Political Economy, 75, 352-365.

[8] Bjorklund, A. and R. Moffitt (1987) "The Estimation of Wage Gains and Welfare Gains in Self-selection", Review of Economics and Statistics, 69, $42-49$.

[9] Blinder, A. and Y. Weiss (1976) "Human Capital and Labor Supply: A Synthesis", Journal of Political Economy, Vol 84.3 pp. 449-472.

[10] Burda, M. and A. Mertens (2001) Wages and Worker Displacement in Germany Labour Economics 8, pp 15-41

[11] Buttler, F., W. Brandes, E. Dorndorf, W. Gaum, and U. Walwei (1992), "Flexibility and Job Security in the Federal Republik of Germany", Technical Report 1, SAM, working paper.

[12] Card, David (2001) "Estimating the Returns to Schooling: Progress on some Persistent Econometric Problems", Econometrica 69 pp 1127-60.

[13] Datta, S. (1995) "Building Trust", LSE, mimeo

[14] Dustmann, C. and U. Schoenberg (2002) "Training and Unions", UCL, mimeo

[15] Eckstein Zvi, and Kenneth Wolpin (1989) Dynamic Labour Force Participation of Married Women and Endogenous Work Experience, Review of Economic Studies Vol. 56.3

[16] Farber, H. S. (1994) "The Analysis of Interfirm Worker Mobility", Journal of Labor Economics, 12, 554-593 
[17] Farber H. S.(1983) "The Determination of the Union Status of Workers" Econometrica, Vol. 51, No. 5. pp. 1417-1438.

[18] Fitzenberger, Berndt and Claudia, Kurz (2002) New Insights on Earnings Trends Across Skill Groups and Industries in West Germany, Empirical Economics

[19] Florens, J.P., J. J. Heckman, C. Meghir and E. Vytlacil (2002) "Instrumental Variables, Local Instrumental Variables and Control Functions", mimeo UCL/IFS.

[20] Garen, John (1984) "The Returns to Schooling: A Selectivity Bias Approach with Continuous Choice Variables", Econometrica 52 pp 1199-1218.

[21] Gibbons, R. and L. Katz (1992) "Does unmeasured ability explain interindustry wage differentials?", Review of Economic Studies, 59, 515-535.

[22] Hall, Peter and Joel Horowitz (1996) Bootstrap Critical Values for Tests Based on Generalized-Method-of-Moments Estimators, Econometrica, Vol. 64, No. 4. July, pp. 891-916

[23] Harris, C. and L. Felli (1996) "Learning, Wage Dynamics, and Firm Specific Human Capital", Journal of Political Economy, 104, 838-868.

[24] Hashimoto, M. (1981) "Firm Specific Human Capital as a Shared investment", American Economic Review, Vol 71.3 pp 475-82

[25] Heckman, J.J. (1974) "Shadow Prices, Market Wages, and Labor Supply", Econometrica 42, 679-694.

[26] Heckman, J.J. (1979) "Selection Bias as a Specification Error", Econometrica $47,153-62$.

[27] Heckman, J.J. (1995) "Instrumental Variables: A Cautionary Tale", mimeo

[28] Heckman, James J. and Richard Robb (1985) Alternative Methods for Evaluating the Impact of Interventions, in Longitudinal Analysis of Labor Market Data Econometric Society Monograph Series no. 10 Heckman, J. J. and Burton Singer eds. Cambridge University Press, 156-245.

[29] Heckman, J.J. and G. Sedlacek (1985) "Heterogeneity, Aggregation and market Wage Functions: An Empirical model of Self-Selection in the Labor Market, Journal of Political Economy 93.6 pp. 1077-1125

[30] Heckman, J. J. and E .Vytlacil (1998) "Instrumental Variables Methods for the Correlated Random Coefficient Model: Estimating the Average Rate of Return to Schooling when the Return is Correlated with Schooling", University of Chicago, mimeo. 
[31] Horowitz, Joel (2000) "The Bootstrap" Forthcoming The Handbook of Econometrics.

[32] Imbens, G.W. and J.D. Angrist(1994) "Identification and Estimation of local Average Treatment Effects", Econometrica 62(2) 467-75

[33] Jovanovic, B. (1979) "Firm Specific Capital and Turnover", Journal of Political Economy 87, 1246-1260.

[34] Killingsworth, M. (1982) "Learning by Doing and Investment in Training: A Synthesis of two Rival Models of the Life Cycle", Review of Economic Studies, 49, 263-271.

[35] Kletzer, Lori G. (1989) "Returns to Seniority after Permanent Job Loss", American Economic Review Vol 79.3 June pp 536-43.

[36] Nagypal, Eva (2002) "Learning by Doing versus Learning about match quality: Can we tell them apart?" mimeo Northwestern University and University of Stockholm.

[37] Neal, D. (1995) "Industry-Specific Human Capital: Evidence from Displaced Workers", Journal of Labor Economics, 13, 653-677.

[38] Newey, Whitney, James Powell and Frank Vella (1999) "Nonparametric Estimation of Triangular Simulataneous Equations models" Econometrica Vol. 67 pp 565-604.

[39] Parent, D. (1995) "Industry-Specific Capital and the Wage Pofile: Evidence from the NLSY and the PSID", working paper No 795, Universite de Montreal, Centre de Recherche et Developement en Economique.

[40] Robin, J.M. and R. Smith (2000) "Tests of Rank", Econometric Theory 16 pp 151-75

[41] Rosen, S. (1972) "Learning and Experience in the Labor Market", Journal of Human Resources, 7, 336-342.

[42] Rosen, S. (1976) "A Theory of Life Earnings" The Journal of Political Economy, Vol. 84, No. 4, Part 2: Essays in Labor Economics in Honor of $\mathrm{H}$. Gregg Lewis. (Aug., 1976), pp. S45-S67.

[43] Scoones, David and Dan Bernhardt (1996) Promotion Turnover and Discretionary Human Capital Acquisition, mimeo

[44] Soskice, D. (1994) "Reconciling Markets and Institutions: The German Apprenticeship System", in Lynch (ed), Training and the Private Sector - International Comparisons, University of Chicago Press for NBER, Chicago.

[45] Topel, R.H. (1991) "Specific Capital, Mobility and Wages: Wages Rise with Job seniority", Journal of Political Economy, 99, 145-176. 
[46] Topel, R.H. and M.P Ward (1992) "Job Mobility and the Careers of Young Men", Quarterly Journal of Economics, 107, 439-479.

[47] Willis and Rosen (1979) "Education and self-selection" Journal of Political Economy Vol 87.5 part2 ppS7-S36 